\title{
The Virtues of Integrity
}

\author{
Daniel Dugger Moseley \\ White Plains, Virginia
}

M.A., Philosophy, University of Virginia, 2005

B.A., Philosophy, Virginia Commonwealth University, 2001

A Dissertation presented to the Graduate Faculty

of the University of Virginia in Candidacy for the Degree of

Doctor of Philosophy or Master of Arts or Master of Science or Master of Fine Arts

Department of Philosophy

University of Virginia

May 2010

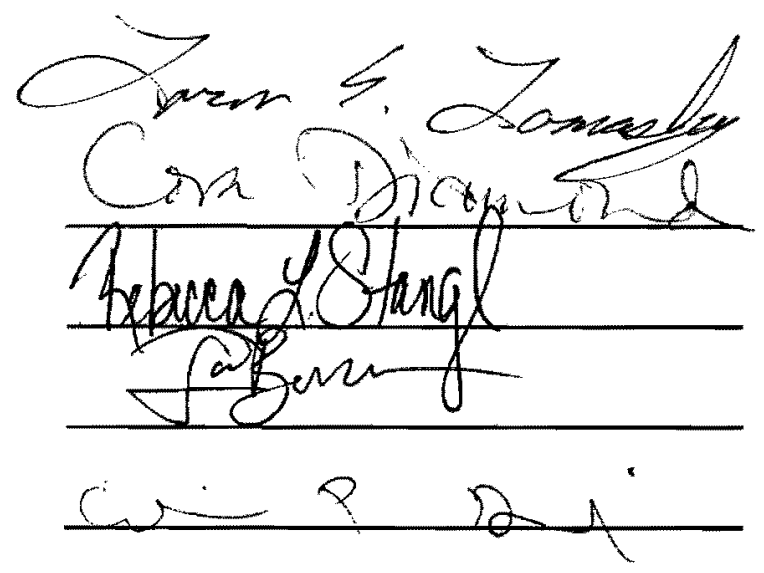




\section{Table of Contents}

$\begin{array}{lr}\text { Acknowledgements } & 2\end{array}$

Preface 4

Chapter 1 The Elusive Nature of Integrity

I. Integrity: Religious and Secular Conceptions 8

$\begin{array}{ll}\text { II. Three Conceptions of Integrity } & 11\end{array}$

$\begin{array}{ll}\text { III. Evil and Integrity } & 17\end{array}$

$\begin{array}{ll}\text { IV. Integrity v. Quasi-Integrity } & 21\end{array}$

Chapter 2 Revisiting Williams on Integrity, Moral Identity and Virtue

$\begin{array}{ll}\text { I. Introduction } & 29\end{array}$

II. Williams’s Critique of Utilitarianism 30

III. Is Integrity a Narcissistic Trait or a Virtue?

IV. Virtue, Authenticity and Morality 50

Chapter 3 The Virtue of Moral Commitment

I. Introduction $\quad 58$

II. Varieties of Commitment 60

III. On Moral Integration $\quad 72$

IV. Moral Conflicts and Moral Dilemmas $\quad 77$

V. On Virtue and Moral Commitment as a Virtue 84

Chapter 4 Integrity's Corresponding Vices and Related Threats to Integrity

$\begin{array}{ll}\text { I. Introduction } & 91\end{array}$

II. Integrity’s Corresponding Vices $\quad 91$

II.1 Wantonness 92

II.2 Weakness of Will $\quad 94$

II.3 Self-Deception 98

II.4 Fanaticism 100

$\begin{array}{ll}\text { III. Psychopathy and Immoralism } & 102\end{array}$

IV. Unjust Social Structures as Threats to Moral Agency 104

$\begin{array}{ll}\text { V. Varieties of Moral Luck } & 107\end{array}$

Chapter 5 Social and Political Dimensions of Integrity

$\begin{array}{lr}\text { I. Introduction } & 109\end{array}$

II. Political Liberty and Respecting the Separateness of Persons 109

$\begin{array}{ll}\text { III. Professional Integrity } & 115\end{array}$

$\begin{array}{ll}\text { IV. Marital Commitment and Divorce } & 117\end{array}$

$\begin{array}{lr}\text { Concluding Remarks } & 120\end{array}$

$\begin{array}{lr}\text { Bibliography } & 122\end{array}$ 


\section{Acknowledgments}

I agree with the contention of Plato and Jim Cargile that philosophy is essentially a form of dialogue. Given its nature in conversation, I must thank many of my interlocutors who have discussed the topic of integrity with me during the past five years. Of course, they bear no responsibility for any of the errors my dissertation may contain.

My dissertation readers were Cora Diamond, Talbot Brewer and, my dissertation director, Loren Lomasky. They provided outstanding feedback on earlier drafts of the dissertation. I am particularly grateful to Cora Diamond for the helpful conversations, and thorough commentary, on almost every topic that the dissertation addresses. My meetings with her have been a wonderful source of intellectual stimulation. I also thank Loren Lomasky for pressing me to articulate my own views about the issues that are discussed. His sound advice and helpful guidance during this project have been enormously valuable.

Earlier versions of various chapters were presented to: the Philosophy Club at Old Dominion University, the Virginia Philosophical Association, the Philosophy Department at Spring Hill College, the Association for the Advancement of Psychiatry and Philosophy, and the Philosophy Department at James Madison University. I am grateful to the participants of those meetings for their feedback.

I would also like to thank some of my fellow denizens of Charlottesville, Virginia who were excellent conversation partners during my research: Joseph Milton, Jacob Pease, Jim Shea, Larry Bouchard and many attendants of the Corner Parking Lot. I am also grateful to numerous others who provided memorable feedback: Brian Powell, Daniel Hedden, Tony Ellis, David Thunder, Bill Brenner, Raimond Gaita, Sarah 
Bachelard, Michael Levine, Damian Cox, Jamie Ferreira, Nancy Schauber, Phillip Pettit, R. Jay Wallace, Barry Stroud and Jason Brennan.

I would also like to thank the University of Virginia's Graduate School of Arts and Sciences for a research fellowship during AY 2006-07. I also owe a great personal debt to Joy Meyer, who has been a wonderful source of greatly needed love and encouragement during the time it has taken me to finish this project. I dedicate this work to her and to one other person: my grandfather, Charles L. Moseley, a man of great integrity. 


\section{Preface}

\section{General Introduction}

Integrity is the cardinal virtue for moral agents. The moral significance of integrity is often unacknowledged because it is usually considered to be a state such as sincerity, having the courage of your convictions, strength of will or standing up for what you believe. Integrity ought not to be construed in such a subjective manner. Persons may have deeply immoral convictions and if integrity consists in a state such as sincerity or having the courage of your convictions, then it is possible for persons with deeply immoral convictions to have integrity. Officers of the SS may be sincere or stand up for what they believe but they ought not to be credited with integrity. There should be some objective constraints on the content of the convictions that persons of integrity may possess. Someone might reply that the intuitive understanding of integrity as a trait such as sincerity or being true to your convictions ought not to be abandoned: since integrity may be possessed by persons with deeply immoral convictions, integrity should not be construed as a moral virtue or any other kind of virtue. The following chapters present a response to this objection that articulates a series of overlapping arguments that reveal integrity to be a virtue of central importance for moral agents. I argue that there are substantive constraints on the content of the commitments of persons of integrity: persons of integrity may pursue a wide range of projects and endeavors but their commitments cannot be evil. I argue that integrity consists in the virtues of moral commitment and standing up for that commitment and these virtues involve integrating one's commitments. So, perhaps instead of contending that integrity is a virtue for moral 
agents, it is more literally accurate to maintain that the virtues of integrity are cardinal virtues for moral agents.

\section{Dissertation Synopsis}

Chapter 1, “The Elusive Nature of Integrity,” presents the main topics that are examined in the dissertation. The following questions identify the main issues. What is the nature of integrity? Is it possible for evil persons to have integrity? Is integrity a virtue? If it is a virtue, what kind of virtue is it? In response to the first question, most conceptions of integrity can be grouped under three main categories: integrity as wholeness, integrity as purity and integrity as an ethical quality. These conceptions of integrity often produce conflicting intuitions when they encounter the issue of whether it is possible for evil persons, such as contract killers and genocidal fanatics, to exemplify integrity. The issue of whether evil persons can have integrity is one of the central topics of my inquiry. I contend that integrity is best understood to consist in the virtues of moral commitment and standing up for that commitment and these virtues shield their possessor from a set of vices that correspond to the virtues of integrity. One consequence of this conception of integrity is that persons of integrity characteristically have morally integrated characters. In many cases in which it seems that morally wicked persons have integrity, the quality that those persons exemplify is a form of quasi-integrity. Integrity is not merely strength of will, constancy or some formal property that describes the structure of a person's will (e.g., volitional consistency). Integrity is a moral quality of a person's character that places substantive constraints on content of that person's will: persons of integrity must be morally decent. 
Chapter 2, "Revisiting Williams on Integrity, Moral Identity and Virtue," examines the argument that brought integrity to the attention of Anglo-American analytical philosophers: Bernard Williams’s integrity-based critique of utilitarianism. My examination of Williams's arguments has two main goals: the historical goal of retrieving the conception of integrity at work in Williams's early writings and the philosophical goal of reconstructing the most plausible conception of integrity suggested by his arguments. My reconstruction of Williams's conception of integrity focuses on the relation of integrity to the related concepts of virtue, commitment, authenticity and moral identity. According to my reconstruction of his arguments, integrity is not a virtue, but it is an admirable human quality that has moral and psychological features which cannot be explained by utilitarianism. It is argued that Williams is overly sympathetic to the idea that integrity is not a virtue, but his conception of integrity does suggest plausible avenues for exploring the relation between authenticity (i.e., being true to oneself) and a range of moral concepts (moral normativity, moral identity and moral commitment).

I maintain that integrity consists in the virtues of moral commitment and standing up for that commitment. Chapter 3, “The Virtue of Moral Commitment,” examines the nature of moral commitment. Moral commitment is distinguished from non-moral commitment by examining a framework for classifying commitments that is formulated by Talbot Brewer in "Two Kinds of Commitments and Two Kinds of Social Groups.” Building upon Brewer's framework, I identify four kinds of commitment: transactional externalist commitments, non-transactional externalist commitments, process internalist commitments and internalist commitments that are states. The virtue of moral commitment is a rich and complex type of commitment that involves all four types of 
commitments. Persons who have the virtue of moral commitment have morally integrated their commitments: moral commitment is a form of integration.

Chapter 4, “Integrity’s Corresponding Vices and Related Threats to Integrity,” discusses a set of vices that correspond to the virtues of integrity: wantonness, weakness of will, self-deception, and fanaticism. Other threats to integrity, such as psychopathy, morally wicked character, and unjust social structures, are also discussed. It is argued that two main kinds of moral luck are necessary for integrity: the luck that is required to achieve one's ends and the luck that is required in order to have morally decent ends.

Chapter 5, "Social and Political Dimensions of Integrity," examines some practical applications of my conception of integrity. I apply it to the issues of political liberty, professional integrity, and marital commitment. The broad range of topics discussed in this chapter provides a glimpse of the wide-ranging implications of one's conception of integrity and it shows the central importance of integrity in normative philosophy. 


\section{Chapter 1 The Elusive Nature of Integrity}

I. Integrity: Religious and Secular Conceptions. The story of Job is one of the most memorable of the Bible. Readers of the book will probably remember these highlights. Yahweh proclaims that Job is his most faithful servant. "The adversary” ${ }^{1}$ bets Yahweh that Job will lose his faith if it is tested. Yahweh accepts the adversary's wager and allows the adversary to test Job’s faith. Job's life is shattered in many ways by the onslaught of miseries that are deviled out to him. Job's family, farm and health are diabolically destroyed. However, Job keeps himself together by staying true to his Lord throughout his suffering: Job remains whole by being an obedient disciple of his Lord and His law. At the end of story Job’s obedience is rewarded: Yahweh restores his health, enhances his wealth and holdings and provides Job with a new family. ${ }^{2}$

Job is perhaps best known for his patience but his distinctive form of integrity is a recurring motif in the major monotheistic traditions: Judaism, Christianity and Islam teach that integrity consists in obedience to God and His law. Moses Maimonides expresses this idea in the maxim, "Everything that you do, do for the sake of God.”3 St. Thomas Aquinas also writes of the religious and moral significance of obedience to God: “[T]he virtue of obedience is more praiseworthy than other moral virtues, seeing that by obedience a person gives up his own will for God's sake, and by other moral virtues

\footnotetext{
${ }^{1}$ The Hebrew text does not provide a name for this character: he is given a definite description that is often translated as "the Satan," "the accuser," or "the adversary." There are interesting questions about the relation of the adversary to the serpent in Genesis and the diabolical characters in other books of the Bible.

${ }^{2}$ The Biblical story of Abraham and Isaac provides another striking example of the arduous demands that God may place upon his faithful servants. In the story Yahweh commands Abraham to kill his only son Isaac. When Abraham is about to thrust a knife into his son Yahweh grants Abraham permission to kill a ram instead. Kierkegaard's Fear and Trembling (in Kierkegaard's Writings, 6, trans., Howard Hong and Edna Hong. Princeton, N.J.: Princeton University Press, 1983) examines several perspectives on the story of Abraham and Isaac while also exploring the nature of religious faith and its relation to moral commitment.

${ }^{3}$ I owe the quotations from Maimonides and Aquinas to Stephen L. Carter, Integrity (New York: Harper Perennial, 1996, 8).
} 
something less.” Islamic moral teachings also instruct believers to lead an undivided life that respects the law of Allah. The Islamic tradition contains the idea that all rules should be guided by the sharia, which is the divine path that Allah commands all humans to follow. ${ }^{4}$ All of these religions teach that a person of integrity is undivided and unified in his or her obedience to God. In these religious traditions the concepts of obedience to God, piety, moral uprightness, moral purity, and integrity go hand in hand. ${ }^{5}$

The religious conception of integrity as obedience to God is widely influential but integrity is not the exclusive property of the religious domain. Integrity is not identical with religious piety and integrity does not presuppose a religious conception of morality. ${ }^{6}$ Some persons of integrity are not religious and integrity may be considered an admirable trait in and by individuals that despise all things religious. Integrity is, and ought to be, a virtue for the religious and non-religious alike. Nietzsche, for instance, contends that integrity is his one and only virtue and he formulates a conception of integrity that sharply contrasts with the religious conception of integrity as obedience to God: ${ }^{7}$

One should surely note that integrity is neither to be found among the Socratic nor the Christian virtues: it is one of the most recent virtues, not

\footnotetext{
${ }^{4}$ This description of the sharia is drawn from Carter, Integrity, 8. The relation between religious conceptions of obedience and integrity is emphasized by Carter. It is also emphasized in Kierkegaard's Purity of Heart is to Will One Thing (trans., Douglas Steere, New York: Harper Torchbooks, 1948).

${ }^{5}$ The relation of these ideas is straightforward in the tradition of theological voluntarism. In this tradition morality is legalistic and the moral law is based on God's will (rather than it being based in some form of the Good that is different than God). Obedience to God and obedience to morality come apart in theologies such as the one suggested by Kierkegaard, who draws a sharp contrast between Religious, Moral and Aesthetic perspectives. Kierkegaard explores the relation between these perspectives (and provides different conceptions of those perspectives) in several of his pseudonymous works, which include Fear and Trembling, Either/Or (in Kierkegaard's Writings 3-4, trans. Howard Hong and Edna Hong, Princeton, N.J.: Princeton University Press, 1990, and Concluding Unscientific Postscript (2 vols., in Kierkegaard's Writings 12, trans., Howard Hong and Edna Hong. Princeton, N.J.: Princeton University Press, 1992).

${ }^{6}$ Kierkegaard presents a passionate account of integrity as religious piety in Purity of Heart is to Will One Thing. Kierkegaard contends that you cannot have integrity if you do not submit yourself to the will of God (or to The Good).

7 For an interesting and plausible reading of Nietzsche's views on integrity, see Wilhelm Wurzer, 'Nietzsche’s Dialectic of Intellectual Integrity: A Propaedeutic Study', Southern Journal of Philosophy, 13 (1975), 235-45.
} 
yet quite mature, often enough mistaken for another, and misunderstood, hardly conscious of itself-something in the becoming, which we may either cultivate or restrain, according to our inclination. ${ }^{8}$

Nietzsche construes integrity as a virtue that is (1) relatively young, (2) "something in the becoming," and (3) difficult to identify (in oneself and in others). The first of these claims is dubious, the second needs explanation and the third is right on the mark. The first assertion, that integrity is "one of the most recent virtues," seems careless. Plato was concerned with integrity, although not by that name. ${ }^{9}$ Nietzsche would probably consider the outlooks of Callicles and Thrasymachus to possess a conception of integrity similar to his own. ${ }^{10}$ Nietzsche's second claim, that integrity is "something in the becoming" that may be cultivated or restrained according to our inclination, is complex and I shall only briefly discuss it here. Nietzsche's idea that integrity is "something in the becoming" suggests that integrity is essentially concerned with the way that individuals experience the world and shape their characters through their actions, and Nietzsche's idea that integrity is something "which we may either cultivate or restrain, according to our inclination" suggests the related idea that integrity is established and sustained by an individual's feelings or passions rather than depending upon, at least a narrow conception of, rationality or reason. Chapter 2 discusses these ideas in the context of Bernard Williams's early writings on integrity. Nietzsche's third claim, that integrity is a virtue

\footnotetext{
${ }^{8}$ This passage is from one of Nietzsche's journal entries and the quotation is from Wurzer, Ibid., p.236. Wurzer contends that Nietzsche's conception of integrity is a precursor to his later idea of the will to power.

${ }^{9}$ The main arguments provided by Socrates in both Gorgias (trans., Donald Zeyl, Indianapolis, IN: Hackett Publishing, 1987) and Republic (trans., G.M.A. Grube, revised by C.D.C. Reeve, Indianapolis, IN: Hackett Publishing, 1992) defend the view that the virtue of justice (in individuals) consists in a type of harmony of the soul: just persons have harmoniously integrated souls, whereas unjust persons have fractured and chaotic souls in which the parts of the soul are at odds with one another.

${ }^{10}$ Here I am referring to Plato's descriptions of Callicles in the Gorgias and Thrasymachus in Book I of the Republic. The spirit of Nietzsche's critiques of morality in Beyond Good and Evil (trans., Walter Kaufmann. New York: Vintage Books, 1966) and in The Genealogy of Morals (trans. and ed., Walter Kaufmann.New York: Vintage Books, 1967) echoes the voices of Callicles and Thrasymachus.
} 
that is "often enough mistaken for another," is perceptive and important. Integrity is commonly mistaken for other virtues (courage and honor) and it is also commonly mistaken for character traits and human dispositions other than virtues. Later I discuss how integrity is often mistaken for various forms of quasi-integrity that come close to being integrity but do not quite hit the mark. Section II discusses some of the other primary sources of the elusive nature of integrity.

In sum, religious and non-religious persons often give a central place to the virtue of integrity and persons of integrity may be religious or non-religious. Integrity is, and ought to be, a virtue for the religious and non-religious alike. Integrity may be an ideal for and it may be exemplified by both religious and non-religious persons.

II. Three Conceptions of Integrity. In the Nicomachean Ethics Aristotle writes,

Our discussion [i.e., inquiring into how one ought to live] will be adequate if we make things perspicuous enough to accord with the subject matter; for we would not seek the same degree of exactness in all sorts of arguments alike, any more than in the products of different crafts. ${ }^{11}$

Aristotle's advice for conducting an ethical inquiry is also sound counsel for someone who has embarked on an inquiry into the nature and significance of integrity. Just as different degrees of exactness should be used in shipping plutonium and pumping gas, different degrees of exactness should be used in testing hypotheses in physics and evaluating conceptions of integrity. Integrity is a messy concept and a logical investigation of the concept must examine the wide range of cases in which the concept can be applied and the various ambiguities associated with it. One helpful way to reveal the logic of the concept of integrity is to examine cases of persons of integrity.

\footnotetext{
${ }^{11}$ Aristotle, Nicomachean Ethics $\left(2^{\text {nd }}\right.$ Edition trans., Terence Irwin, Indianapolis, IN: Hackett Publishing,
} 1999, 1094b, 13,14). 
Consider the story of Job again. The ordinary English usage of the word 'integrity' highlights qualities that Job possesses. The Oxford English Dictionary observes that 'integrity' connotes: ${ }^{12}$

(OED1) The condition of having no part or element taken away or wanting; undivided or unbroken state; material wholeness, completeness, entirety. (OED2) The condition of not being marred or violated; unimpaired or uncorrupted condition; original perfect state; soundness.

or

(OED3) Soundness of moral principle; the character of uncorrupted virtue, esp. in relation to truth and fair dealing; uprightness, honesty and sincerity.

Job exemplifies each of these qualities. (OED1) construes integrity as wholeness. Although certain dimensions of Job’s life are fractured (e.g., his family life, property and physical health), his life is unified by his loyalty and obedience to Yahweh. Job resists the corrupting forces of the adversary and Job stands up for his core values in the face of significant obstacles and coercion. (OED2) construes integrity as purity. Job’s material wealth, bodily health, friendships and family are destroyed by the adversary, but Job does not succumb to the adversary's temptations to turn against Yahweh-Job’s loyalty to Yahweh is not corrupted and it remains pure. (OED3) construes integrity as a number of different ethical qualities: moral uprightness, virtue, honesty, or sincerity. Job remains truthful (to his friends and to Yahweh) throughout his ordeal and he remains an obedient servant to Yahweh. In the Biblical sense of the concept, Job does not speak falsely about

\footnotetext{
${ }^{12}$ Each of the following definitions of 'integrity’ are emphasized by Carter in Carter, Ibid., 17,18.
} 
Yahweh. ${ }^{13}$ In short, Job possesses each of these qualities, (OED1), (OED2) and (OED3), and they mutually reinforce one another. Job’s life is integrated by his loyalty and obedience to his Lord.

(OED1), (OED2) and (OED3) also identify three main categories of conceptions of integrity. Most conceptions of integrity may be classified under the headings of integrity as wholeness, integrity as purity or integrity as an ethical quality. ${ }^{14}$ Rather than construing these categories of integrity as rivaling theories of the nature of integrity, it is reasonable to understand each of these categories as providing alternative models of integrity. Integrity can be construed as a type of wholeness, purity or some type of ethical quality. Each of these categories provides a reasonable way to describe relatively uncontroversial examples of persons of integrity. Socrates, Mahatma Gandhi, Dietrich Bonhoeffer, George Orwell and Mother Theresa are widely considered to be persons of integrity. One of the main reasons it is relatively uncontroversial to attribute integrity to each of these persons is that each one is widely believed to possess a great deal of wholeness, honesty and moral uprightness. Moreover, each one is widely regarded as having the virtues of moral commitment and standing up for that commitment and these virtues can be understood as manifesting forms of wholeness, purity and morally upright character.

Controversy about the nature and significance of integrity quickly arises when you consider examples of persons whose lives, characters or actions are unified, or

\footnotetext{
${ }^{13}$ For discussion of the Biblical concept of speaking falsely see Sissela Bok Lying: Moral Choice in Public and Private Life (New York: Vintage Books, 1979).

${ }^{14}$ Although these exact classifications are not used by any particular theorist of integrity, there are many conceptions of integrity that can by fairly categorized with this rubric. For other classifications of integrity, see Damian Cox, Marguerite La Caze and Michael P. Levine's Integrity and the Fragile Self (Burlington, VT: Ashgate Publishing, 2003) and their entry 'Integrity' in the Stanford Encyclopedia of Philosophy, (ed., Edward Zalta, URL $=<$ http://plato.stanford.edu./entries/integrity $/>$ ).
} 
integrated in some sense, by the pursuit of projects or principles that are evil. ${ }^{15}$ I shall not venture to explain the nature of evil here, but clear examples of evil persons and deeds abound in literature, film, journalism, comic books and history. Cases of serial killers, rapists and genocidal fanatics provide striking examples of it. The following two examples are rather thinly described, but they are only intended to identify a cluster of conflicting pre-theoretical intuitions that make it difficult to analyze the concept of integrity.

First case (inspired by the hit-men in the film Michael Clayton): Consider a contract killer, hereafter 'C', who regularly kills people that are an inconvenience for the killer's employer. $\mathrm{C}$ is aware that most of his contracts are placed on people who are, for the most part, innocent. C's primary concerns are excelling at his career and executing a thrilling hunt. C does not regret any of his assignments: he accomplished his goals in every job, the work has paid well, and the assignments were exhilarating. $\mathrm{C}$ is striving for a reputation as the best professional in the business and this pursuit structures his everyday activities (say, acquiring the most deadly guns, knives, poisons and explosives he can find) and it structures most of his short-term goals (such as, pulling off the next contract). C is reliable: give him the money and the job will get done. $\mathrm{C}$ is also a murderer. Does C have integrity?

\footnotetext{
${ }^{15}$ Theologians commonly distinguish natural evil and moral evil. The former includes phenomena such as diseases and the havoc resulting from natural disasters such as hurricanes and earthquakes. The latter requires the moral responsibility of agents and includes actions such as murder. My inquiry is concerned with the issue of whether a person of integrity may have morally evil character.
} 
Second case (which is inspired by the actual case of a captured Nazi officer ${ }^{16}$ ): Consider a Nazi officer, hereafter ' $F$ ', who is fully devoted to ideals and policies of the National Socialist Party. F considers them to be more important than his own life. F joined the German army as an expression of his zealous support of the Nazi march on Europe. Eventually F is captured by Allied forces. As a prisoner it is discovered that F has a rare disease that requires a blood transfusion. $\mathrm{F}$ is offered medical treatment but he refuses it because he knows that the blood they would pump into his veins might be mixed with the blood of Jewish persons or homosexuals. F refuses the transfusion on the grounds that his blood must remain pure no matter what the costs. F experiences an agonizing death as a result of his decision. $\mathrm{F}$ was willing to stand up for his values and principles in the face of great risk. F was not willing to risk losing his purity or undermining his principles. Does F have integrity?

In these types of cases it seems that the three main categories of conceptions of integrity come apart. The stories of $\mathrm{C}$ and $\mathrm{F}$ seem to provide situations in which integrity as wholeness is exemplified but integrity as an ethical quality is not. C and F have selves, lives or characters that are unified and whole in some sense, but they are unified by principles, projects and actions that are evil. The story of F seems to provide a situation in which integrity as purity comes apart from integrity as an ethical quality. F remains pure, by his own lights, but his conception of purity largely contributes to his evil character. C

\footnotetext{
${ }^{16}$ This example is a version of the case of the Nazi officer that is described in Cora Diamond's entry on 'Integrity' (in The Encyclopedia of Ethics, $2^{\text {nd }}$ Edition, vol 2, eds. Lawrence Becker and Charlotte Becker, London: Routledge, 2001, 863-866). This example also resembles the description of the Nazi fanatic in R.M. Hare's Freedom and Reason (Oxford: Oxford University Press). Explaining the exact relation between integrity and fanaticism is a desideratum for any ethically significant conception of integrity.
} 
and F may exemplify consistency or constancy and they may adhere to their own principles but, in their cases and given their values and principles, those traits undermine their moral decency.

Someone might reply that integrity as wholeness and integrity as an ethical quality do not come apart in these cases because people that do evil things or have core principles and projects that are evil may possess certain virtues. Since C and F may possess a certain kind of self-integration and possess certain virtues, $\mathrm{C}$ and $\mathrm{F}$ do not necessarily present examples of integrity as wholeness existing in isolation from integrity as an ethical quality. $\mathrm{C}$ may possess the virtue of being an honest professional and $\mathrm{F}$ may possess the virtue of being an honest soldier. ${ }^{17}$ If $\mathrm{C}$ and $\mathrm{F}$ do exemplify integrity as wholeness and integrity as an ethical quality, then there may continue to be conflicting intuitions about whether $\mathrm{C}$ and $\mathrm{F}$ have integrity because the forms of wholeness and virtue that they exemplify are not grounded in morally decent lives-their lives are integrated by evil ends, evil deeds and virtues that advance those ends and deeds. The cases of $\mathrm{C}$ and $\mathrm{F}$ also help to reveal widespread, pre-theoretical uncertainty about the nature of morality, virtue and their relation. The cases of $\mathrm{C}$ and $\mathrm{F}$ show how conceptions of integrity as an ethical quality, e.g., integrity as moral character, integrity as honesty, integrity as virtue, constitute a heterogeneous collection of qualities. The issue of whether evil persons can be persons of integrity uncovers some of the deep, pre-reflective conceptual confusions about the nature of integrity.

\footnotetext{
${ }^{17}$ Here I leave aside perennial questions about the unity of the virtues. The unity of the virtues is the doctrine that if a person possesses any of the virtues, then that person possesses all of them. So, according to this view, either you have all of the virtues or you have none of them. For the sake of this discussion it is assumed that the doctrine of the unity of the virtues is not true.
} 
Someone might argue that the different senses of 'integrity' described above do not pick out different conceptions of a single concept; rather, the word 'integrity' expresses different concepts in different contexts. Thus, according to this line of criticism, my attempt to uncover the logic of a single concept is misguided because debates that I have described as concerning the nature of integrity are actually semantic quibbles about the "best" or "most appropriate” way to use a word that is not univocal. I have two responses to this linguistic objection. First, this objection is a general problem for any attempt either to deploy conceptual analysis or to construct a normative theory. The words 'obligation', 'knowledge' and 'justice' have different senses in different contexts. However, each one expresses a concept that is commonly the subject of conceptual analysis and normative theorizing. Second, the concept of integrity is of central importance for moral philosophy and for the moral life. It is doubtful that confusions pertaining to such an important concept are merely the result of semantic ambiguity.

III. Evil and Integrity. Is it possible for persons of integrity to be evil? This question ought to be of central concern for any inquiry into the nature and significance of integrity. Can persons of integrity have characters, principles or projects that are evil? Situating this issue in a broader philosophical context reveals its theoretical significance. The philosophical significance of this issue can be exposed by considering some of the central claims of Plato's Republic and Alasdair MacIntyre's After Virtue. ${ }^{18}$ Plato famously argues in the Republic that justice is both good in itself and good for its

\footnotetext{
${ }^{18}$ The relevance of Plato's discussion of justice in the Republic and MacIntyre's discussion of narrative in After Virtue, $2^{\text {nd }}$ Edition (Notre Dame, IN: Notre Dame Press, 1984) to the topic of integrity is discussed in Cora Diamond 'Integrity'.
} 
consequences because, in part, the soul (psyche) of a just person is unified and harmonious by its nature whereas the soul of an unjust person is characteristically fractured, divided, chaotic and cannot be integrated or harmonized. A familiar objection to Plato's view is that there appear to be many examples of unjust persons that have integrated and harmonious souls: consider C and F. Many unjust persons appear to have lives or practical identities that are unified and harmonious: these people wholeheartedly pursue immoral ends with unswerving zeal and conviction. Plato's arguments raise the question whether an evil person can have a unified soul and his arguments to the contrary do not make a decisive case that evil persons cannot have a unified soul. Plato's arguments leave open the question of whether evil persons can have integrity.

The issue of whether evil persons can have integrity reemerges in consideration of some of the central claims in Alasdair MacIntyre's After Virtue. MacIntyre contends that the ethical life, the virtues and personal identity are all grounded in a certain kind of narrative unity - the narrative unity of a quest. ${ }^{19}$ Related to MacIntyre's claim that the virtues are grounded in the narrative unity of a quest is MacIntyre's contention that a person's obligations and commitments are also grounded in the narrative unity of a quest. Some of MacIntyre's critics deny that commitments, obligations and virtues can be grounded in the narrative unity of a quest, because some evil persons (pick your favorite tyrant) have lives that exemplify the narrative unity of a quest but their journeys are directed towards immoral and unjust ends - their quests are aimed at injustice and thus

\footnotetext{
${ }^{19}$ In one particularly striking expression of the importance of narrative in MacIntyre's picture of the self and the ethical life, he writes, "Narrative is not the work of poets, dramatists and novelists reflecting upon events which had no narrative order before one was imposed by the singer or the writer; narrative form is neither disguise nor decoration. Barbara Hardy has written that 'we dream in narrative, day-dream in narrative, remember, anticipate, hope despair, believe, doubt, plan, revise, criticize, construct, gossip, learn, hate and love by narrative' in arguing the same point (Hardy 1968, p.5)." (After Virtue, $2^{\text {nd }}$ Edition, Notre Dame, IN: Notre Dame Press, 1984, 211)
} 
something other than the narrative unity of a quest grounds the moral life. ${ }^{20,21}$ So, the issue of whether evil persons can have integrity is of central importance for MacIntyre's version of Neo-Aristotelianism/Neo-Thomism.

There are reasons for being skeptical about my claim that an inquiry into the nature and significance of integrity should address the issue of whether evil persons can have integrity. The following two arguments provide the strongest and most commonly offered grounds for this skepticism-each is followed with my response. First, it might be argued that people who live in secular societies should be uneasy with describing horrible things as evil, because the concept of evil is essentially wed to religious outlooks-evil things are sinful and sin is essentially a religious concept. This worry is unfounded. Although religious conceptions of evil may construe it as essentially involving sin, there are secular conceptions of evil which maintain that evil things are essentially immoral or unethical. ${ }^{22}$ (Noteworthy secular conceptions of evil are developed in the work of Jean-Jacques Rousseau, Immanuel Kant, Iris Murdoch and Raimond Gaita. $^{23}$ ) Secular conceptions of evil usually do not contend that evil is identical with

${ }^{20}$ Cora Diamond, in 'Integrity', observes that J.B. Schneewind, in 'Virtue, Narrative and Community: MacIntyre and Morality' (Journal of Philosophy, 79, 1982, 653-663) raises the issue of whether the narrative unity of a character or life can ground virtues, obligations and commitments.

${ }^{21}$ Another noteworthy criticism of MacIntyre's arguments is presented by Bernard Williams in 'Life as Narrrative' (European Journal of Philosophy, forthcoming). Williams's objections to MacIntyre focus on the nature of narrative explanation. The issue of the nature of narrativity and its role in virtue ethics is a rich topic that is beyond the scope of the present inquiry. For thought provoking discussions of this topic, see Raimond Gaita 'Narrative, Identity and Moral Philosophy' (Philosophical Papers, 32, 261-277), Margaret Urban Walker Moral Understandings: A Feminist Study in Ethics. London: Routledge, 1998, and David Velleman 'Narrative Explanation', The Philosophical Review, 112, 2003, 1-25.

${ }^{22}$ This claim raises the issue of whether moral considerations can be grasped or evaluated independently of any religious social context. Arguments that they cannot are developed by Alasdair MacIntye in After Virtue and are also advanced by C.S. Lewis in Mere Christianity (New York: Harper Collins, 1952). Strong evidence for the view that moral concepts do not presuppose the existence of God, divine law or religious institutions is found in many secular moral theories that have been developed in the history of ethics (e.g., Kant's moral theory).

${ }^{23}$ See Rousseau's widely influential reflections on amour-propre in Discourse on the Origins of Inequality, The Social Contract,(in his Basic Political Writings, trans. Donald Cress, Indianapolis, IN: Hackett 
unethical conduct. They usually deny that everything that is immoral is also evil; they usually contend that some things are immoral or unethical but are not evil. For instance, in certain circumstances it may be immoral or unethical to be condescending towards a stranger but doing so would not necessarily be evil. Evil is worse than being immoral or unethical—evil is more monstrous. Since the concepts of immoral and unethical conduct are of central importance for many religious and secular outlooks, there should be no uneasiness about purported religious connotations associated with the concept of evil. A secular person may sincerely, intelligibly and legitimately claim that Stalin was evil. There are difficult questions that arise in this context about the exact relation that obtains between immortality, free will, God, unethical conduct and evil but I shall not discuss these challenging questions here.

A second argument for skepticism about my emphasis on the issue of whether persons of integrity can be evil contends that the concept of evil is too rhetorical and emotionally charged to aid in the conceptual elucidation of the concept of integrity. Someone might argue that in ordinary conversation, when people describe things as evil, those descriptions usually constitute a cheap attempt to put an end to argument-consider George W. Bush’s hasty and irresponsible label “the Axis of Evil.” Discussions of what is good and what is evil in public life often lead to polarized discussions that easily turn into combat between "our good cause” and "their evil agenda." ${ }^{24}$ Since rhetoric about

Publishing) and Emile (trans., Alan Bloom, New York: Basic Books, 1979). Kant's writings on evil are developed in the moral psychology he formulates in Religion Within the Boundaries of Reason Alone (trans. and eds., Allen Wood and George Di Giovanni, Cambridge: University of Cambridge Press, 1999). Also see Iris Murdoch's discussion of evil in "On 'God' and 'Good'” (in The Sovereignty of Good, London: Routledge, 1971, 45-74), and Raimond Gaita Good and Evil: An Absolute Conception, $2^{\text {nd }}$ Edition (New York: Macmillan, 2004).

${ }^{24}$ For a vivid account of this problem in contemporary American political debates see Ronald Dworkin Is Democracy Possible Here? (Princeton, N.J.: Princeton University Press, 2006). Dworkin suggests plausible ways for people on the left and the right to find common ground in order to advance political debate. 
evil often leads to inarticulate or ruthless combat in public life (combat that often involves character assassination or, in its extreme forms, may involve political assassination) there are reasons to be weary of using the concept of evil to determine whether a person has integrity. It is easy to simply describe one's opponents as evil, but it is usually difficult to determine whether one’s opponents are advancing evil ends or using evil means to achieve those ends. The dangers of introducing talk of evil into the rhetoric of public life are serious, but it would impoverish our moral vocabulary to completely eliminate it from public discussions. The wars of the Twentieth Century have shown human beings the reality of evil on a scale and in a way that has never been experienced in history. In light of those experiences, attention to the presence of evil is of central importance for persons committed to morality in the world we live in.

Persons of integrity characteristically exemplify the virtues of moral commitment and standing up for that commitment, and a central concern for anyone who is committed to morality is whether your actions or ends are evil. Moral commitment is not only concerned with avoiding evil; it is also concerned with being morally decent. Persons of integrity have lives that are imbued with moral texture and moral richness that is, in large part, established and sustained by their distinctive projects, intimate relationships and personal life narratives. Persons of integrity integrate their lives by exemplifying the virtues of moral commitment and standing up for that commitment.

IV. Integrity v. Quasi-Integrity. My dissertation explores, clarifies and defends the thesis that integrity consists in the virtues of moral commitment and standing up for 
that commitment. ${ }^{25}$ There is a general objection to my view that should be discussed before I describe the view any further. Someone might contend that integrity does not consist in the virtues of moral commitment and standing up for that commitment, because integrity is not a virtue at all. One might argue that since integrity is not a virtue, it is unclear why integrity is worth striving for at all. ${ }^{26}$

If integrity is not a virtue, then my conception of integrity cannot get off the ground. Chapter 2 discusses the strongest argument of which I am aware for the claim that integrity is not a virtue: Bernard Williams's argument for the view that integrity is not a virtue. I argue that Williams' own conception of integrity is best understood as a conception of integrity as a virtue. One desideratum for any conception of integrity as a virtue is to provide an account of what kind of virtue integrity is. In the following chapters I shall attempt to satisfy this desideratum by defending the thesis that integrity consists in the virtues of moral commitment and standing up for that commitment. The overall conception of integrity that is articulated in the following chapters makes my case for the view that integrity is a virtue, and it is the cardinal virtue for moral agents.

According to my view, persons of integrity are true to their commitments by having morally integrated characters. If one does not have a morally unified character, then one does not have integrity. However, a person may lack moral decency and exemplify a certain type of unified character. There are various types of quasi-integrity

\footnotetext{
${ }^{25}$ My dissertation defends a version of the Platonic thesis that persons of integrity are good. However, it does not defend the dubious Platonic claim that evil persons must lead lives that are fractured or chaotic.

${ }^{26}$ Nancy Schauber 'Integrity, Commitment and the Concept of a Person' (American Philosophical Quarterly, 33, 1996, 119-129) presents an argument along these lines. A compelling critique of Schauber's arguments is offered in Cox, LaCaze and Levine's Integrity and the Fragile Self: they argue that integrity is virtue and they correctly observe that Schauber's argument rests on a distinction between active commitments and passive commitments. Cox, LaCaze and Levine convincingly argue that the distinction that Schauber deploys is untenable. Chapter 3 discusses various kinds of commitment and the nature of moral commitment.
} 
that are simulacra of the real thing: strength of will, honesty/sincerity, or some type formal integrity (e.g., consistency or coherence). In cases in which it seems that persons of integrity may be evil, the case usually involves a character who possesses some kind of quasi-integrity. To illustrate this point, consider whether the Nazi fanatic F has integrity. It is clear that F has the strength of will to carry out his convictions, but it is unclear and doubtful that F has integrity. Strength of will often appears to be a type of integrity but it is a mere simulacrum of the real thing. Persons of integrity usually are not massively selfdeceived (perhaps some degree of self-deception is inescapable for human beings), but it is possible for strong-willed persons to be swimming in it. Persons of integrity are often zealous in the pursuit of their principles and projects but their zeal may dissipate and persons of integrity may experience long periods of doubt and confusion about the value of their principles and projects. Fanatics exemplify strength of will by zealously clinging to their principles and projects regardless of the evidence or the consequences; ${ }^{27}$ if the zealousness of a fanatic wanes, so does the fanaticism. In everyday life it is a challenge to differentiate integrity from fanaticism and strength of will but many other virtues are difficult to identify in everyday practice.

One reason it is easy to regard strength of will as integrity is that persons of integrity are usually tenacious - their commitments to their principles and projects require a distinctive form of tenacity. Persons of integrity tenaciously strive for moral clarity. They tenaciously strive for clarity concerning moral questions. Strength of will may be necessary for integrity but it is not sufficient. Strength of will has the appearance of integrity but it is not the real thing.

${ }^{27}$ Chapter 9, "Toleration and Fanaticism," of R.M. Hare’s Freedom and Reason presents a classic discussion of the nature of fanaticism. 
Honesty and sincerity are also commonly confused with integrity. The mere fact that someone keeps his or her promises or asserts claims that he or she believes to be true is not sufficient for integrity. If someone promises to so something foolish or immoral, then breaking one's word may not count as a lack of integrity. Honesty that expresses ignorance, cruelty or an immoral character may indicate a lack of integrity. Consider the case of $\mathrm{C}$ again. $\mathrm{C}$ may agree to kill an enemy of his employer for a sum of money and carry out the job quickly, stealthily and efficiently but that would not reveal that $\mathrm{C}$ has integrity. Perhaps C always keeps his word in the domain of hired killings and in all other areas of his life. There may be something admirable about C's honesty (it is valuable to C's employer and it is instrumentally valuable for his professional reputation) but this aspect of his character is at odds with some of C's deeper commitments. C's honesty commits him to flout his general moral obligation to not murder, and his honesty may turn out to be at odds with other personal commitments of central importance. What if C is questioned by the police or by enemies of his employer? If $C$ refuses to answer their questions, then he may end up spending the rest of his life in prison or his refusal may lead to his imminent demise. Moreover, C may agree to kill a person who he later discovers to be a close friend or relative and the deed would tear him apart. As this type of case illustrates, honesty can lead to a form of moral disintegration. Honesty is a form of quasi-integrity but it is not the real thing.

Sincerity is another form of quasi-integrity that is commonly confused with integrity. Lionel Trilling, in his influential study of sincerity in Sincerity and Authenticity, writes of the word 'sincerity' that "it refers primarily to a congruence between avowal 
and actual feeling.”28 However, this cannot be exactly right. Persons are often sincere or insincere about statements other than avowals. ${ }^{29}$ If $\mathrm{T}$ believes that there is going to be a thunderstorm this evening and tells his enemy $\mathrm{E}$ that there is no chance that there is going to a storm this evening, then $\mathrm{T}$ has been insincere. Sincere persons say what they believe in the sense that if $\mathrm{S}$ makes an assertion, then that assertion expresses a proposition that $\mathrm{S}$ believes to be true but this fact about assertion is merely a tautology about the nature of assertion. Sincerity and honesty both require being truthful and avoiding deception in one’s dealings with others.

Sincerity is neither necessary nor sufficient for integrity. Sincerity is not sufficient for integrity because someone may sincerely assert their beliefs and lack integrity. Consider the assertions of hypocrites, sell-outs and persons who are massively selfdeceived, ignorant or morally wicked. The virtue of standing up for your moral commitment does not consist in expressing or sincerely avowing your most intense moral beliefs, principles or convictions. Moreover, sincerity is not necessary for integrity, because there may be circumstances in which persons of integrity may need to deploy deception. A person of integrity may need to be insincere about what his or her moral commitments are in oppressive and unjust political arrangements-in those circumstances standing up for your commitments may require being deceptive about what your real moral commitments are and it may require using covert actions to eliminate injustice.

The last type of quasi-integrity to be examined here involves a collection of formal qualities. It is helpful to contrast substantive conceptions of integrity with merely

\footnotetext{
${ }^{28}$ Lionel Trilling, Sincerity and Authenticity, Cambridge, MA: Harvard University Press, 2.

${ }^{29}$ For discussion of this point see Charles Guignon On Being Authentic, London: Routledge, 2004.
} 
formal conceptions of integrity. ${ }^{30}$ Formal conceptions of integrity maintain that integrity consists in integrating one's volitional or cognitive structure into a consistent or coherent whole. ${ }^{31}$ These conceptions of integrity emphasize the wholeness that is exemplified by persons of integrity. So, according to formal conceptions of integrity, the beliefs, desires, evaluations, projects, intentions and actions of persons of integrity exemplify a large degree of consistency or coherence. These conceptions of integrity are merely formal because they do not place any constraints on the content of the beliefs, desires, evaluations, projects and intentions of persons of integrity. Formal conceptions of integrity emphasize the structure of the integration achieved by persons of integrity. Substantive conceptions of integrity maintain that achieving volitional or cognitive consistency is not sufficient for integrity. They maintain that there are substantive constraints on the content of the beliefs, desires, evaluations, projects, and intentions of persons of integrity: persons of integrity cannot have projects, principles or characters that are evil and such persons are, at least, morally decent. ${ }^{32}$ Formal conceptions of integrity constitute another form of quasi-integrity: they resemble integrity but they are not the real thing.

In this dissertation I argue for a substantive conception of integrity. According to this my view, integrity can be construed as (1) a form of wholeness (the wholeness of a moral life), (2) a form of purity (moral purity) and (3) as an ethical quality that brings

\footnotetext{
${ }^{30}$ I borrow this terminology from David Thunder's account of the concept of integrity in 'Rethinking Modern Citizenship: Towards a Politics of Integrity and Virtue', Dissertation, Notre Dame, 2006.

${ }^{31}$ For examples of this kind of conception of integrity, see Harry Frankfurt The Reasons of Love (Princeton, N.J.: Princeton University Press, 96-100) and John Bigelow and Robert Pargetter, 'Integrity and Autonomy' (American Philosophical Quarterly, 44, 2007, 39-49).

${ }^{32}$ Thunder distinguishes two types of substantive conceptions of integrity: partially substantive conceptions and fully substantive conceptions. The former maintain that persons of integrity must be minimally decent or reasonable; i.e., they must not become morally wicked. The latter maintain that persons of integrity must fully achieve the morally good life. Thunder defends a fully substantive conception of integrity; whereas here I defend what he describes as a partially substantive conception of integrity.
} 
together sound moral judgment and virtue (the virtues of moral commitment and standing up for that commitment). The imagery of wholeness, purity and virtue provide a wide range of helpful models for understanding integrity. According to my conception of the virtues of integrity, these virtues involve virtues of thought (cognitive virtues and affective virtues) and virtues of action. My conception of integrity draws attention to the way in which integrity is a virtue for the individuals who possess it and how societies should not impose barriers that impede their citizens from possessing integrity. ${ }^{33}$

One worry immediately facing my conception of integrity is that if integrity is nothing over and above the virtues of moral commitment and standing up for that commitment, why not simply drop the discussion of integrity and discuss these virtues? ${ }^{34}$ I have two related replies to this worry. First, the everyday rhetoric about integrity is important and the concept of integrity has connotations and significance that would be lost if the concept of integrity dropped out of view. The concept of integrity that is found in its everyday rhetorical deployment can be clarified and vindicated with a conception of integrity as involving moral commitment and standing up for that commitment. My conception of integrity is intended to clarify and vindicate our concepts of personal integrity, moral integrity and professional integrity. One purpose of my conception of integrity is to provide an integrated conception of integrity. Second, the concept of integrity has connotations of integration and unification that are not suggested by the idea of moral commitment and those connotations can help to elucidate the nature of the virtue

\footnotetext{
${ }^{33}$ For a defense of view that integrity consists in standing for something, see Cheshire Calhoun 'Standing for Something' (Journal of Philosophy, 92, 1995, 235-260). It is beyond the scope of this discussion to compare and contrast Calhoun's conception of integrity with my own.

${ }^{34}$ This worry is Loren Lomasky's central objection to the conception of integrity defended in Stephen Carter's Integrity: see Loren Lomasky 'Its Own Reward' (Reason, August/September, 1996). My own conception of integrity is largely in the spirit of Carter's view. However, I do want to distance myself from Carter's preachy tone and some of the implications he draws from his conception of integrity. The following replies are intended to defend both Carter's view and my own.
} 
of moral commitment. Focusing on the way in which a moral life is integrated illuminates the nature of the moral commitment. So, examining the relation between integrity and moral commitment provides reciprocating insights for each concept. 


\section{Chapter 2 Revisiting Williams on Integrity, Moral Identity and Virtue}

I. Introduction. About forty years ago it would have been correct to say that integrity is a neglected topic in analytical discussions of ethics. ${ }^{35}$ Bernard Williams's integrity-based critique of utilitarianism, and his more general attack on the dominant impartialist moral theories of the day, deontological and consequentialist moral theories, brought an end to this trend in the early 1970 's. ${ }^{36}$ Williams's early writings on integrity initiated serious analytical discussions about integrity and his work on the topic revealed its significance for philosophical ethics. ${ }^{37}$

In this chapter I reconstruct the conception of integrity at work in Williams's early writings on the topic. My interest in Williams's conception of integrity is both historical and philosophical—Williams's early writings on integrity were an important part of a dramatic shift in the topics of interest for Anglo-American moral philosophy. Williams's discussion of integrity is important for understanding issues of central importance for normative philosophy-issues about the nature of morality and moral commitment.

\footnotetext{
${ }^{35}$ Although integrity was widely ignored in the mainstream Anglo-American writings on ethics during the $20^{\text {th }}$ Century prior to 1970 , it was a topic of ethical discussion on the Continent. It is reasonable to suppose that Nietzsche's widespread influence on Continental philosophy during the first half of the $20^{\text {th }}$ Century was a major source of the Continental interest in the topic of integrity. It is no surprise that Nietzsche was also a major influence on Williams's ethical thinking-evidence of Nietzsche's influence on Williams is found in the section on Nietzsche in Williams's The Sense of the Past: Essays in the History (ed., Myles Burnyeat, Princeton N.J.: Princeton University Press, 2006, 297-337).

${ }^{36}$ Williams's "A Critique of Utilitarianism", which was an essential part of his contribution in Utilitarianism: For and Against (eds. J.J.C. Smart and Bernard Williams, Cambridge: Cambridge University Press, 1973) has been discussed, at some point, by most of the prominent contemporary moral philosophers in the Analytic tradition.

${ }^{37}$ All of my references to Williams's 'early writings' refer to his writings prior to Ethics and the Limits of Philosophy (Cambridge, MA: Harvard University Press, 1985). There is an interesting discontinuity between Williams's early writings on morality and his critique of "the morality system" in Ethics and the Limits of Philosophy. His earlier writings suggest a moral critique of impartialist moral theories and the latter suggests an extra-moral critique, or a critique of based on non-moral values, of impartial moral theories: see footnote 36 for more on this point.
} 
My reconstruction of Williams's conception of integrity shows its relation to the ideals of authenticity and individuality — topics of concern for philosophers usually categorized as Existentialists. ${ }^{38}$ Williams's arguments pose challenging questions about the relation between authenticity, individuality, morality and the virtues.

Section II sketches the main arguments involved in Williams's critique of utilitarianism and provisionally sets out his conception of integrity. Section III continues reconstructing Williams's conception of integrity and examines his arguments for the claim that integrity is neither narcissistic nor a virtue. Section IV examines three main criticisms of Williams's conception of integrity and shows how the central aspects of Williams's position can be defended against those criticisms.

II. Williams's Critique of Utilitarianism. In this section I examine Williams's early writings on integrity with the intention of reconstructing the conception of integrity deployed in those arguments. It is assumed that Williams's integrity-based critique of utilitarianism contains a single conception of integrity. Someone may argue that Williams's arguments contain multiple conceptions of integrity, but this interpretation of Williams's critique of utilitarianism should be rejected since it uncharitably weakens Williams’s criticisms of utilitarianism. If Williams's arguments against utilitarianism shift from one conception of integrity to another, then his arguments involve fallacious

\footnotetext{
38 Authenticity and integrity have central roles in the ethical theorizing of Nietzsche, Kierkegaard, Heidegger, Sartre and Camus. For excellent discussions of these topics and how they bear on Existentialism, see Fredrick Olafson's Principles and Persons: An Ethical Interpretation of Existentialism (Baltimore, MD: The Johns Hopkins Press, 1967), Lionel Trilling's Sincerity and Authenticity (Cambridge, MA.: Harvard University Press, 1972), Charles Taylor's Ethics of Authenticity (Cambridge, MA: Harvard University Press, 2002) and Charles Guignon’s On Being Authentic (London: Routledge, 2004).
} 
equivocation. Surely, it would be unfair to attribute such an egregious error to Williams's arguments.

Reconstructing the conception of integrity that is working behind the scenes in Williams's arguments is an important and challenging task because Williams writes little about the nature of integrity. The conception of integrity that I attribute to Williams may not capture his view to the letter, but I am motivated by the sometimes conflicting goals of presenting a conception of integrity that is true to the text and also presenting a view that makes the strongest case for Williams's conclusions. Moreover, in this chapter I do not discuss whether Williams's case against utilitarianism has the resources for a decisive refutation of the theory. My primary goal is to unpack the conception of integrity at work in his arguments.

Williams's central criticism of utilitarianism is that it attacks the integrity of persons. The conception of integrity he uses to support this criticism is intended to show that utilitarianism presupposes distorted conceptions of persons, projects, desires, commitments, actions and moral identity. Williams's argument for the claim that utilitarianism attacks the integrity of persons discusses the cases of two characters that have become part of the lingua franca of contemporary ethics, George and Jim. These cases involve situations in which the protagonist must make a significant, charactershaping choice.

George's Career Choice: George recently received a degree in chemistry and is having serious difficulties finding a job. His health is poor and his illness limits his job prospects. George is also married and has young children. He urgently needs a job to help his family. An older chemist who knows about George's situation informs George about 
a well paying job that is available at a laboratory that is involved in research for biochemical warfare. George is strongly opposed to bio-chemical warfare and does not want to do anything that would directly support it. However, he needs the money and he is informed that if he does not take the job, there is another candidate who has no scruples about bio-chemical warfare and will pursue the research with much greater zeal and efficiency than George would. In fact, the older chemist has approached George with the job offer because of his concern for George's family and the zealousness of the other candidate. Williams asks, "What should he do?”39

Jim in the Jungle: Jim is on a botanical expedition in South America and stumbles into a horrible situation. He wanders into the central square of a remote village in which twenty people are restrained against a wall and are being guarded by armed men in uniforms. The captain in charge questions Jim and comes to believe that his presence in the village is a mere coincidence. The captain informs Jim that the captives are a randomly selected group of inhabitants that are about to be killed in order to put an end to recent acts of protest against the government. The captain is honored by Jim's presence and he is happy to offer Jim the opportunity to kill one of the innocent villagers himself. If Jim accepts the offer, the captain will release the surviving nineteen villagers. If Jim refuses, the captain will go ahead with the original plan and kill all twenty prisoners. Violent resistance is not an option—it would result in Jim and the twenty villages getting killed. Williams asks, "What should he do?"40

Williams contends that if utilitarianism is true, then it is obviously true that George should take the job and it is obviously true that Jim should shoot the innocent

\footnotetext{
${ }^{39}$ Williams, Utilitarianism: For and Against, 97, 98.

${ }^{40}$ Ibid., 98, 99.
} 
villager. ${ }^{41}$ Williams suggests what I call the obviousness objection to utilitarianism, which is the charge that utilitarianism makes it too easy to determine the morally right course of action: utilitarianism does not give adequate weight to considerations that bear on a person's integrity. The obviousness objection suggests that there is more involved in practical and moral deliberation than utilitarianism considers: even in stories as roughly formulated as those featuring George and Jim, utilitarianism has a ready-made moral decision for George and Jim to make-maximize aggregate utility. Williams’s arguments suggest that it is a shortcoming of an ethical or moral theory to have such straightforward answers to such under-described situations: a plausible moral theory ought to appreciate the richness and texture of the moral life.

In response to the obviousness objection a utilitarian might deny that utilitarianism presupposes that all persons should actively pursue the project of maximizing aggregate utility. It may be an empirical fact that persons do a better job of maximizing aggregate utility by pursuing their lower-order projects: consciously deploying the principle of utility in everyday decision making may not maximize aggregate utility. In other words, a utilitarian may deny that utilitarianism is a good decision procedure for the actual practice of practical deliberation and instead construe utilitarianism as a metaphysical theory that explains the nature of moral obligation. ${ }^{42}$ One challenge facing this utilitarian response is that by conceding that utilitarianism is not a good decision procedure for everyday practical deliberation, the utilitarian has given up

\footnotetext{
${ }^{41}$ Ibid., 99. Williams's arguments are intended to undermine act-utilitarianism. He observes that a rule utilitarian can avoid some of his main arguments, but it has other problems. Hereafter, my discussion of utilitarianism is only focused on act-utilitarianism, which contends that an action is morally wrong if and only if it does not maximize expected aggregate utility.

${ }^{42}$ This point is clearly formulated and defended in Peter Railton 'Alienation, Consequentialism and the Demands of Morality’, Philosophy and Public Affairs, 13, 1984, 134-171.
} 
one feature of the theory that is purported to be one of its most attractive featuresnamely, that utilitarianism is helpful for making decisions in everyday practical affairs. Of course, there is much more that a sophisticated utilitarian could say in response to this challenge, but pursuing this topic any further would lead us too far astray from the task of re-constructing Williams's conception of integrity.

In addition to the obviousness objection, Williams develops the charge that utilitarianism attacks the integrity of agents by formulating what I call the alienation objection to utilitarianism, which states that utilitarianism cannot make sense of the way that individuals are related to their own actions and it cannot make sense of significant differences between your own actions and the actions of others. ${ }^{43}$ According to this objection, utilitarianism alienates persons from their own projects and it cannot make sense of morally significant differences between your deepest projects and desires and the deepest projects and desires of others. ${ }^{44}$ In short, the alienation objection states that utilitarianism presupposes an inadequate and impoverished moral psychology.

Williams's argument for the alienation objection rests upon a criticism of the consequentialist doctrine of negative responsibility. Williams formulates the doctrine of negative responsibility as follows: "if I am ever responsible for anything, then I must be just as much responsible for things that I allow or fail to prevent, as I am for things that I myself, in the more everyday restricted sense, bring about." ${ }^{25}$ This formulation of the doctrine is not as lucid as one would like. To understand the doctrine of negative responsibility and why consequentialists are committed to it, it helps to examine some of

\footnotetext{
${ }^{43}$ Ibid., 99.

${ }^{44}$ There are salient relations between Williams's alienation objection to utilitarianism and Rawls's claim that utilitarianism does not respect the separateness of persons. This point is discussed in Chapter 6 .

${ }^{45}$ Ibid., 95.
} 
Williams's assumptions about consequentialist moral theories. According to Williams, consequentialist moral theories are characteristically concerned with maximizing certain states of affairs in the world and from a consequentialist point of view it is irrelevant whether the states of affairs to be maximized are of the results my own deeds or are the results of other causal factors: "for consequentialism, all causal connexions are on the same level, and it makes no difference, so far as that goes, whether the causation of a given state of affairs lies through another agent, or not." ${ }^{46}$ Williams holds that the doctrine of negative responsibility is an upshot of consequentialism's commitment to regarding states of affairs in the world as the bearers of ultimate value. Since consequentialism only regards states of affairs as morally valuable, consequentialist theories leave no room for me to see my actions and my projects as valuable ${ }^{47}$ Williams suggests that the utilitarian neglect of the moral significance of an agent's own actions and projects is the result of the extreme form of impartiality that that pervades utilitarianism. Utilitarianism assumes that moral considerations are essentially impartial: it assumes that moral considerations require the existence of moral principles that should be endorsed by all moral agents. Utilitarianism presents an extremely impartial conception of morality and its excessive impartiality is related to Williams's critique of the doctrine of negative responsibility and to the alienation objection. From the point of view of the utilitarian calculus, there is no comprehensible moral difference between me bringing about a certain outcome rather than someone else producing it. Utilitarianism

\footnotetext{
${ }^{46}$ Ibid., 94.

47 Since my primary concern is to unpack Williams's conception of integrity, I shall not discuss complications that arise when you consider maximizing, agent-relative moral theories. On the distinction between maximizing and non-maximizing moral theories and agent-neutral and agent-relative moral theories, see Derek Parfit's Reasons and Persons (New York: Clarendon Press, 1987). For a critique of this distinction, see Christine Korsgaard's "The Reasons We Can Share: An Attack on the Distinction Between Agent-Relative and Agent-Neutral Value” (in her Creating the Kingdom of Ends, Cambridge: Cambridge University Press, 2000, 275-310).
} 
views all actions from a perspective of the world sub specie aeternitatis and Williams suggests that this God's eye perspective on the world is not, and should not, be considered the point of view that we must view the world as moral agents. The doctrine of negative responsibility is the consequence of an excessively impartial moral theory that abstracts from the identity of the agent, leaving just a locus of causal intervention in the world, and this feature of such theories is not merely a surface paradox. ${ }^{48}$ In sum, Williams criticizes the doctrine of negative responsibility on the grounds that it makes a person's own projects and actions no more morally important than the projects and actions of others since from the point of view of the utilitarian calculus neither your own projects and actions nor the projects and actions of others have greater inherent moral significance. Williams challenges you to see the inherent moral significance of your own actions, a consideration that falls out of view if you accept utilitarianism. Williams contends that utilitarianism and the doctrine of negative responsibility do not adequately describe the moral significance of other people's projects on our decisions:

It is absurd to demand of such a man [i.e., a man of integrity, a man with commitments], when the sums come in from the utility network which the projects of others have in part determined, that he should just step aside from his own project and decision and acknowledge the decision which utilitarian calculation requires. It is to alienate him in a real sense from his actions and the source of his action in his own convictions. It is to make him into a channel between the input of everyone's projects, including his own, and an output of optimific decisions; but this is to neglect the extent to which his actions and his decisions have to be seen as the actions and decisions which flow from the projects and attitudes with which he is most clearly identified. It is thus, in the most literal sense, an attack on his integrity. ${ }^{49}$

\footnotetext{
${ }^{48}$ Ibid., 96.

${ }^{49}$ Ibid., 1116, 117. Williams's emphasis on "his actions" and "his decisions" bears a striking similarity to a passage from section 8, "Unconscious Virtues," of Nietzsche's The Gay Science. Nietzsche writes that certain virtues are barely visible in persons and thereby those virtues are analogous to the microscopic scales of some reptiles, "Thus we have, for example, our industry, our ambition, our acuteness-all the world knows that - but in addition to all that we probably also have our industry, our ambition, our
} 
Williams contends that utilitarianism and its doctrine of negative responsibility gloss over morally significant differences in the ways that the projects of others may bear on our decisions. ${ }^{50}$ Williams suggests that in the case of George, considering the projects of his wife and his other family members may plausibly issue in a morally grounded decision that contravenes the course of action required by utilitarianism—his family members may be deeply concerned with George's commitments, moral identity and integrity. ${ }^{51}$ The impartial standpoint from which utilitarianism makes moral judgments runs roughshod over the standpoint from which George forms his moral commitments. Williams also suggests that considering the case of Jim may not demand a different course of action than what utilitarianism demands, but utilitarianism and the doctrine of negative responsibility fail to accurately describe the influence of the captain's projects on Jim's decision and it fails to register the moral significance of Jim's personal commitments on the situation. If Jim does not shoot one villager, then his decision results in the killing of twenty other villagers. His decision is causally responsible for the resulting deaths of twenty villagers, but utilitarianism and the doctrine of negative responsibility do not register the moral significance of the fact that the death of the twenty villagers is the result of the captain's projects and actions. These doctrines also fail to describe the intrinsic differences between the captain's projects and Jim's projects. The captain is morally responsible for both the order to kill the innocent villagers and the dilemma that Jim must face.

acuteness; but for these reptile scales no microscope has been invented yet.” In section IV I briefly discuss the relation of some of Nietzsche's views on integrity to those of Williams.

50 For a persuasive development of this line of reasoning see Loren Lomasky's 'A Refutation of Utilitarianism', Journal of Value Inquiry, 17, 1983, 259-279.

${ }^{51}$ Ibid. 117. 
A utilitarian may reply to both the alienation objection and Williams's related critique of the doctrine of negative responsibility, with what I call the charge of selfindulgence, which maintains that acting contrary to the verdicts of the utilitarian calculus on the grounds that Williams suggests constitutes a morally repulsive act of squeamishness or self-indulgence. According to the charge of self-indulgence, if an agent refuses to maximize aggregate utility because doing so would alienate that agent from his or her own projects, then that agent is either too selfish or too squeamish to do what that agent has a moral obligation to do. A utilitarian may contend that Jim may feel moral repulsion at the thought of shooting an innocent person and Jim may shatter his selfimage by doing so (and such repulsion is praiseworthy since it usually maximizes aggregate utility), but Jim's (utilitarian) moral obligation to maximize aggregate utility demands that he must shoot the innocent villager and, thus, it is morally impermissible for him to refrain from shooting the person because of his own self-image. Jim may have a wide range of unpleasant feelings after shooting the villager but his moral obligation to do so is sufficiently weighty to justify his action. According to this objection, the alienation objection expresses a narcissistic point of view that would give greater priority to psychological considerations than it would to moral ones: it seems that Williams would give one's own sense of moral purity greater weight than he would give to one's actual moral obligations.

Williams predicts the utilitarian charge of self-indulgence and responds as follows.

The reason why the squeamishness appeal can be very unsettling, and one can be unnerved by the suggestion of self-indulgence in going against utilitarian considerations, is not that we are utilitarians who are uncertain what utilitarian value to attach to our moral feelings, but that we 
are partially at least not utilitarians, and cannot regard our moral feelings merely as objects of utilitarian value. Because our moral relation to the world is partly given by such feelings, and by a sense of what we can or cannot 'live with', to come to regard those feelings from a purely utilitarian point of view, that is to say, as happenings outside one's moral self, is to lose a sense of one's moral identity; to lose, in the most literal way, one's integrity. At this point, utilitarianism alienates one from one's moral feelings... it alienates one from one's actions as well. ${ }^{52}$

Williams emphasizes that integrity is primarily a moral quality that goes hand in hand with having a moral self or a moral identity. Williams also stresses that having a moral self or a moral identity requires integrating one's own moral feelings and utilitarianism is an untenable moral theory since it alienates an agent from his or her moral feelings and prevents the agent from having the form of integrity that is required for possessing a moral self or moral identity. ${ }^{53}$

Examining the dialectical moves involved in the debate between Williams and the utilitarian with regards to the alienation objection assists in the project of unearthing Williams's conception of integrity. The following two utilitarian responses to the alienation objection help to elucidate Williams's conception of integrity. ${ }^{54}$ The first response grants Williams’s conclusion that integrity is not available to the utilitarian, but then contends that Williams's conception of integrity does not have moral significance. According to this response, Williams' conception of integrity expresses a narcissistic point of view that gives psychological consideration greater ethical weight than moral considerations. ${ }^{55}$ The second response contends that, contrary to Williams's arguments,

\footnotetext{
52 Ibid., 103, 104.

${ }^{53}$ Williams provides a moral critique of utilitarianism in this argument. Williams adopts an extra-moral critique of utilitarianism in Ethics and the Limits of Philosophy: there he argues that non-moral considerations can give an agent reasons for rejecting the extreme impartiality of utilitarianism.

${ }^{54}$ Both of these responses are suggested in Peter Railton's “Alienation, Consequentialism and the Demands of Morality” (Ibid.).

55 As Daniel Markovits expresses this objection in "The Architecture of Integrity” (in Reading Bernard Williams, ed., Daniel Calcutt, London: Routledge, 2009, 110-138): "it is not obvious that the burdens
} 
obeying the deliverances of the utilitarian calculus can be a source of integrity. The first response and Williams's replies to it are discussed both in the remaining parts of this section and in section III (which also presents Williams' argument that integrity is not a virtue). The second response is discussed in section IV.

In response to Williams's contention that integrity is not available to the utilitarian, a utilitarian may bite the bullet and contend that it is not morally problematic for agents to lose their integrity—so, it is not morally problematic for agents to be alienated from their projects and actions in the way that Williams describes. This response denies that the alienation objection constitutes a reductio ad absurdum of utilitarianism: utilitarianism can live with the trade-off that it produces the form of alienation that Williams describes. According to this utilitarian response, although utilitarianism does require that persons may have to sacrifice their integrity in certain extreme circumstances, the sacrifice is morally admirable since utilitarianism is the correct theory of moral obligation. Hence, if Jim must sacrifice his integrity in order to fulfill his (utilitarian) moral obligations, then he must make the sacrifice. According to this line of utilitarian reasoning, Williams's argument begs the question against utilitarianism by asserting that moral feelings and a certain self-image that Williams characterizes as moral presents a problem for utilitarianism: his accusation that utilitarianism alienates agents from their moral identities and actions is nothing over and above an appeal to self-indulgence under the guise of a moral identity.

associated with lost integrity are ethical, rather than emotional." (121) Markovits is not convinced by this objection to Williams' alienation objection, but he does consider it to be a serious challenge. I concur with Markovits's assessment. 
To avoid an impasse with the utilitarian on this point, Williams discusses the charge of self-indulgence in "Utilitarianism and Moral Self-Indulgence." ${ }^{56}$ Williams’s response to the charge of self-indulgence is noteworthy for my purposes, because his response explains his conception of integrity more than his earlier writings: this article is one of the few places in which Williams explicitly writes about the nature of integrity. Williams argues that if the utilitarian charge of self-indulgence is to avoid begging the question against his own conception of integrity as moral identity, then the charge of selfindulgence must not be equivalent to expressing disapproval of persons that knowingly act in an anti-utilitarian way. ${ }^{57}$ Williams claims that the utilitarian charge of selfindulgence must emphasize features of self-indulgence that do not presuppose utilitarianism so that the charge of self-indulgence is not question-begging. So, Williams contends, the utilitarian charge of self-indulgence ought to rest upon considerations that are acceptable to non-utilitarians in order for the utilitarian critique to be compelling.

Williams formulates a version of the charge of self-indulgence that does not presuppose utilitarian considerations: it involves describing the features of self-indulgent actions that are unacceptable for reasons that do not presuppose utilitarianism. Williams replies to this version of the charge of self-indulgence by arguing that his conception of integrity does not have the unacceptable features of self-indulgence. ${ }^{58}$ Williams contends that if a person's actions are self-indulgent, then those actions do not express a concern for other people; at best they express a concern for himself caring for other people (and

\footnotetext{
${ }^{56}$ Bernard Williams, 'Utilitarianism and Moral Self-Indulgence' in his Moral Luck (Cambridge: Cambridge University Press, 1981, 40-53).

${ }^{57}$ Ibid., 44. There are difficult questions about where the burden of proof lies in this argument. I do not discuss these questions since my primary concern is to reconstruct Williams's conception of integrity.

${ }^{58}$ I shall ignore worries about whether Williams has set up a straw man or whether there are other considerations that may show why integrity is problematically self-indulgent.
} 
such concern is blameworthy but not for utilitarian reasons. ${ }^{59}$ For instance, a person may act in this problematically self-indulgent manner if he performs a generous action because he is motivated by a concern for his own generosity. For example, if Alexander gives money to the poor and thereby performs a generous action but he performs the action because he wants to be a generous person (or because he wants other people to perceive him as a generous person), then his generous action expresses a concern for himself caring for other people and it would be natural to say that his action is generous but it is not performed generously (or, perhaps, his action is generous but it is not motivated by the virtue of generosity). An objectionably reflexive concern with one's self is at the heart of the charge of self-indulgence. ${ }^{60}$ I shall describe this form of selfindulgence as narcissistic concern and actions that express narcissistic concern as narcissistic actions. So, the utilitarian charge of self-indulgence suggests that if George and Jim do not perform the actions mandated by utilitarianism because George and Jim are concerned with their own integrity, then they are performing narcissistic actions in virtue of their own narcissistic concern. So, their narcissistic actions are deplorable not only for utilitarian considerations but for independent non-utilitarian considerations as well—narcissistic concern is inherently blameworthy. ${ }^{61}$

Williams contends that his conception of integrity neither expresses a form of narcissistic concern nor does it imply the presence of narcissistic concern in persons of integrity. Williams's argument that integrity is not narcissistic is supported by the claim

\footnotetext{
59 Ibid., 45.

${ }^{60}$ Ibid., 47.

61 An ethical egoist or a Randian Objectivist my construe narcissistic concern as a virtue, but construing narcissistic concern as a virtue constitutes a straightforward reductio of their positions.
} 
that integrity is not a virtue. Section III discusses Williams's arguments for the claims that integrity is neither narcissistic nor a virtue.

III. Is Integrity a Narcissistic Trait or a Virtue? Williams's argument that being concerned with your own integrity does not characteristically exemplify narcissistic concern articulates the broad contours of his conception of integrity and it is worth quoting at length.

What about a concern with one's own integrity? The simplest thing to say about this would be that integrity is one case of a virtue, and that, like other virtues, it is subject to reflexive deformation [i.e., narcissistic concern]. But I think that this would be wrong; rather, one should perhaps say that integrity is not a virtue at all. In saying that, I do not mean that there is not all that much to be said for it, as one might say that humility was not a virtue. I mean that while it is an admirable human property, it is not related to motivation as the virtues are. It is not a disposition which itself yields motivations, as generosity and benevolence do; nor is it a virtue of that type, sometimes called 'executive' virtues, which do not themselves yield a characteristic motive, but are necessary for that relation to oneself and the world which enables one to act from desirable motives in desirable ways - the type that includes courage and self-control. It is rather that one who displays integrity acts from those dispositions and motives which are most deeply his, and has also the virtues that enable him to do that. Integrity does not enable him to do it, nor is it what he acts from when he does so.

If this is right, we can see why integrity, regarded as a virtue, can seem to smack of moral self-indulgence. For if it is regarded as a motive, it is hard to reconstruct its representation in thought except in the objectionable reflexive way: the thought would have to be about oneself and one's own character, and of the suspect kind. If integrity had to be provided with a characteristic thought, there would be nothing for the thought to be about except oneself-but there is no such characteristic thought, only the thought associated with the projects, in carrying out which a man may display his integrity. Relatedly, one cannot directly bring someone up to possess integrity, in the sense of teaching him to display or exercise it; rather one brings it about that he genuinely cares for something and has the characteristics necessary to live in the spirit of that. $^{62}$

\footnotetext{
${ }^{62}$ Bernard Williams, 'Utilitarianism and Moral Self-Indulgence’ in his Moral Luck, 49.
} 
It will help to summarize the main points of Williams's arguments in the above passage.

(W1) Integrity is an admirable human property, but

(W2) integrity is not a virtue.

Williams argues for (W2) on the grounds that integrity is not related to human motivation in the same way that virtues are. Williams suggests that virtues are dispositions that yield characteristic representations in thought (so, a virtue such as generosity may characteristically involve a thought like this person needs help), and integrity is not a virtue because it is not a disposition that produces any distinctive representation in thought. Moreover, he claims, integrity is not an executive virtue. Williams also argues for (W2) on the basis of the following instance of modus tollens:

(W3) If integrity is a virtue, then it exemplifies narcissistic concern, and (W4) integrity does not exemplify narcissistic concern.

Also, consider the contraposition of (W3): if integrity does not exhibit narcissistic concern, then integrity is not a virtue. The contraposition of (W3) provides a premise for a straightforward modus ponens for the conclusion that integrity is not a virtue.

Williams argues for (W3) on the grounds that if integrity is a virtuous disposition that produces motives, then it is hard to see how integrity could be construed in a way that does not exemplify narcissistic concern. That is, he contends, if integrity is a virtue, it is hard to see how it could motivate a person to be concerned with something other than oneself and one’s own character.

Williams explains (W1), the claim that integrity is an admirable human quality, and he argues for (W4) on the grounds that 
(W5) integrity is the result of a person carrying out his or her deepest motives and dispositions.

(W5) further clarifies (W1) because integrity is considered to be an admirable human property because persons of integrity pursue their deepest motives. As quoted above, Williams holds that "one who displays integrity acts from those dispositions and motives that are most deeply his, and has also the virtues that enable him to do that.” According to Williams, integrity is not a unique disposition or motive that enables $\mathrm{S}$ to act from S's deepest motives. He contends that integrity may result from a heterogeneous mix of dispositions: if S acts from S's deepest motives or dispositions, then S displays integrity but $\mathrm{S}$ is not motivated by S's integrity, $\mathrm{S}$ is motivated by those deep motives and dispositions. Since the deepest motives of persons are highly idiosyncratic, there will be wide array of motives, concerns and dispositions that issue in integrity. One way to state Williams's position is to describe integrity as an achievement that is the result of an individual's deeds and pursuits but it is not a motivation or a disposition with a characteristic thought associated with it. According to this view, integrity is more like an award than a virtue or a character trait. The achievement of integrity is not causally efficacious for the individuals that achieve it since it is not a motivational state. Integrity, like an award, may indirectly motivate someone, for instance, if someone has the strong desire to have integrity. However, in that case, it is the desire to have integrity that is motivating the person and not the integrity itself. So, Williams suggests, S achieves integrity by pursuing S's deepest motives or dispositions and also having the virtues required for successfully pursuing them, but integrity does not cause or directly motivate a person to pursue his or her deepest projects. Moreover, (W5) supports (W4) because 
pursuing one's deepest motives and dispositions need not be narcissistic: other-regarding desires such as a parent's concern for his or her child or a citizen's love of his or her country may be deep motives that are sources of integrity. At bottom, Williams's contention that utilitarianism attacks the integrity of agents centers on the claim that utilitarianism alienates persons from their deepest concerns and it does not leave any conceptual room for understanding the inherent moral significance of these endeavors. ${ }^{63}$ In other words, Williams contends that moral deliberation and moral commitment may require responding and acting on the basis of highly personal and partial considerations and allowing those considerations to either silence or outweigh the impartial considerations of the utilitarian calculus.

In section II I observed that Williams maintains that integrity centrally involves (1) a person's moral feelings, (2) a person's moral relation to the world and (3) a person's moral identity. These claims help to clarify Williams's claims that (W1) integrity is an admirable quality, but (W2) integrity is not a virtue, and (W5) integrity is exemplified by a person carrying out his or her deepest motives or dispositions. There are important conceptual connections between Williams's emphasis on the relation of a moral identity and integrity and also (W1), (W2) and (W5).

Williams's first book, Morality, contains some insights into his understanding of the moral significance of integrity. ${ }^{64}$ In a chapter entitled "What is Morality About?" Williams sympathetically considers a moral outlook inspired by D.H. Lawrence's

\footnotetext{
${ }^{63}$ This point may be developed by construing it as an emphasis on agent-centered restrictions: for a development of this approach see Samuel Scheffler's The Rejection of Consequentialism (Oxford: Oxford University Press, 1982).

${ }^{64}$ Morality: An Introduction to Ethics (New York: Harper Torchbooks, 1972), among other things, presents a critique of utilitarianism and Kantianism that elucidates Williams's other influential essays written in the early 1970's that also criticize those moral theories. Because of the overlapping themes in much of his early work, a full appreciation of most of his essays written during that period involves a study of Morality, Problems of the Self (Cambridge: Cambridge University Press, 1973), and Utilitarianism: For and Against.
} 
response to Benjamin Franklin’s conventional moral virtues-Lawrence encourages his readers to "Find your deepest impulse and follow that." ${ }^{65}$ Elaborating on Lawrence’s counsel, Williams writes,

The notion that there is something that is one's deepest impulse, that there is a discovery to be made here, rather than a decision, and the notions that one trusts what is so discovered, although unclear where it will leadthese, rather, are the point. The combination-discovery, trust, and riskare central to this sort of outlook, as of course they are to the state of being in love. It is even tempting to find, among the many historical legacies of Protestantism to Romanticism, a parallel between this combination and the pair so important to Luther: obedience and hope. Both make an essential connection between submission and uncertainty; both, rather than offering happiness, demand authenticity. ${ }^{66}$

Williams's development of the Lawrencean idea that morality is about finding your deepest impulse and following it is part of a larger argument that he formulates against the idea that morality is primarily a matter of maximizing aggregate utility. ${ }^{67}$ This Lawrencean moral outlook assigns a great deal of moral significance to an individual's authenticity. This passage may also be construed as an elaboration of (W5) - integrity is the product of a person carrying out his or her deepest motives or dispositions. Since authenticity is commonly regarded as being true to one's commitments, it is intuitively plausible to see a close relation between Williams's concerns with the moral significance of (1) a person's commitments, (2) authenticity, and (3) moral identity. Williams asks us to consider widening the scope of morality to include personal and partial considerations: a person's moral identity and moral commitments may involve a concern for one’s own authenticity, friendships and intimate relationships.

\footnotetext{
${ }^{65}$ Ibid., 86. Morality is published in 1972 and “A Critique of Utilitarianism” is published one year later. It is plausible to assume Williams' views on the topic were roughly stable during the period of writing these essays.

${ }^{66}$ My italics, Ibid., 86.

${ }^{67}$ Robert Solomon defends a similar Romantic moral outlook in "The Virtues of a Passionate Life: Erotic Love and 'The Will to Power'” (in Virtue and Vice, eds. Ellen Paul, Fred Miller, and Jeffrey Paul, New York: Cambridge University Press, 1998, 91-118).
} 
Williams's invitation to consider widening the scope of morality to include partial and personal considerations raises concerns with the other prominent impartial moral theory of the day: Kantian deontology. Williams’s concern with the moral significance of authenticity and his integrity-based critique of utilitarianism is closely related to one of his main criticisms of Kantian deontology. Williams criticizes Kantian deontology on the grounds that it ignores or rejects the moral significance of individuals and their character. In “Persons, Character and Morality,” Williams writes,

There can come a point at which it is quite unreasonable for a man to give up, in the name of the impartial good ordering of the world of moral agents [i.e., the Kingdom of Ends], something which is a condition of his having any interest in being around in that world at all. Once one thinks about what is involved in having a character, one can see that the Kantians' omission of character is a condition of their ultimate insistence on the demands of impartial morality, just as it is a reason for finding inadequate their account of the individual. ${ }^{68}$

Williams's integrity-based critique of utilitarianism and his critique of Kantian deontology in "Persons, Character and Morality" both claim that these impartial moral theories fail to provide adequate conceptions of individuals. Since utilitarianism and Kantian deontology demand that all moral agents either act in accordance with or out of respect for impartial moral principles, he contends that these impartial moral theories do not assign the appropriate moral status to an individual's deepest projects and commitments. Kantian deontologists and utilitarians do not acknowledge the inherent moral significance of a person's deep concerns. Williams invites one to widen one's conception of morality to include deeply personal considerations. Impartial moral theories contend that the moral status of an individual's deepest projects and commitments depends upon whether those projects and commitments are performed in

\footnotetext{
${ }^{68}$ Bernard Williams, 'Persons, Character and Morality’ in his Moral Luck, 14.
} 
accordance with (or done for the sake of) the verdicts of impartial principles of action (e.g., the principle of utility or the categorical imperative). Alternatively, impartial moral theories may grant that an individual's deepest projects and commitments have moral significance but their moral significance must be derived from impartial moral principles. Williams rejects these assumptions of impartial moral theories on the grounds that that they do not take seriously a type of Lawrencean moral outlook that assigns inherent moral status or moral weight to an individual's deepest projects and commitments. In the final paragraph of Williams's integrity-based critique of utilitarianism, he writes, "Philosophers, not only utilitarian ones, repeatedly urge one to view the world sub specie aeternitatis, but for most human purposes that is not a good species to view it under."69 Williams's remark suggests that impartial moral theories ignore or reject the inherent moral significance of the partial ties that people have to other particular human beings. Williams's concern with integrity suggests that partial considerations, considerations about one's friendships, loyalties, intimate relationships, one’s own sanity, familial ties and cultural interests, have inherent moral significance that is not registered by moral theories that are essentially impersonal or impartial. This view suggests that viewing the world sub specie aeternitatis can be a vice if viewing the world from that perspective blinds one to the moral significance of many of the partial and particular ties that human beings have to one another and to their own projects and deepest concerns. Impartial moral theories and their accompanying demand to view the world from nowhere suggests an antiseptic and rigid conception of morality. As Williams writes, "The correct perspective on one's life is from now." 70

\footnotetext{
${ }^{69}$ Bernard Williams, Utilitarianism: For and Against, 118.

70 This quotation is from Bernard Williams's 'Persons, Character and Morality' in Moral Luck.
} 
IV. Virtue, Authenticity, and Morality. A vast body of literature has emerged in response to Williams's early arguments against the traditional, impartial moral theories. ${ }^{71}$ Williams’s arguments have pressured many Kantians and Utilitarians to find a place for partial relations in their moral theories. Rather than focusing on that literature, I shall examine three objections to Williams's conception of integrity that directly bear on the central questions of this dissertation: What is the nature of integrity? Can evil persons have integrity? Is integrity a virtue? If it is a virtue, what kind of virtue is it?

The first main objection to Williams's conception of integrity is that he does not make a convincing case that integrity is not a virtue. (To be fair, Williams only tentatively puts forward this suggestion: he writes that "one should perhaps say" that integrity is not a virtue.) Williams's main support for the claim that (W2) - integrity is not a virtue, is the claim that (W3) — if integrity is a virtue, then it exemplifies narcissistic concern. Williams's argument for (W2) is unsound because (W3) is not true. It is not the case that if integrity is a virtue, then it exemplifies narcissistic concern.

One dubious claim that Williams uses to defend (W3) is the suggestion that virtues are either dispositions that characteristically involve distinctive representations in thought or they are executive virtues (e.g., courage). Perhaps it is true that some virtues involve distinctive representations in thought-justice may involve seeing certain

\footnotetext{
${ }^{71}$ Williams's arguments are sympathetically developed in Loren Lomasky 'A Refutation of Utilitarianism' (Ibid.), Loren Lomasky Persons, Rights and the Moral Community (Oxford: Oxford University Press, 1987), and Samuel Scheffler's The Rejection of Consequentialism (Ibid.). For representative consequentialist criticisms of Williams's arguments in 'A Critique of Utilitarianism', see Peter Railton's 'Alienation, Consequentialism, and the Demands of Morality' and Liam Murphy's Moral Demands in Nonideal Theory (Oxford: Oxford University Press, 2000). For representative Kantian responses to Williams's arguments in 'Persons, Character and Morality' see Barbara Herman's 'Integrity and Impartiality' (in her The Practice of Moral Judgment, Cambridge: Harvard University Press, 1993, 23-44), Marcia Baron’s Kantian Ethics Almost Without Apology (Ithaca, N.Y.: Cornell University Press, 1995) and Christine Korsgaard's “The Reasons We Can Share: An Attack on the Distinction Between Agent-Relative and Agent-Neutral Values” (Ibid.).
} 
considerations as just or as right. However, the suggestion that all virtues require distinctive representations in thought is uncharacteristic of Williams's views on the virtues-I am unaware of any argument for this claim in any of his other works. ${ }^{72}$ Arguably, character traits such as tranquility, hospitality, wit and patience are virtues even though these traits do not require any distinctive representation in thought. Rather than deny that integrity is a virtue at all, it seems more plausible that the admirable nonmotivating achievements that Williams describes identify an often unnoticed category of virtues. Many of the dispositions listed above that do not require any distinctive representation in thought: tranquility, hospitality, wit and patience, seem to fall in this category. It is possible for these traits to be motivating dispositions but it is also possible that these traits are, at least in some circumstances, non-motivating achievements that are the result of a person's actions. It is also possible that authenticity and individuality are virtues that fall into this category of achievements. Integrity, authenticity and individuality are traits that involve being true to one's commitments, and, accordingly, these traits are often the result of one's own choices. Chapter 3 discusses the nature of commitment and it is argued that moral commitment is a virtue that is essential for integrity. According to this conception of integrity, it is a virtue that often eliminates narcissistic concern in its possessor.

The second main objection to Williams's conception of integrity is that a unified conception of moral identity and authenticity would be unstable, because morality and authenticity are inconsistent ideals. According to this objection, there are counter-

\footnotetext{
${ }^{72}$ Williams's discussion of the virtues in 'Acting as the Virtuous Person Acts' (in The Sense of the Past: Essays in the History of Philosophy, ed. Myles Burnyeat, Princeton: Princeton University Press, 2006, 189197) does not provide any motivation for the requirement that all virtues must involve a distinctive representation in thought.
} 
examples to the thesis that authenticity can provide a stable grounding for moral considerations. That is, authenticity cannot sustain a moral outlook because evil persons (e.g., Hitler) may exemplify a great deal of authenticity but their authenticity does not imbue their characters, concerns, or deeds with any inherent moral significance. Accordingly, since authenticity cannot sustain a moral outlook, Williams's conception of authenticity and moral identity suggests that it is possible for an evil person to have integrity and a moral identity. So, the objection goes, it is egoistic, amoral or immoral to maintain that authenticity can sustain a conception of moral identity and moral commitment: authenticity cannot sustain a conception of morality since it can also sustain immoral outlooks. Moreover, it is often argued by critics of individualist and existentialist moral theories that their outlooks are not compassionate or other-regarding enough to sustain a moral point of view-authenticity is too voluntaristic and atomistic to ground moral considerations.

Williams's arguments suggest that authenticity and individuality have inherent moral significance but they do not suggest that all moral considerations involve or are based upon an agent's authenticity or individuality. A concern for one's authenticity and individuality is one kind of partial moral consideration whose moral significance is unacknowledged by most impartial moral theories. Williams maintains that there are other kinds of partial considerations that have moral significance: friendships, intimate relationships and bonds of loyalty. Williams is also not putting forth a moral theory that always gives priority to partial and personal considerations over impartial moral principles. Williams does not regard his integrity-based critique of utilitarianism to provide a decisive refutation of the doctrine: his argument has the modest goal of 
showing that utilitarianism and other impartial moral theories are too ideological and the priority that they give to impartial moral principles serves to distort morally significant features of the world. Williams suggests that utilitarianism's description of morally decent action is psychologically and ethically unrealistic because its focus on valuable states of affairs that must be maximized leaves no conceptual space for the moral significance of one’s own authenticity or being true to oneself.

Authenticity has inherent moral significance and it helps one to correct certain vicious tendencies of human nature. It is a corrective to human tendencies towards (1) passive conformity to social conventions, (2) escaping from one’s first-person perspective on the world to an overly abstract view of the world sub specie aeternitatis, and (3) a self-indulgent and narcissistic view of the world. ${ }^{73}$ Persons who are authentic pursue projects that are their own and their projects are not the products of blind or mechanical allegiance to social conventions. Authentic persons are also not alienated (emotionally or intellectually) from their own projects and deepest desires by the tendency to view the world from the perspective of the Cosmos. Also, authentic persons are not characteristically self-indulgent or narcissistic: the deepest desires of authentic persons (e.g., the desire to be a good friend, a good spouse or a good parent) are usually other-regarding. However, it must be admitted that some persons who are true to themselves have authentically embraced other-regarding desires that are the opposite of compassionate. ${ }^{74}$ Human beings contain a heart of darkness that may unleash relentless

\footnotetext{
${ }^{73}$ For an interesting discussion of the challenges facing an existentialist approach to virtue ethics (and some plausible solutions to those challenges), see Christine Swanton's "Can Nietzsche be Both an Existentialist and a Virtue Ethicist?" in Values and Virtues: Aristotelianism in Contemporary Ethics, ed. Timothy Chappell, Oxford: Clarendon Press, 2006, 171-188).

${ }^{74} \mathrm{~A}$ helpful discussion of this point is provided in Chapter 4, 'Romanticism and the Ideal of Authenticity' and Chapter 5 'The Heart of Darkness’ of Charles Guignon, On Being Authentic (Ibid.).
} 
horror. Writers such as the Marquis de Sade, Émile Zola, and Joseph Conrad vividly describe the dark, sadistic and cruel desires that reside in human beings. Those desires run deep in human nature and they are quickly discovered when one looks inward in an attempt to be true to oneself. Persons can authentically inhabit horrific worldviews and strive to change the world to fit that point of view. Although dark desires do run deep in human nature, it is reasonable to think that there is a desire for the Good that runs deeper. Being true to oneself does involve a turn inward that orients one towards one's deepest desires and commitments, and that inward turn may lead one upward if that mode of reflection leads one grasp the Good. ${ }^{75}$ Authenticity leads one inward and upward and since authenticity directs one towards the Good, it is a virtue. ${ }^{76}$ Inwardness is not narcissistic when it is directed at the idea of the Good.

The third main objection to Williams' conception of integrity is that it seems possible for a utilitarian to authentically inhabit the point of view of utilitarianism and, thus, utilitarianism does not constitute an attack on the integrity of agents. ${ }^{77} \mathrm{~A}$ utilitarian may grant, for the sake of argument, Williams' claim that integrity centrally involves pursuing one's deepest concerns and reply that it is unclear why utilitarianism cannot be

\footnotetext{
${ }^{75}$ To develop an argument for this view, I would build upon Descartes' version of the ontological argument in his Meditations on First Philosophy. The notion of the Good that I am describing here is what Descartes describes as "the idea of the infinite." Here I assume that the idea of the Good is a transcendental idea that is discovered a priori. I argue for this view in a paper in progress tentatively titled, 'The Ontological Argument and Divine Voluntarism', which contends that a certain conception of God's Perfection can be used to both strengthen the ontological argument and resolve the Euthaphro dilemma for divine command theorists.

${ }^{76}$ I borrow the phrase "inward and upward" from Charles Guignon in On Being Authentic (Ibid.). For other suggestions on how authenticity or being true to oneself may require being morally decent (or reasonable), see Charles Taylor's The Ethics of Authenticity (Ibid.). For a overly neglected conception of an ethics of inwardness, see Roy Holland 'Morality and the Two Worlds Concept' in his Against Empiricism (Totowa, N.J.: Barnes and Noble Books, 1980, 75-91).

${ }^{77}$ Forms of this objection are raised in Cheshire Calhoun's 'Standing for Something' (Journal of Philosophy, Vol. 92, 1995, 235-260), Spencer Carr 'The Integrity of a Utilitarian’ (Ethics, 86, 1976, 298311), and Gregory Trianosky 'Moral Integrity and Moral Psychology: A Refutation of Two Accounts of the Conflict Between Utilitarianism and Integrity’ (Journal of Value Inquiry, 20, 1986, 279-288).
} 
one of a person's deepest concerns. A utilitarian might contend that utilitarianism does not have to be an alienating demand that is coercively implemented on agents: a person may authentically embrace a naturalistic worldview that affirms a utilitarian moral theory. Many people have actually adopted utilitarian perspectives: Bentham, Sidgwick, Parfit and Singer. A utilitarian may also argue that it is an unfortunate, contingent fact about human sociology and psychology that so many people are not utilitarians and reject the ideal of maximizing aggregate utility. Perhaps, the argument continues, with the appropriate upbringing and education, more individuals and societies would deeply embrace utilitarianism. George and Jim may feel alienated from their core projects because they did not have the appropriate upbringing and education: if they had stronger utilitarian convictions, they would not be undone by doing what maximizes aggregate utility and if they did feel guilt after doing what the utilitarian calculus demands, then they would celebrate their guilt as a good sign that they have dispositions that usually do maximize aggregate utility. Utilitarians can have integrity by steeling themselves in the service of the principle of utility and seeing its role as part of a larger, naturalistic worldview.

Williams could, and probably would, concede that utilitarian morality could be a deep concern for certain individuals. However, given the contingent, actual psychological makeup of human beings, our deepest desires usually involve many partial and highly particularistic considerations about things such as loyalty, friendship, promises, intimate relationships, cultural interests and spiritual endeavors. These deep concerns are not merely contingent products of evolutionary development (although having these concerns probably has a certain survival value for the species), but they are desires whose 
satisfaction is of central importance for the flourishing of human beings. Perhaps these desires could be eliminated from our contingent motivational sets but doing so would come at the expense of the enormous value that these deep concerns have for many individuals. Utilitarianism may not register the inherent moral significance of these deep concerns, but the theoretical elegance and simplicity of these theories comes at the cost of rejecting the moral significance of the particularity, untidiness and commonplace features of human life. Also, the integrity of moral agents and their commitments lack the rigidity of the mere affirmation of an impartial moral principle such as the principle of utility; the dynamic nature of a moral agent's commitments raises doubts that the principle of utility could be reflectively sustained by reflective human beings. ${ }^{78}$ Perhaps Mr. Spock from the original Star Trek television series could display the integrity of a utilitarian, but Mr. Spock was not fully human. ${ }^{79}$ As Nietzsche writes, "I mistrust all systematizers and I avoid them. The will to a system is a lack of integrity." ${ }^{80}$ Moreover, and in a far less Nietzschean vein, acting on the basis of one's most intense wholehearted and felt convictions is not integrity. Integrity requires a form of inward reflection on the Good that provides one's own projects and perspective with moral significance that is not registered by the value theory and metaphysics that is presupposed by utilitarianism.

V. In closing, I maintain that integrity consists in the virtues of moral commitment and standing up for that commitment. This chapter has examined Bernard

\footnotetext{
${ }^{78}$ Chapter 3 discusses the dynamic nature of the virtue of moral commitment.

${ }^{79}$ Cheshire Calhoun, in 'Standing for Something', contends that Mr. Spock is an example of a person of integrity who is an ardent utilitarian. Damian Cox, Marguerite La Caze and Michael Levine discuss Calhoun's argument and make a strong case that committed utilitarians would live without integrity in Chapter 3 of Integrity and the Fragile Self, Ibid., 73-100).

${ }^{80}$ Friedrich Nietzsche, Twilight of the Idols, "Maxims and Arrows," §26, in The Portable Nietzsche, ed., Walter Kaufmann, Penguin, 1976, 470.
} 
Williams's conception of integrity with an emphasis on determining what insights it may provide regarding the nature of moral commitment. Williams's conception of integrity reveals the importance of widening one's conception of morality to include partial considerations and considerations about authenticity, moral identity and commitment. Chapter 3 examines the nature of moral commitment and its status as a virtue. 


\section{Chapter 3 The Virtue of Moral Commitment}

Here we should note that in times of social doubt and loss of faith in long established values, there is a tendency to fall back on the virtues of integrity: truthfulness and sincerity, lucidity and commitment, or, as some say, authenticity. If no one knows what is true, at least we can make our beliefs our own in our own way and not adopt them as handed to us by others. If the traditional moral rules are no longer relevant and we cannot agree which ones should take their place, we can in any event decide with a clear head how we mean to act and stop pretending that somehow or other it is already decided for us and we must accept this or that authority. Now of course the virtues of integrity are virtues, and among the excellences of free persons. Yet while necessary, they are not sufficient; for their definition allows for most any content: a tyrant might display these attributes to a high degree, and by doing so exhibit a certain charm, not deceiving himself by political pretenses and excuses of fortune. It is impossible to construct a moral view from these virtues alone; being virtues of form they are in a sense secondary. But joined to the appropriate conception of justice, one that allows for autonomy and objectivity correctly understood, they come into their own. The idea of the original position, and the principles chosen there, show how this is achieved. ${ }^{81}$

I. Introduction. Rawls, in this characteristically dense passage, makes a number of thought-provoking claims about "the virtues of integrity." One of his main theses is that the virtues of integrity are secondary virtues, which are "virtues of form" and since these virtues can work in the service of immoral ends, they cannot, in themselves, support a sound moral outlook. According to Rawls, these virtues must be supplemented by a sound theory of justice in order to count as bona fide virtues. Rawls suggests that the "virtues of integrity" are secondary virtues because a person's integrity may consist in the affirmation of bad, immoral or unjust principles. The conception of integrity that Rawls adopts is similar to the commonplace view that integrity is a trait such as sincerity or having the courage of your convictions. Such traits clearly do not require that their possessor have convictions that are good or beliefs that are true. Nazis may be sincere and have the courage of their convictions. Against both Rawls's contention that the

\footnotetext{
${ }^{81}$ John Rawls, A Theory of Justice, Revised Edition (Cambridge, MA: Harvard University Press, 455, 456).
} 
virtues of integrity are secondary virtues and the widely held view that integrity is primarily a matter of being sincere and truthful, I shall argue that the virtues of integrity are full-fledged, bona fide virtues and that the virtues of integrity place substantive constraints on the content of the convictions that their possessor may endorse: the virtues of integrity require that the principles and projects of their possessor are morally decent and, thus, are not evil.

Someone might argue that my disagreement with Rawls is merely a linguistic confusion. According to this objection, Rawls is using the phrase 'virtues of integrity' in one sense (a sense that does not place objective constraints on the contents of the commitments of persons of integrity) and I am using the phrase in another sense (a sense that does place objective constraints on the contents of the commitments of persons of integrity). Thus, I am merely taking issue with the way Rawls is using a phrase and I do not have a substantial debate with him concerning a specific virtue or set of virtues. It is true that I disagree with Rawls's use of the phrase 'virtues of integrity' but my concern with his usage is not directed at his word choice. I take issue with the conception of integrity that Rawls is expressing with these words. Deontologists disagree with the way that utilitarians use the words 'moral obligation' and 'rights' but this debate is not merely a linguistic confusion; it is a debate about the concepts expressed by these words. Likewise, my disagreement with Rawls is focused upon the conception of integrity that he uses to describe the concept of integrity. We are both concerned about a concept that is of central importance to moral philosophy and the moral life. There is some common ground between Rawls's conception of integrity and my own. Rawls claims that "lucidity and commitment” are among the virtues of integrity. The virtues of integrity do involve 
lucidity and commitment. However, our conceptions of integrity conflict because I maintain that the virtues of integrity are properly understood to consist in the virtues of moral commitment and standing up for that commitment and those virtues do place substantive constraints on the content of the convictions that their possessor may endorse. The virtue of moral commitment is not merely a matter of doing what one thinks is right or standing by one's moral convictions. Arguably, the virtue of moral commitment involves a dynamic process that places objective constraints on the kinds of actions that a moral agent can perform.

II. Varieties of Commitment. Integrity is commonly understood to be a matter of being true to one's commitments. There is some truth in this folk wisdom and Rawls's conception of the virtues of integrity seems closely related to this conventional understanding of integrity. However, the virtue of integrity consists in the virtues of moral commitment and standing up for that commitment and these virtues place objective, substantive constraints on the actions that a person of moral commitment can perform. In order to defend this idiosyncratic thesis, it is important to describe the nature of moral commitment and to clearly distinguish moral commitment from non-moral commitment. Clarifying one's understanding of the concept of commitment serves to strengthen one's grasp of the concept of integrity. One difficulty facing this line of inquiry is that the concept of commitment is particularly complex and difficult to analyze. A wide range of words and deeds commit persons to various things: vows, declarations of one's intentions, assertions, affirmations and promises are just a few of the ways that persons commit themselves. Rather than embark upon the intractable task of providing 
non-trivial necessary and sufficient conditions for commitment, it will be helpful to examine a particularly subtle, nuanced and robust classification of various types of commitment. ${ }^{82}$ This classification of commitments provides a strikingly helpful way to identify and characterize the form of moral commitment that the virtue of integrity requires.

\section{Brewer on Commissives and Two Kinds of Commitments}

Talbot Brewer's “Two Kinds of Commitments (And Two Kinds of Social Groups)" provides a classificatory scheme for commissive utterances and the types of commitments that are associated with them. ${ }^{83}$ The two kinds of commitments that Brewer describes are externalist and internalist commitments. Following Brewer, it is helpful to briefly delve into the pragmatics of everyday speech and examine the kinds of words that commit persons to various undertakings. Brewer's classification of commitments draws from a range of observations about the types of words and speech acts that commit us. Drawing from J.L. Austin's list of “commissives”, Brewer constructs a table that describes five groups of commissive utterances. ${ }^{84}$ (The verbs contained in this list are called “commissives” because when they are used in the first-person indicative form, they usually commit one to performing certain actions in the future.)

\footnotetext{
${ }^{82}$ Nancy Schauber's 'Integrity, Commitment and the Concept of a Person' (American Philosophical Quarterly, 33, 1996, 119-29) and Damian Cox, Marguerite La Caze and Michael Levine's Integrity and the Fragile Self (Burlington, VT; Ashgate Publishing: 2003) provide two noteworthy accounts of the relation of integrity and commitment. Their arguments provide alternative classifications of types of commitment. Shauber distinguishes active commitments and passive commitments. Cox, La Caze and Levine soundly criticize Schauber's classificatory scheme on the grounds that it fails to distinguish active commitments that are transactional and active commitments that are non-transactional. It is beyond the scope of the current inquiry to discuss that debate here.

${ }^{83}$ Talbot Brewer, 'Two Kinds of Commitments (And Two Kinds of Social Groups)', Philosophy and Phenomenological Research. 66, 2003, 554-583

${ }^{84}$ J.L. Austin discusses commissives in How to Do Things with Words (Cambridge, MA: Harvard University Press, 1962).
} 


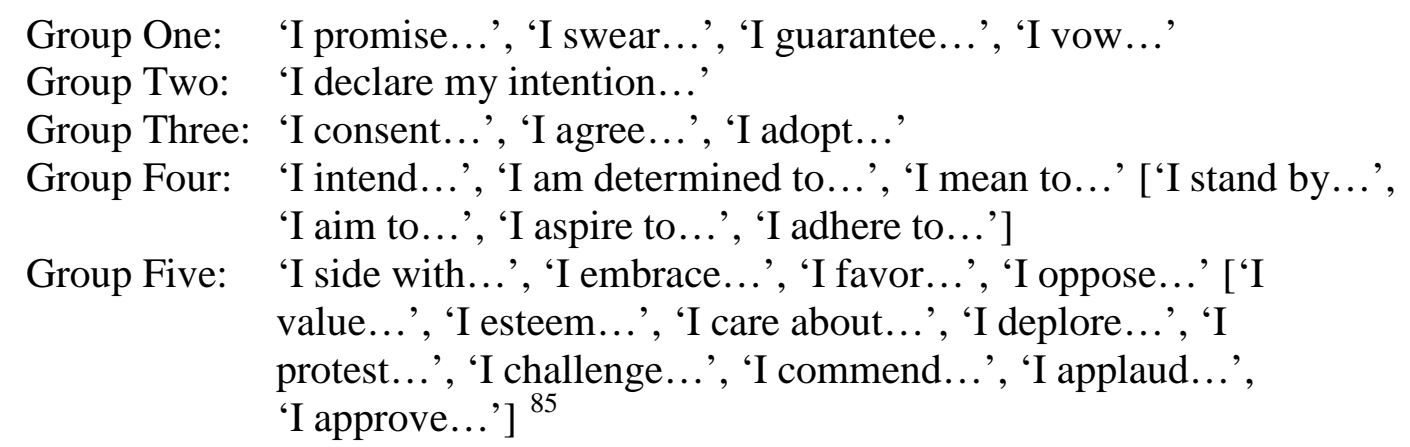

The verbs in each group and the ordering of the groups are intended to highlight important differences in the types of commitments that are produced by ordinary utterances of these verbs. ${ }^{86}$ The ordering of the groups identifies a continuum that places externalist commitments on one side and internalist commitments on the other. Externalist commitments are on the side of the continuum with the Group One verbs and here one finds verbs whose ordinary utterance does not primarily describe a state of affairs. Brewer contends that such utterances "do not so much say something as do something: they bring about a normative change in the world, giving rise to a commitment where previously there was none.”87 Internalist commitments are on the other side of the continuum with the Group Four and Group Five verbs. On this side of the continuum one finds verbs whose utterance is straightforwardly understood to describe a state of the agent who utters them. ${ }^{88}$ In sum, ordinary uses of the Group One verbs generate externalistist commitments: these utterances change the normative

\footnotetext{
${ }^{85}$ The items listed in the brackets are added by Brewer. The other items on the list draw from J.L. Austin's list of commissives, Ibid., 157-158.

${ }^{86}$ Ibid., 559.The account of Brewer's analysis of Austin’s commissives is abbreviated here.

${ }^{87}$ Ibid., 559.

${ }^{88}$ By saying that ordinary utterances of Group 4 and Group 5 verbs describe a state of speaker, a form of moral cognitivism is suggested. However, this characterization of internalist commitments is agnostic with regards to the meta-ethical debate between cognitivists, non-cognitivists and quasi-realists. Even if utterances of the verbs in these groups express various emotions, desires and attitudes of the speaker, there is a stark difference between ordinary uses of Group 1 verbs on the one hand and ordinary uses of Group 5 verbs on the other.
} 
structure of the world; whereas, ordinary uses of the verbs in Groups Four and Five function to describe antecedently determined states of the speaker. ${ }^{89}$

In addition to the observations from the pragmatics of everyday speech just described, Brewer also observes that ordinary usage of the verb 'to commit' reveals a division between externalist and internalist commitments. Brewer argues that there are two importantly different ways that we use the noun 'commitment' and the various forms of the verb 'to commit': “[1] we say that P is committed to øing (or has a commitment to ø) if others can legitimately demand that $\mathrm{P} \varnothing$, and [2] we can also say that $\mathrm{P}$ is committed to øing (or has a commitment to ø) if his own deeply rooted values, or life projects, give him a reason to ø."90 These two senses of commitment can come apart. Others may legitimately demand that $\mathrm{P}$ keep a promise that he made but $\mathrm{P}$ has no reason to do so given his values and life projects. The first sense of 'commitment' identifies externalist commitments and the second sense picks out internalist commitments. The Group One verbs are commonly used to express externalist commitments: acts of promising, swearing to do things, making guarantees and making vows provide clear examples of this sense of externalist commitments. Externalist commitments license others to make legitimate judgments and expectations concerning one's actions regardless of what one’s intentions were when using the commissive utterance that generated the commitment. If S promises to $\mathrm{P}$ that $\mathrm{S}$ will $\emptyset$, then $\mathrm{P}$ may legitimately rebuke $\mathrm{S}$ if $\mathrm{S}$ does not $\varnothing$, even if $\mathrm{S}$ had no intention to ø when making the promise. The verbs contained in Group Four and Group Five are commonly used to express internalist commitments. According to Brewer, the internalist sense of commitment "is more connected to the principles, goals

\footnotetext{
${ }^{89}$ Ibid., 560.

${ }^{90}$ Ibid., 562.
} 
and values that we affirm and characteristically act on." ${ }^{\text {,1 }}$ He maintains that "when we speak of (internalist) commitments, we refer either to reflectively affirmed convictions or to their practical dictates." 92 In addition to the verb groups that are straightforwardly used to express internalist commitments or externalist commitments, the verbs in Group Two ('I declare my intention...) and Group Three (e.g., 'I consent...') can be used to express either externalist commitments or internalist commitments (or both). The groups of verbs provided on this list identify a continuum that identifies externalist commitments on one side and internalist commitments on the other.

\section{Four Kinds of Commitment}

The two kinds of commitment that Brewer describes can help to sharpen one's focus on the nature of moral commitment, but by additionally distinguishing between two kinds of externalist commitments and two kinds of internalist commitments, one can form an even sharper conception of moral commitment. The following chart of commitments expands Brewer’s classification of externalist commitments and internalist commitments.

\section{Commitments}

Externalist Commitments

\section{Transactional}

\section{Non-Transactional}

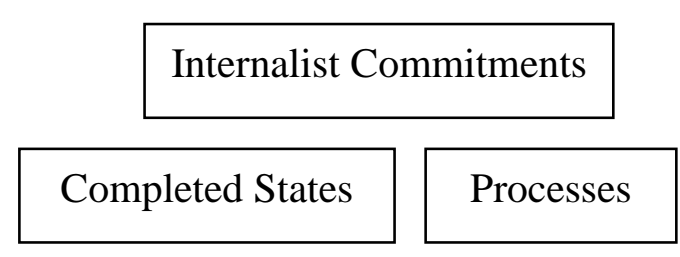

Brewer's classification of commitments does not register an important difference between two kinds of externalist commitments (transactional and non-transactional) and

\footnotetext{
${ }^{91}$ Ibid., 562.

${ }^{92}$ Ibid., 562.
} 
two kinds of internalist commitments (completed states and processes). This fourpronged distinction will help to identify and characterize the virtue of moral commitment. The categories of commitment that are described are neither intended to provide a comprehensive list of the various types of commitments nor intended to suggest that the categories cannot overlap.

\section{Two Kinds of Externalist Commitments}

As noted above, externalist commitments are those commitments that license others to make legitimate judgments and expectations concerning one's own actions regardless of what one's intentions were when using the commissive utterance that generated the commitment. If others can legitimately demand that $\mathrm{P} \emptyset$, then $\mathrm{P}$ has an externalist commitment to ø. Transactional externalist commitments are commitments whose binding force originates from or is sustained by societal conventions: without the appropriate background social conditions, utterances of these verbs lack any binding force. ${ }^{93,94}$ Ordinary uses of the Group One verbs generate clear examples of transactional commitments: promising, swearing to do things, making guarantees and making vows to others are ways of being bound by transactional commitments. Commissive utterances that deploy the Group One verbs are actions that, when performed in the presence of social norms that sustain a context in which those utterances have binding force, place one in the state of being committed to performing (or refraining from doing) some further

\footnotetext{
${ }^{93}$ Cox, La Caze and Levine, Ibid., criticize Schauber's conception of commitment on the grounds that it fails to distinguish transactional and non-transactional commitments. The distinction between transactional and non-transactional commitments is important, but it does not collapse Brewer's distinction between externalist and internalist commitment - the former distinction can be used to expand the latter.

${ }^{94}$ The relation of social practices to the normative force of promises is a topic that is more complex that I suggest here. For outstanding discussions of this topic, see Chapter 7 "Promises" of T.M. Scanlon's What We Owe to Each Other (Cambridge: Harvard University Press, 1998, 295-327) and T.M. Scanlon’s "Promises and Practices" (Philosophy and Public Affairs, 19, 199-226). The complexity and difficulty of the topic is suggested by the changes in Scanlon's own view in the earlier essay to his later view in What We Owe to Each Other.
} 
act. So, in the case of transactional commitments, there is a public transaction that an agent performs that is the source of the legitimate expectations that others have of an agent, which are the expectations that are essential to externalist commitments. Transactional commitments originate from certain commissive utterances: they have a determinate starting point (the time that the commissive utterance is made) and determinate end point (when the promise, vow, guarantee, etc., is fulfilled). Promises and contracts are transactional externalist commitments because, in the appropriate social contexts, the recipient of a promise can legitimately expect the person who made the promise to fulfill it.

There are social contexts in which it would be foolish to expect a person to fulfill a promise, vow or guarantee to perform certain deeds. Consider a society of pirates that is known to have the rule that pirates must always be truthful to other pirates but they must do their best to deceive outsiders for sport or profit. ${ }^{95}$ These pirates are known to take pride in successfully deceiving outsiders. Given that the social conventions of these pirates are well-known to outsiders, it would be foolish for an outsider F, who is aware of the rules of these pirates, to accept their promise to give F safe voyage to a distant island in exchange for a large sum of money. The pirates may swear, vow, promise or otherwise guarantee that they will take the outsider to the island but F may not legitimately expect that the pirates would keep their word (even if the pirates persistently tell $\mathrm{F}$ that they absolutely will carry out their word on this occasion). So, their utterances of Group One verbs do not constitute a transactional commitment to keep their word and ordinary

\footnotetext{
${ }^{95}$ A fascinating discussion of European pirates during the Seventeenth-Century is provided in Chapter 9, “Pirates” of Christopher Hill’s Liberty Against the Law (New York: Penguin, 1996, 114-122).
} 
utterances of these verbs generate commitments because of our ordinary practice of promise-keeping.

In addition to transactional commitments, there are non-transactional externalist commitments which are commitments that license others to make legitimate judgments and expectations concerning one's own actions regardless of either one's intentions, the social conventions where one resides or the contractual obligations that the person has undertaken. Externalist commitments are those commitments that license others to from legitimate expectations and judgments concerning your actions, but some of the legitimate judgments and expectations that persons have towards your actions and the actions of others are not held in virtue one's intentions, one's promises or social conventions. Familial obligations provide a clear example of a non-transactional externalist commitment. Arguably, the obligations that parents have to their children and that children have to their parents and siblings are not solely based upon their intentions, promises, the social conventions where they live or some combination of those factors. Other examples of non-transactional externalist commitments include general moral duties to others (e.g., the duty to respect the human dignity of others) and logical commitments (e.g., if I believe that $\mathrm{P}$ is true and $\mathrm{P}$ entails $\mathrm{Q}$, then I am logically committed to believing that $\mathrm{Q}$ is true).

Non-transactional externalist commitments are typically grounded in certain properties of agents. Familial obligations are grounded in an agent's status as a member of a particular family. Mary Ann's obligation to give aid to Anna is grounded in the fact that Anna is Mary Ann's mother. Certain moral commitments are bestowed upon individuals in virtue of their status as moral agents: moral agents are required to abide by 
certain moral and logical commitments. Certain commitments are bestowed upon individuals in virtue of their status as moral agents: moral agents are required to abide by certain moral and logical commitments. (Controversy surrounds determining exactly which properties ground moral agency. Some common proposals are: the property of being human, the property of being a person, the property of being rational or the property of being reasonable. This challenging issue is beyond the scope of the current inquiry.) It is my contention that moral agents are characterized, at least in part, by their capacity to detect and appropriately respond to moral normativity. Moral agents are prohibited from performing wanton acts of cruelty, cultivating vicious character traits, and they are more generally committed to their moral duties and logical obligations. The moral and logical obligations of moral agents are non-transactional externalist commitments: moral agents are bound by these obligations in virtue of their status as moral agents. Moral obligations are a source of legitimate expectations and judgments that others may have in relation to a moral agent's actions, regardless of the societal customs in which those agents are situated. ${ }^{96}$ Persons of integrity are moral agents who appropriately respond to moral normativity and they navigate their way through life in a morally decent manner.

Moral patients complicate the account of the relation between moral obligation and non-transactional commitments that is presented here. Moral agents and moral patients are beings that have moral status: it is possible to do wrong to moral agents and to moral patients. The main difference between them is that moral agents are capable of

\footnotetext{
${ }^{96}$ One upshot of the distinction between transactional externalist commitments and non-transactional externalist commitments is that some externalist commitments describe states of an agent. This conclusion is at odds with Brewer's contention that externalist commitments do something, whereas internalist commitments say something. Brewer's contention may be true of transactional externalist commitments but it is not true of all non-transactional externalist commitments.
} 
moral action and moral patients are not. Examples of moral patients commonly involve persons in comas, infants, severely demented persons and animals. Moral patients do not have a non-transactional commitment to carry out moral obligations because they are incapable of moral action. Hence, moral obligations are non-transactional commitments for moral agents but they are not commitments for moral patients since moral patients are incapable of moral action. So, having moral status is insufficient for having nontransactional moral commitments, but being a moral agent is sufficient for having nontransactional moral commitments. It is one's status as a moral agent that is the source of non-transactional moral commitments. These commitments are one component of the kind of moral commitment that is required for integrity but they do not exhaust it. The moral commitment that is required for integrity is more dynamic than this: it is discussed in greater detail below.

\section{Two Kinds of Internalist Commitments}

Examining commissive utterances is one way to discover the origins of certain types of commitment, but there are limits to this methodology. ${ }^{97}$ It is important to consider the ontological status of different types of internalist commitments. Since internalist commitments involve an agent's values and life projects, at first glance one might reasonably think that the relevant ontological status to be considered is whether the relevant internalist commitment describes a state such as an intention, a belief, a desire, an emotion, a pro-attitude or a similar type of item in an agent's subjective motivational

\footnotetext{
${ }^{97}$ The following quotation from Peter Geach expresses an outright rejection of the methodology: "It is a curiously common delusion of philosophers that promises, or at least the really important ones, are made by saying 'I promise', so that the particular force of these words is what we must above all investigate." (The Virtues, Cambridge: Cambridge University Press, 1977, 117). Geach’s skepticism raises important questions about Austin’s approach to ordinary language philosophy that I shall not discuss here.
} 
set. $^{98}$ (Brewer suggests that the strongest internalist commitments are a person's reflectively affirmed convictions or their practical dictates. ${ }^{99}$ However, the relevant ontological status to be considered involves more general considerations about the nature of the relevant properties picked up by utterances of the Group 4 verbs (e.g., 'I intend ...' and 'I stand by...') and Group 5 verbs (e.g., 'I embrace ...', 'I oppose...', 'I care for ...' and 'I protest...'). The question to ask is whether the relevant property that is being exemplified is either a state or a process. There may be alternative ontological categories available for classifying commitments (e.g., sets of counterfactuals, types, tokens, etc.), but the categories of state and process are helpful for my purposes since I contend that moral agency and moral commitment are more akin to processes than states.

Convictions are one source of internalist commitments, and convictions may take the form of a state or a process. Gandhi strongly believed that violent revolt is not a legitimate form of political dissent. Gandhi formed this conviction as a result of reflective deliberation. He was in the state of holding this belief during most (or perhaps all) of his adult life. However, there are also convictions that are not states of an agent, but are processes of an agent. At certain points during his adult life, Thomas Jefferson believed that violent revolt is an important component of healthy democratic autonomy: “The tree of liberty must be refreshed from time to time with the blood of patriots and tyrants”. However, this conviction was not one of Jefferson's fixed states. His conception of the relation of between violence and democratic autonomy consisted in processes of reflection about the nature and value of democracy. Some reflectively affirmed convictions are states that are the products of a completed process (such as Gandhi's

\footnotetext{
${ }^{98}$ I borrow the phrase 'subjective motivational set' from Bernard Williams's famous essay "Internal and External Reasons” in his Moral Luck (New York: Cambridge University Press; 1981, 101-113).

${ }^{99}$ Ibid., 562.
} 
pacifism); other reflectively affirmed convictions are components of a process that is not completed or those convictions are sub-processes of a larger process (such as Jefferson's views on violent revolution). The former are rigid, complete states of an agent, whereas the latter are incomplete and more dynamic. ${ }^{100}$

To further illustrate the difference between internalist commitments that are states and internalist commitments that are processes it is helpful to consider two rough and ready conceptions of religious commitment. On the one hand, religious commitment may be construed as being a kind of state: the state of believing that God exists (and a number of other propositions). The expression of this kind of religious commitment is primarily a matter of asserting one's belief in God, and this conception of religious commitment depicts this kind of commitment as a propositional attitude. According to this propositional conception of religious commitment, believing in God consists in having the belief that God exists. On the other hand, religious commitment may be understood to be an incomplete and ever-deepening process that has no end (except, perhaps, in death). According to this view, the process of religious commitment may involve periods in which the faithful person may no longer be in the state of believing in God (i.e., the belief that God exists may not be present): ${ }^{101}$ perhaps during a period in which the faithful person has experienced a great tragedy. Periods of doubt may be important steps during the development of one's religious commitment. The state of propositional belief (i.e., believing that ...) is neither necessary nor sufficient for this process of religious commitment. Explaining the nature of religious commitment is beyond the scope of this

\footnotetext{
${ }^{100}$ Talbot Brewer articulates and defends a robust picture of the dynamic nature of human agency in The Retrieval of Ethics (Oxford: Oxford University Press; 2009).

${ }^{101}$ Theological defenses of this kind of religious faith are formulated in John Robinson's Honest to God (London: SCM Press, 1963) and Karl Barth’s Dogmatics in Outline (New York: Harper and Row, 1959).
} 
inquiry. These examples are primarily intended to show the important differences between internalist commitments that are states and internalist commitments that are processes. The classification of the four types of commitment described above (transactional externalist commitments, non-transactional externalist commitments, internalist commitments that are states and internalist commitments that are processes), help one to identify and characterize the type of moral commitment that is exemplified by persons of integrity. Persons of integrity morally integrate their own lives by integrating their commitments.

III. Integrating One's Commitments. Moral commitment is essentially a trait of moral agents and a necessary condition for being a moral agent is the capacity to form moral judgments and respond to moral normativity. Briefly examining some of Kant's general reflections on the capacity to form moral judgments is an instructive way to characterize the capacity to respond to moral normativity. ${ }^{102}$ Kant's distinction between rule-following (e.g., following community norms or narrowly construed prudential dictates) and acting from the motive of duty (which involves the deployment of good judgment) is pertinent here. ${ }^{103}$ Acting in conformity with rules is a mechanical process that can be performed by machines and cognitively developed, non-human animals. However, the ability to form sound moral judgments requires a capacity for reflection and stepping back from both one's desires and one's grasp of community norms that is not

\footnotetext{
${ }^{102}$ A strong and insightful account of normative concepts is developed in Geoff Sayre McCord's, currently unpublished, paper "Rational Agency and Normative Concepts." My discussion of normative concepts in this paragraph is greatly indebted to Sayre-McCord's arguments.

${ }^{103}$ See Immanuel Kant's views on the freedom and rationality of moral conduct in Groundwork for the Metaphysics of Morals. Here I ignore Kant's extreme views about noumenal selves, the categorical imperative, and the impurity of empirical observation.
} 
required for rule-following. ${ }^{104} \mathrm{~A}$ chess program can follow rules but lack the capacity to act for moral reasons. Also, a pack of wolves may follow the rule to never attack other members of the pack but the members of the pack may lack the capacity to have moral reasons for doing so. If wolves have a moral conscience and the capacity for moral judgment, their capacity to follow rules in a community does not provide evidence for attributing those capacities to them. ${ }^{105}$ The emphasis that Kant and many Kantians place upon our ability to step back from community norms and our inclinations and to form moral judgments about those norms and inclinations is an important dimension of our capacity to form moral judgments and respond to moral normativity. This ability to step back from the community norms and inclinations is a central feature of having the concept of moral normativity.

Integrity is primarily a matter of being true to one's commitments and being true to one's moral commitments requires moral agents to integrate their commitments. ${ }^{106}$ Moral commitment usually requires moral deliberation, forming intentions on the basis of that deliberation and acting on the basis of those intentions. In order for persons to have moral commitment, they usually need to have the time, will and energy to engage in moral deliberation, they must have the ability to form intentions to do what deliberation recommends, and they must be able to carry out those endeavors. Moral commitment

\footnotetext{
${ }^{104}$ Here I shall not discuss the issue of whether non-human animals can act on the basis of moral judgment. I do not assume that human beings are the only creatures capable of it. For arguments that some canines are capable of moral motivation, see Cora Diamond's “The Dog that Gave Himself the Moral Law” in Midwest Studies in Philosophy, 13, 1988, 161-179.

105 For a great story about the relationship of a philosopher and a wolf, see Mark Rowlands's autobiographical reflections in The Philosopher and the Wolf (New York: Pegasus Books, 2009).

${ }^{106}$ For an excellent account of the nature of moral integration that is consistent with and reinforces my own, see "Moral Integration and Virtue" (in Robert Adams's A Theory of Virtue: Excellence in Being for the Good, Oxford: Oxford University Press, 206-211).
} 
requires clarity of moral vision but that vision must also shape one's actions and life in order to count as a full-fledged commitment.

Moral agents that possess the virtue of moral commitment are committed to their moral obligations and they are committed to being morally decent persons. These requirements go hand in hand: decent persons fulfill their moral obligations and fulfilling one's obligations is what it is to be a morally decent person. ${ }^{107}$ It is an a priori truth about moral agency that moral agents are required to fulfill their moral obligations and to be morally decent persons. ${ }^{108}$ The virtue of moral commitment requires moral agents to fulfill their moral obligations and thereby be morally decent persons. If a moral agent strives to be a morally decent person and fails to do so, then his moral commitment is not virtuous. If a moral agent encounters an epistemic moral dilemma and makes the wrong choice about what to do, then that agent may have acted on the basis of his or her conscience and convictions, but that action led the agent to do what is wrong and moral agents are committed to being free from evil. So, being true to one’s moral convictions or having the courage to act on the basis of one's moral beliefs is insufficient for the virtue of moral commitment. Occasional wrongdoing is consistent with moral virtue, but performing great evils or consistently doing what is wrong is not.

Moral agents who possess the virtue of moral commitment lead morally decent lives. There are cases in which an agent does his or her best to lead a morally decent life

\footnotetext{
${ }^{107}$ Providing a tenable conception of moral decency is more difficult and controversial I suggest here. A helpful starting point for discussing this issue is Thomas E. Hill, Jr.'s discussion of Kant's conceptions of moral worth and moral decency in Human Welfare and Moral Worth: Kantian Perspectives (Oxford: Clarendon Press, 2002).

${ }^{108}$ I take this a priori truth to be a conceptual truth. However, it may be a synthetic a priori truth. Christine Korsgaard argues for the view that moral agents are committed to their moral obligations in virtue of the internal structure of practical reflection and agency in her works: Creating the Kingdom of Ends (Cambridge: Cambridge University Press, 2000), The Sources of Normativity (Cambridge: Cambridge University Press, 2000), The Constitution of Agency (Oxford: Oxford University Press, 2008), and SelfConstitution: Agency, Identity and Integrity (Oxford: Oxford University Press, 2009).
} 
but, due to unconscious conflicts between the agent's conscience and values and the agent's actual moral obligations, the agent will fall short of leading a morally decent life. Consider a soldier who has fought and given his life to defend a nation that he believed to be just but, in fact, the nation for which he gave his life is thoroughly corrupt. This nation has efficiently and effectively used propaganda to convince most of its citizens that their aggressive actions are just. This soldier did his best to lead a morally decent life but he did not exemplify the virtue of moral commitment. The appearance of being morally decent is not directly relevant to whether a person has integrity and the corresponding virtue of moral commitment: moral agents are required to be morally decent. The virtue of moral commitment is exemplified by persons who are actually morally decent and manage to fulfill their moral obligations; the appearance of doing so or thinking that you have done so when you have not does not generate the virtue of moral commitment. Moral agents are committed to being free from evil. This commitment is discerned $a$ priori from the first person perspective of moral agents. Moral agents are not committed to the appearance of being free from evil; they are committed to actually being free from evil. Moral agents are committed to having morally decent lives.

Rawls correctly observes that it is impossible to construct a moral point of view from the virtues of integrity. The virtues of moral commitment and standing up for that commitment do not create a moral point of view. Rawls ignores the possibility that the virtues of integrity presuppose a moral point of view: the virtue of moral commitment is not intended to provide the grounds for moral obligations. Rather, moral decency, fulfilling one's moral obligations and integrating one's various commitments are 
concepts that are presupposed by the virtue of moral commitment: they constitute the ends of the virtue of moral commitment.

Moral integration may be an achievement but it is also a process. Internalist process commitments are of central importance to the virtue of moral commitment. It may sound as if the virtue of moral commitment is a fixed state: moral agents that achieve it are morally decent, they fulfill their moral obligations and they have integrated their internalist and externalist commitments. However, there is reason to believe that moral decency, the fulfillment of one's moral obligations and integrating one's internalist and externalist commitment are ongoing processes for moral agents. The work of being morally decent is never over while we live. If an agent has not killed an innocent person up to this point in her or her life, then that agent has not fulfilled the moral obligation to never kill an innocent person because that agent may do so in the future. All of one's actions up to this moment may have been morally decent, but the rest of one's life remains. Fulfilling one's moral obligations is a process that occurs over a lifetime. Integrity requires the hard work of achieving moral clarity and doing what is morally good. Moreover, reflective moral agents often have shifting perspectives on the nature of moral decency, moral obligation and one’s own commitments.

The virtue of moral commitment requires a cultivated and exercised responsiveness to moral normativity. This cultivated responsiveness is sometimes grounded in the moral significance of the social structures, cultures and practices that individuals are members of-i.e., moral commitment is sometimes grounded in certain transactional commitments and in certain special obligations. For example, one's integrity may be grounded in one’s membership in a certain nation (Israel, Pakistan, India 
or the United States) or in a certain profession (e.g., teaching, medicine or law). Moreover, in individuals that exemplify robust forms of moral commitment, these partial ties are the focal point of a kind of internalist commitment that is associated with genuine moral commitment: these partial ties are the focal point of an ever-deepening process of understanding what it is to be an exemplary member of the group or to make that relationship the best in can be in the circumstances. ${ }^{109}$

IV. Moral Conflicts and Moral Dilemmas. Integrating one’s moral commitments requires resolving conflicts between commitments and it involves resolving other types of conflict as well. The four-fold distinction of different types of commitment can be used to identify some of the main types of conflict involved in integrating one's commitments. This form of integration requires one to resolve various type moral conflicts, conflicts such as the ones that occur between moral obligations and conflicts that occur between one's moral commitments and the demands of one's conscience. The former may be construed as a conflict between different types of externalist commitments, and the latter may be construed as a conflict that may occur between one's externalist commitments and one's internalist commitments. I argue that persons of integrity have the good fortune to successfully resolve these moral conflicts and integrate their moral commitments. Persons of integrity manage to be morally decent persons during their process of being moral agents and being morally decent requires moral

\footnotetext{
${ }^{109}$ Moral agents who have the virtue of moral commitment, in this sense, are similar persons who possess what Raimond Gaita describes as a vocation. In Good and Evil: An Absolute Conception, $2^{\text {nd }}$ Edition (London: Routledge, 2004, 86), Gaita writes that persons who have vocations "are engaged in a limitless process of self-exploration through an exploration of what they do."
} 
agents to fulfill their moral obligations and to exercise a cultivated responsiveness to moral normativity.

\section{Conflicts Between Externalist Commitments}

Moral commitment requires fulfilling one's moral obligations and these obligations correspond to many of the externalist commitments of moral agents. Some of these moral obligations correspond to transactional externalist commitments; other moral obligations correspond to non-transactional externalist commitments. Many special obligations are the products of transactional externalist commitments. For instance, if Joe promises to meet Sam for lunch at the College Inn at noon tomorrow, then Joe has created a special obligation to be at the College Inn at noon tomorrow (and Joe has a transactional externalist commitment to be there). Other special obligations are nontransactional commitments and are grounded in a moral agent's particular status or role. For example, it is arguably the case that a parent's obligation to care for his or her young child is grounded in that agent's status as a parent. ${ }^{110}$ One way that special obligations differ from general moral obligations is that persons are committed to their general moral obligations in virtue of their status as moral agents and persons are committed to special obligations as a result of one’s particular circumstances (e.g., one’s status as a contracting party, friend or parent). ${ }^{111}$ There are tremendous difficulties involved in explaining the exact relation between special obligations and general moral obligations and it is unnecessary to attempt to characterize that relation here. However, it is important to note

\footnotetext{
${ }^{110}$ The issue of whether the status of being a parent is grounded in social conventions or biological factors is not uncontroversial. Here it is assumed that biological parents have a moral obligation to care for their infants (or, at least, they have an obligation to ensure that care is being provided for their offspring).

${ }^{111}$ More specifically, moral agency is a necessary condition for having special obligations but special obligations differ from general moral duties because moral agents have special obligations in virtue of their particular circumstances (e.g., as a friend or family member).
} 
that some conflicts between special obligations and general moral obligations provide clear instances of a type of conflict between partiality and impartiality. Consider a case in which the only way for S to save S's own child is for S to murder a stranger (perhaps an honest but ruthless villain has kidnapped S's child and has forced S into this situation). This case can be reasonably described as a conflict between one's special obligation as parent to care for one's child (a non-transactional externalist commitment) and one's general moral obligation not to murder (which is another non-transactional externalist commitment). It can also be reasonably described as a conflict of S's partial commitments to her child and S's commitment to the demands of impartial morality. Conflicts between special obligations and general moral obligations are an important kind of conflict that persons of integrity may encounter, because as moral agents, persons of integrity are committed to fulfilling their moral obligations and integrating their commitments. Persons of integrity face these conflicts with a cultivated sensitivity to moral normativity that enables them to see the problems clearly and navigate through them in a way that coheres with a morally decent way of life.

\section{Moral Dilemmas}

Considering both (1) conflicts between special obligations and general moral obligations and (2) conflicts between partial commitments and commitments to impartial morality raises the issue of whether there are genuine moral dilemmas. ${ }^{112}$ A genuine moral dilemma is defined, roughly, as a situation in which all of the alternative courses of

\footnotetext{
${ }^{112}$ There is an enormous body of literature on the topic of whether there are genuine moral dilemmas. For two outstanding discussions of the issue, see Alasdair MacIntyre's "Moral Dilemmas" (in his Ethics and Politics, Selected Essays, Volume 2, Cambridge: Cambridge University Press, 2006, 85-100) and Geoffrey Sayre-McCord's “A Moral Argument Against Moral Dilemmas” (unpublished). These essays provide excellent overviews of the large body of contemporary literature on the topic and their arguments are valuable contributions to the topic. The discussion of moral dilemmas in this section does not purport to provide a comprehensive discussion of the arguments for and against the possibility of moral dilemmas.
} 
action available to an agent require the agent to do something wrong. A classic example of a purported genuine moral dilemma is Sophie's choice (which is a believable fictional case from the book Sophie's Choice): a Nazi guard forces Sophie to choose between the killing of one of her two children (presumably, if she refuses to answer, then either both children or all three of them will be killed). It seems that no matter which choice Sophie makes in the situation, she will do something wrong.

In considering the issue of whether there are genuine moral dilemmas it is important to distinguish two kinds of moral dilemmas: epistemic moral dilemmas or genuine moral dilemmas. In what I call an “epistemic moral dilemma” a moral agent faces a decision in which he or she does not know the right course of action to take and it seems that every alternative is wrong. In a genuine moral dilemma a fully informed and ideally reasonable agent would not know which course of action is right, because every alternative course of action is wrong. ${ }^{113}$ In cases of epistemic moral dilemmas, a moral agent may think that he or she has encountered a genuine moral dilemma but a lack of important information or a deficiency or rationality or reasonableness on the part of the agent creates the appearance of a genuine moral dilemma. If there are genuine moral dilemmas, then there are situations in which there is no morally acceptable course of action for an agent to take because every available course of action to take would be morally wrong. The existence of epistemic moral dilemmas is not controversial since persons often face moral questions in the face of insufficient information or cannot comprehend the question clearly because of factors such as emotional bias.

113 Geoff Sayre-McCord, Ibid., formulates this distinction between "epistemic moral dilemmas" and "genuine moral dilemmas". 
If there are genuine moral dilemmas, then moral agents may encounter situations in which there is no morally right course of action. Thus, if a moral agent $\mathrm{M}$ encounters a genuine moral dilemma, then $\mathrm{M}$ cannot achieve the moral integration that moral commitment requires. So, if there are genuine moral dilemmas, those situations would destroy the integrity of persons who encounter them.

One of the strongest arguments against the possibility of moral dilemmas involves the deployment of the principle that "ought implies can.”" ${ }^{114}$ According to this principle, if a moral agent ought to ø, then that agent can do it, and conversely, if an agent cannot $\varnothing$, then it is not the case that the agent ought to do it. It is challenging to specify the exact nature of the modality involved in this principle-i.e., it is no easy matter to specify in exactly what sense it must be possible for a person to perform the action in question. However, with regards to the issue of whether or not there are moral dilemmas, the principle begs the question. If there are moral dilemmas, then the principle that "ought implies can” is false. ${ }^{115}$ A defender of genuine moral dilemmas will declare modus ponens, and an advocate of “ought implies can” will proclaim modus tollens. I find neither argument to be more compelling than the other. ${ }^{116}$ However, I deny that there are genuine moral dilemmas for another reason. It seems reasonable to hold that it is a virtue

\footnotetext{
${ }^{114}$ Terrance McConnell's entry on 'Moral Dilemmas' in the Stanford Encyclopedia of Philosophy presents and excellent discussion of the relevance of principle that "ought implies can" (and other deontic principles) to the issue of whether there are moral dilemmas: URL $<$ http://plato.stanford.edu/entries/moraldilemmas/>.

$\frac{\mathrm{d} 15}{115} \mathrm{I}$ think this point is correct but it does ignore an important issue in the literature. Some defenders of moral dilemmas accept the principle that "ought implies can" but they reject the principle of conjunction when it is applied to ought-claims (i.e., they deny that "I ought to do $a$ " and "I ought to do $b$ " entails "I ought to do $a$ and $b$ "). For an example of this approach, see Bernard Williams's arguments for the denial of the agglomeration principle in "Ethical Consistency" (in his Problems of the Self, Cambridge: Cambridge University Press, 1973, 166-186). I find the arguments against the agglomeration principle to be ad hoc and question-begging.

${ }^{116}$ The most persuasive argument of which I am aware against the principle that "ought implies can" is presented in John Kekes 'The Reflexivity of Evil' (in Virtue and Vice, Miller, Paul and Paul, eds., 216232).
} 
to have the hope that persons will have the power to choose what is right and to do what is good in any situation. ${ }^{117}$ If there are no genuine moral dilemmas, then it may be the case that in every situation that moral agents encounter, there is a morally right course of action available to those agents, regardless of whether they know which option that it is. It is reasonable to hope that we can always resist doing wrong. However, if we cannot do so, then we've identified one type of luck involved in possessing integrity: persons of integrity have the good luck to never encounter a genuine moral dilemma.

\section{Conflicts Between Internalist and Externalist Commitments}

Another type of moral conflict that illuminates the way in which persons of integrity are true to their commitments involves conflicts between externalist commitments and internalist commitments. Internalist commitments (both process commitments and commitments that are states) involve our conceptions the goals and values that we characteristically act upon. A person's moral beliefs, moral convictions and the demands of one's conscience are internalist commitments and they can come into conflict with one’s externalist commitments.

It is important to distinguish between conscious conflicts between internalist commitments and externalist commitments and unconscious conflicts of this nature. Conscious conflicts between internalist commitments and externalist commitments occur when an agent is aware that he or she has externalist commitments that are not consistent with his or her values, goals, or convictions. For example, in cases of fraud an agent may consciously and explicitly make a promise, utter a vow or state an oath that the agent has no intention to uphold. A conscious conflict between externalist commitments and

\footnotetext{
${ }^{117}$ This rationale for denying that there are genuine moral dilemmas is similar to Peter Geach's claim in The Virtues (Cambridge: Cambridge University Press, 1977) that it is a virtue to hope that persons will always have the power to reject sin.
} 
internalist commitments may also occur to an agent whose social roles are in conflict with that agent's values, goals and moral convictions: a disillusioned soldier may retain the externalist commitments that are associated with being a soldier but he or she may lose the internalist commitments, such as the desires for glory and adventure, that were previously motivating the agent's to undertake the commitments of the profession. One last type of conscious conflict between one's externalist and internalist commitments may occur when an agent comes becomes aware that his or her lifestyle and values are at odds with his or her moral obligations: a Mafioso may come to think that he is going to hell because of the wrongs that his profession demands of him. Unconscious conflicts between a moral agent's externalist and internalist commitments may also occur. For instance, an agent's conscience may deliver false dictates and lead an agent to do wrong. Hitler's conscience may have led him to give the order for the "Final Solution" but his conscience was distorted. Unbeknownst to him, his internalist commitments to Nazi ideology were at odds with his non-transactional externalist commitment to never kill innocent people. ${ }^{118}$

Persons who have integrity in the fullest sense are persons who have integrated their internalist commitments and their externalist commitments: their core values, goals and projects are consistent and cohere with their general moral duties, special obligations and other transactional commitments.

\footnotetext{
${ }^{118}$ It is possible that Hitler knew that what he was doing was morally wrong. His psychology is clearly more opaque than is suggested here. Regardless of the strict accuracy of the historical claim, it is primarily intended to make a conceptual point about unconscious conflicts between internalist commitments and externalist commitments.
} 
IV. The Virtues and the Virtue of Moral Commitment. To clarify the thesis that integrity consists in the virtues of moral commitment and standing up for that commitment, it is helpful to briefly discuss the nature of virtue and why moral commitment is a virtue. Only a schematic conception of virtue will be provided here: the analysis of virtue is far beyond the scope of this inquiry. Aristotle's Nicomachean Ethics provides a classic and plausible account of the nature of the virtues. ${ }^{119}$ Aristotle used the Greek term aretē to describe the virtues, and aretē can be properly translated as either ‘virtue' or 'excellence'. Virtues are qualities that make something a better instance of the kind of thing that it is. Hence, flying is an excellence for birds and sharpness is an excellence for knives. Virtues are traits that contribute to the eudaimonia of their possessor. For human beings, virtues are excellences of character: virtues are character traits that make one a better human being. Aristotle also claims that the virtues are character traits that aim at things that are kalos (fine). Virtuous persons decide to do what is fine and deciding what is fine is to choose to do what is right and correct. Virtuous persons act for the sake of the fine and doing so involves choosing things that are either valuable in themselves or instrumentally valuable. Aristotle emphasizes that phronēsis (practical wisdom) is necessary and sufficient for the complete virtue: practical wisdom requires one to have scientific knowledge and "knowledge of particulars." A person who has practical wisdom is capable of knowing the right thing to do in the right circumstances and in the right way: he or she is capable of determining what is kalos in the particulars of everyday life and he or she will characteristically act on that knowledge. For Aristotle, practical wisdom involves an intelligent perception of

\footnotetext{
119 The definitions of the Greek terms provided in this paragraph are from Terrance Irwin's 'Glossary' to Aristotle's Nichomachean Ethics (Indianapolis, IN: Hackett Publishing, 1999).
} 
particulars that enables the person of practical wisdom to see what ought to be done. Aristotle's catalogue of the virtues lists two classes of virtues: virtues of thought and virtues of character. The virtues of thought include scientific and mathematical knowledge, understanding and instrumental rationality. The virtues of character include generosity and temperance. According to Aristotle, practical wisdom turns out to be both a virtue of thought and a virtue of character.

The presence of different and often incompatible catalogues of the virtues throughout different cultures, societies and eras raises questions about the nature of kalos. If there are different virtues in different cultures, societies and eras, does that suggest a form of relativism with respect to the things that are fine? Or, is it an objective matter whether something is kalos?

Alasdair MacIntyre, in After Virtue, describes various catalogues of the virtues that have appeared in the history of Western civilization. MacIntyre shows that the Western tradition contains various catalogues of the virtues and these catalogues contain different, and sometimes incompatible, items on their lists and where there is overlap on the lists those overlapping virtues are often afforded different weights. The Homeric virtues take the warrior as a paradigm of the virtuous person and their catalogues of the virtues include items such as physical strength. The Aristotelian virtues take the wellbred Athenian male citizen as their paradigm and emphasize the importance of the virtues of the mind. The virtues of the New Testament, as they are articulated by St. Thomas Aquinas, include the theological virtues (faith, hope, and charity)—virtues that are foreign to both of the earlier Greek lists. Benjamin Franklin's well-known list of the virtues contains a great deal of overlap, at least in name, with the earlier New Testament 
virtues. Franklin's catalogue of virtues includes temperance, silence, order, resolution, frugality, industry, sincerity, justice, moderation, cleanliness, tranquility, chastity and humility. However, Franklin’s conception of their nature reveals a serious departure. For instance, Franklin's definition of chastity implores you to "Rarely use Venery but for Health or Offspring; Never to Dullness.” It doubtful that Aquinas would approve of this definition, but neither would D.H. Lawrence who replies to Franklin's definition of charity with his own: "Never use venery.” Lawrence revises Franklin's definitions of the virtues with his own pagan conception of the virtues. ${ }^{120}$ Lawrence's pagan and Romantic virtues sharply contrast with the Homeric, Aristotelian, and New Testament virtues. For instance, Lawrence playfully suggests that virtue of silence involves following the injunction to "Be still when you have nothing to say; when genuine passion moves you, say what you've got to say, and say it hot.” These considerations strongly suggest that virtues emerge in clusters. The Homeric virtues, the Aristotelian virtues, the New Testament virtues, Franklin's virtues and Lawrence’s Romantic virtues present different clusters of virtues.

A critic might respond to these suggestions by arguing that there are no clusters of virtues because human nature is a fixed state. For instance, a Thomist might argue that what Aquinas dubbed the moral virtues (prudence, temperance, fortitude and justice) captures a great deal of the spirit of Aristotle's virtue theory, but Aquinas adds to it by drawing from lessons learned from the life and teachings of Christ. The moral virtues are imperfect virtues; they are the virtues of the imperfect world that we inhabit. Aquinas also maintains there are also theological virtues (faith, hope, and charity) that are perfect

\footnotetext{
${ }^{120}$ D.H. Lawrence's catalogue of the virtues is presented in 'Benjamin Franklin' (in his Studies in Classic American Literature, New York: Double Anchor Books, 1953, 19-30).
} 
virtues; they are the virtues that are necessary for human beings to achieve perfection in the afterlife (they are not sufficient because one must also have grace to achieve the beatific vision of God). A Thomist would contend that the so-called virtues listed by Lawrence and many of the definitions of the virtues provided by Franklin are simply mistaken: they rest upon a corrupted understanding of human nature. ${ }^{121}$

To reach any definite conclusions on the nature of the virtues, one must grapple with the notoriously difficult topic of human nature. I shall not venture to settle this dispute here. Rather, I shall register some assumptions that help to clarify the conception of the virtues of moral commitment and standing up for that commitment that are provided here. Human nature is not a fixed property: what it is to be human is a process that has changed, is changing and will change during the course of human history. These changes have brought changes in what it is for human beings to live well. However, there are some fixed aspects of human nature. Human beings that have the capacity of choice are moral agents. ${ }^{122}$ The virtues of moral commitment and standing up for that commitment are closely related to Aquinas's moral virtues (prudence, temperance, fortitude and justice). The virtues of moral commitment and standing up for that commitment are virtues for moral agents that live in an imperfect world. Moreover, the

\footnotetext{
${ }^{121}$ For interpretations of Aquinas's conception of the virtues, see Chapter 33, 'St. Thomas Aquinas-IX: Moral Theory' in Frederick Copleston, S.J., A History of Philosophy, Vol.2, Medieval Philosophy (New York: Doubleday, 1993, 398-411), Chapter 7, “Theological Ethics” of Fergus Kerr After Aquinas: Versions of Thomism (Oxford: Blackwell Publishing, 2002, 114-133) and Part I, "Learning from Aristotle and Aquinas" of Alasdair MacIntyre Ethics and Politics, Selected Essays, Vol.2 (Cambridge: Cambridge University Press, 1-84).

${ }^{122}$ For a defense of the claim that there is an a priori justification for moral agency requiring free will, see Immanuel Kant Groundwork for the Metaphysics of Morals (trans. Thomas E. Hill Jr. and Arnulz Zweig, Oxford: University of Oxford Press, 2002).
} 
virtues of moral commitment and standing up for that commitment are virtues for moral agents. Human beings that have free will are moral agents. ${ }^{123}$

The virtue of moral commitment requires doing one's best to resolve moral conflicts and it requires deepening one's own understanding of what it is to be a morally decent and morally upright person. These requirements are not sufficient for having integrity because a person may fulfill them and fail to lead a morally decent life. The types of moral conflicts described in the previous section are exactly the kinds of moral conflicts that generate questions of great concern for persons of integrity. Moral commitment often involves seriously reflecting on these types of conflicts, because doing so is often required to achieve the clarity of moral vision that moral commitment demands. A central task of moral commitment is to reflect upon these kinds of moral conflicts in a way that guides one towards being a morally decent person and being a morally decent person requires cultivating and exercising one's responsiveness to the normativity of moral reasons.

The cultivation and exercise of responsiveness to moral normativity requires tenacity and moral seriousness: seriousness about moral questions and considerations. So, moral commitment requires seriously attending to moral questions and moral considerations. Although moral commitment requires seriously attending to moral questions and moral considerations, it does not require a churchy or solemn attitude towards morality—attitudes that may be involved in a pejorative sense of moralism and moral fanaticism.

\footnotetext{
${ }^{123}$ For a careful historical analysis of the relation of free will and moral agency see J.B. Schneewind's The Invention of Autonomy (Cambridge: Cambridge University Press, 1998).
} 
Moral commitment is a virtue because it is an excellence of character for moral agents. Moral commitment requires moral seriousness and moral action, and the form of attention and action that this trait requires is sensitive to a specific form of value-moral normativity. Integrity consists of a specific package of the virtues: the virtues of moral commitment and standing up for that commitment.

Persons of integrity have integrated their externalist and internalist commitments. Professional commitments provide clear examples of this kind of complex commitment. ${ }^{124}$ If an agent takes up the role of professor at a certain college, then that agent may simultaneously (1) have a transactional externalist commitment that is grounded in a promise to take on the position, (2) have non-transactional externalist commitments to adhere to that agent's general moral duties as a moral agent, (3) have an internalist commitment that places that agent in the state of having a specific institutional role (which is also related to non-transactional externalist commitments that the agent may have in virtue of being a professor at this specific institution) and (4) have an internalist commitment that places the agent in the process of acquiring an everdeepening understanding of what it is to be a good professor. ${ }^{125}$ This kind of deep professional commitment is a paradigmatic case of integrity, which involves a robust form of moral commitment that involves the integration of one's internalist and externalist commitments.

\footnotetext{
${ }^{124}$ An excellent meditation on the nature and value of motorcycle maintenance is presented in Matthew Crawford Shop Class as Soulcraft: An Inquiry into the Value of Work (New York: Penguin, 2009).

${ }^{125}$ An excellent story about the vocation of teaching and an account of its nature is provided in Raimond Gaita A Common Humanity: Thinking About Love and Truth and Justice (London: Routledge, 2002, 194199 and 230-233).
} 
V. Conclusion. In the opening passage of this chapter Rawls writes that "joined to the appropriate conception of justice, one that allows for autonomy and objectivity correctly understood, they [i.e., the virtues of integrity] come into their own.” If the arguments of this chapter are correct, then the virtues of integrity do not simply "come into their own”, whatever that might mean, if they are conjoined to an appropriate conception of justice; rather, my arguments suggest that one must have an appropriate conception of justice in order to have integrity at all. 


\section{Chapter 4 Integrity's Corresponding Vices and Related Threats to Integrity}

I. Introduction. This chapter examines various threats to the virtues of moral commitment and standing up for that commitment. Section II describes a catalogue of vices that correspond to the virtue of integrity. Section III describes two other character traits that are inimical to integrity. Section IV discusses how various social structures that sustain unjust societies work to undermine integrity. Section V describes several forms of moral luck that are required for integrity.

II. Integrity's Corresponding Vices. Certain character traits are antithetical to integrity. ${ }^{126}$ There is not a one to one correlation between these traits and the virtues of integrity. It is doubtful that every virtue has one and only one corresponding vice. (However, it is likely that every virtue has at least one corresponding vice.) The character traits described in this section are difficult to pin down in analysis but one does not need a fully developed theory of these traits in order to see how they function to undermine integrity. Wantonness commonly leads agents to have wills that are too unstable to sustain commitments. Weakness of will often prevents agents from sustaining settled evaluative outlooks. Self-deception often causes agents to be ignorant of their moral obligations. Fanaticism often results in agents forming crystallized and unflinching convictions that are not responsive to reasonable criticism.

\footnotetext{
${ }^{126}$ The list of the vices included in this chapter is suggested in Jeffrey Blustein Care and Commitment: Taking the Personal Point of View (Oxford: Oxford University Press, 1991), Gabrielle Taylor 'Integrity' (Proceedings of the Aristotelian Society, Supplementary Volume, 55, 1981, 143-159) and Cox, La Caze and Levine Integrity and the Fragile Self (Burlington, VT: Ashgate Publishing, 2003).
} 


\section{II.1. Wantonness}

Harry Frankfurt's account of what is to be a wanton, in "Freedom of the Will and the Concept of a Person,” is the defining discussion of the topic in contemporary moral psychology. ${ }^{127}$ Frankfurt provides the following definition of wantons: "I shall use the term "wanton" to refer to agents who have first-order desires but who are not persons because, whether or not they have desires of the second order, they have no second-order volitions." 128 By 'first-order desires', Frankfurt refers to desires that have the form "S wants X”. If Jeanette wants to drink the coffee on her desk, then she has a first-order desire. By 'second-order desires', Frankfurt refers to desires of the form " $\mathrm{S}$ wants to want X.” Second-order desires are desires about one’s own desires. If Jeanette wants to want to drink the coffee on her desk, then she has a second-order desire. Second-order volitions are essential to Frankfurt's conception of free will and personhood. According to Frankfurt, second-order volitions are different than second-order desires because if one has a second-order desire, then one simply wants to have a certain first-order desire, but if one has a second-order volition, then one wants a certain first-order desire to be part of one’s will. ${ }^{129}$ So, if Jeanette merely has a fleeting desire to want the coffee on her desk, then she merely has a second-order desire. However, if she wants to want the coffee on her desk because, say, she wants to be the kind of person who drinks coffee while working, then she has a second-order volition. According to Frankfurt's theory, wantons are essentially characterized by the fact that they lack second-order volitions: wantons do not care about their own wills. According to Frankfurt, wantons are motivated by the

\footnotetext{
${ }^{127}$ Harry Frankfurt, 'Freedom of the Will and the Concept of the Person', in his The Importance of What We Care About (Cambridge: Cambridge University Press, 1988).

${ }^{128}$ Ibid., 16.

${ }^{129}$ Ibid., 16.
} 
economy of their first-order desires and they do not care about which desires they have: they are carried through life by whichever of their desires and impulses are the strongest and they do not care about which desires are the strongest. ${ }^{130}$ Frankfurt claims that nonhuman animals and very young children are wantons in this sense. Frankfurt's conception of being wanton suggests that wantons cannot be moral agents because they are incapable of free choice: the behavior of a wanton is completely determined by the wanton's firstorder desires and the wanton has no desire to have those first-order desires. ${ }^{131}$ (Frankfurt claims that wantons are not persons, but that strong thesis need not be maintained: I affirm the weaker thesis that wantons are not moral agents.)

It is important to distinguish wantons and wanton behaviors. Although most adult human beings are not wantons, presumably everyone displays various amounts and degrees of wanton behavior. Wanton behaviors are events that are motivated by firstorder desires but they are performed without any concern for the first-order desire that motivates the event. A person behaves wantonly whenever that person is indifferent to the presence of the desire(s) that motivate his or her behavior. A certain amount of wanton behavior in a person's life does not constitute a threat to moral agency: wantonly picking a flower and smelling it or wantonly petting a friend's cat may not threaten a person's moral agency. These types of wanton behaviors may be respectable parts of a morally decent life. However, wanton behaviors that cause one to become a wanton are a threat to moral agency. Becoming a wanton constitutes a loss of moral agency since

\footnotetext{
${ }^{130}$ Ibid., 16-19. Frankfurt's conception of being wanton does not entail that wantons cannot deliberate or use instrumental rationality. He maintains that wantons may deliberate about how to obtain their strongest first-order desires; they simply do not have any concern about which desire is the strongest.

${ }^{131}$ This discussion of free will is working on an intuitive level. Examining the nature of free will and moral responsibility is far beyond the scope of this inquiry. However, assumptions about the nature of these concepts must be made in order to have a working conception of moral agency.
} 
wantons do not choose which course of action to pursue and they do not care about which desires are motivating the direction of their lives. Of course, wantonness and moral agency come in degrees. A small degree of wanton behavior in a person's life is no threat to moral agency. However, the more wanton an individual's behavior becomes, the less that individual is capable of being a moral agent.

Persons of integrity must be moral agents and must be capable of standing up for their moral commitments. Wantons are too volitionally fragmented to integrate their internalist and externalist commitments. Integrity requires self-direction and the increasing wantonness of a person's character indicates a loss of self-direction. Wantonness is antithetical to integrity since it undermines one's moral agency and capacity for moral integration.

\section{II.2 Weakness of the Will}

Determining the nature and scope of weakness of will is a source of great controversy in the field of moral psychology. My discussion of the topic builds upon the general outlines of Aristotle's discussion of akrasia in Book VII of the Nicomachean Ethics. ${ }^{132}$ (I set aside the Socratic theory that weakness of will is an illusion.) The Greek word 'akrasia' is commonly translated in English as 'incontinent' but a more suitable translation is 'lack of self-control' since the former commonly suggests an inability to control certain bodily functions. ${ }^{133}$ Aristotle distinguishes two kinds of akrasia:

\footnotetext{
${ }^{132}$ My exposition of Aristotle's conception of weakness of will is rough and is only intended to present a broad outline of his view. It is difficult to clearly articulate a coherent and plausible conception of weakness of will from Aristotle's entire discussion of the topic in Book VII of the Nicomachean Ethics. My exposition ignores the complications that arise from the role of the practical syllogism in Aristotle's moral psychology. There is a large body of literature on Aristotle's conception of akrasia. For a clear exposition and critical examination of these topics see Chapter VII of David Bostock Aristotle's Ethics (Oxford: Oxford University Press, 2000, 123-142). Bostock provides helpful suggestions for further reading Ibid. 142.

${ }^{133}$ Bostock makes this useful point, Ibid.123.
} 
impetuousness and weakness of will. The former is akin to wantonness, which was discussed above. ${ }^{134}$ The latter is the trait of having correct moral judgment but lacking the fortitude to do what it demands. Aristotle writes that a weak-willed person "is like a city that votes for all the right decrees and has excellent laws but does not apply them.... The base person, by contrast, is like a city that applies its laws, but applies bad ones.”135 In more contemporary language one might say that weak-willed persons have correct moral judgment or moral knowledge, but they do not act on the basis of it.

It is important to distinguish weak-willed persons and weak-willed actions. The latter occurs when an agent knows that $\mathrm{P}$ is the correct course of action to take but that agent pursues another course of action. A person of integrity may commit weak-willed actions on occasion, but they cannot be weak-willed persons since weak-willed persons do not fulfill their moral obligations. Weak-willed actions diminish a person's integrity and the more a person performs these kinds of actions, the less integrity one has.

A critic of this view might argue that in some cases weakness of will is good for moral agents. It might be argued that if a person has the wrong moral judgments, then it is good for that person to be weak-willed, because being weak-willed will prevent that person from doing what is wrong. This objection is in the same spirit as a sophistical puzzle that Aristotle describes:

A certain argument, then, concludes that foolishness combined with weakness of the will is a virtue. For weakness of the will makes someone act contrary to what he supposes [is right]; but since he supposes that good

\footnotetext{
134 The interesting project of comparing and contrasting Aristotle's conception of impetuousness and Frankfurt's conception of wantonness is beyond the scope of this inquiry.

${ }^{135}$ Nicomachean Ethics, trans., Terence Irwin, Indianapolis: Hackett, 1999, 1152a, 20-24.
} 
things are bad and that it is wrong to do them, he will do the good actions, not the bad. ${ }^{136}$

For instance, consider a popular case from a well-known version of an episode from Mark Twain's Adventures of Huckleberry Finn. ${ }^{137}$ According to this version of the story, Huck helps Jim, who is a slave, to escape from his owners but Huck believes it is immoral to free a slave. ${ }^{138}$ Huck does not simply do something that he thinks is wrong, but he does what he thinks is wrong because of his strong feelings of sympathy towards Jim. Since Huck exemplifies weakness of the will with regards to this mistaken moral belief, it seems that Huck's weakness of the will is a virtue. Aristotle's definition of weakness of the will requires that a weak-willed agent has moral knowledge or correct moral judgment but lacks the volitional strength to do what that agent knows to be morally right. So, according to this definition of akrasia, Huck could not have weakness of the will because Huck lacks the moral knowledge that it requires. Aristotle's conception of weakness of the will implies the presence of moral knowledge or correct moral judgment and a lack of volitional strength. This Aristotelian conception of weakness of will describes a trait that is antithetical to integrity, because persons of integrity have the virtues of moral commitment and standing up for that commitment and persons exemplify this kind of weakness of will fail to have the virtues of integrity.

If one sets aside the Aristotelian conception of weakness of will and supposes that weakness of the will is a matter of having the volitional strength to act on the basis of one's considered convictions (regardless of the content of those convictions). The

\footnotetext{
${ }^{136}$ Ibid., 1146a, 27-31. I have altered the translation. The italicized phrases have been inserted by me. Irwin uses the word 'incontinence' to translate akrasia in this passage. I have used 'weakness of will' to clarify which form of akrasia is being discussed here. The bracketed phrase is inserted by Irwin.

137 The version of the story described here is extracted from Jonathan Bennett 'The Conscience of Huckleberry Finn' Philosophy, 49, 1974. Bennett's version of the story is widely discussed.

${ }^{138}$ Huck's feelings of guilt about helping Jim are more subtle than I suggest here. I am merely using Bennett's influential version of the story to illustrate the sophistical puzzle described by Aristotle.
} 
“sophistical puzzle” described above shows that certain types of volitional weakness may be virtuous. The volitional weakness described in the case of Huck Finn may indicate that he is a morally decent person or it may show that the does not have integrity. The case is currently too thinly described to determine whether Huck's volitional weakness is virtuous or not. If Huck lacks the volitional strength to do what he thinks is morally right because he sees a glimmer of evil in those moral convictions, then his volitional weakness is probably virtuous. If Huck's friendship with Jim is causing him to have doubts about his conviction about the immorality of freeing slaves, then Huck's weakness of will is admirable. More generally, if a person S loses the volitional strength to carry out S’s own convictions because S suspects that those convictions are misdirected, then those suspicions may be the workings of the virtue of moral commitment, and, thus such volitional weakness may increase S's integrity. Sometimes a failure to maintain one's non-moral commitments is a first step towards developing one’s moral commitmentsthis kind of akratic action may not undermine integrity; it may actually work to advance it. However, Huck’s weakness of the will may not be virtuous if Huck’s weakness of will was the result of a growing inability to stand behind any evaluative outlook. If Huck helps Jim because of his strong concern for him on one day but then turns Jim in to the police because be becomes angry with him the next day, then Huck's weakness of the will is not admirable and it suggests the absence of integrity.

There are several forms of weakness of the will, in the sense of volitional weakness, which can undermine a person's moral commitment. The virtue of moral commitment usually requires deliberation, forming intentions to act on the basis of that deliberation, and acting on the basis of that intention. Volitional weakness may occur in 
the forms of (1) lacking the strength to carry out moral deliberation, (2) lacking the strength to form an intention on the basis of one's deliberation, or (3) lacking the strength to act on the basis on one's intentions. Each of these forms of volitional weakness can undermine a moral agent's integrity if they prevent that agent from being a morally decent person.

\section{II.3 Self-Deception}

Self-deception appears to be a commonplace occurrence. A credible survey of university professors once reported that $94 \%$ of them believed that they were better at their jobs than their average colleague. Another reliable survey of high school seniors found that all of the students believed that they were above average in their ability to get along with others. ${ }^{139}$ Self-deception seems easy to identify. Consider a spouse who refuses to believe that his or her partner is unfaithful in light of very strong evidence to the contrary or a parent who believes that his or her child is not using drugs when there is compelling evidence that the child is using them. Although self-deception appears easy to identify, it is difficult to explain its nature, and its existence seems to generate paradoxes. $^{140}$

Sartre's discussion of self-deception in Being and Nothingness is particularly helpful. ${ }^{141}$ Sartre observes that it is natural to think of self-deception as a matter of lying to oneself. However, he contends, lying to oneself should not be understood to have the

\footnotetext{
${ }^{139}$ The results of both of these surveys are reported in T. Gilovich's How Do We Know What Isn't So? (New York: Macmillan, 1991). I owe this reference to Alfred Mele's Self-Deception Unmasked (Princeton, N.J.: Princeton University Press, 2001).

${ }^{140}$ Alfred Mele’s Self-Deception Unmasked (Princeton, N.J.: Princeton University Press, 2001) presents an outstanding discussion of the various paradoxes associated with self-deception. Chapter 1 presents a useful general survey of the paradoxes. The account of self-deception I present below is greatly indebted to Mele's discussion.

${ }^{141}$ See the chapter on "Self-Deception" in Sartre's early masterpiece Being and Nothingness. Sartre's account of mauvaise foi, which is translated as either 'self-deception' or 'bad faith', plays an important role in his philosophical system and it makes an important contribution to the topic of self-deception.
} 
same conceptual structure as lying to others. If someone S lies to another person Q, then $\mathrm{S}$ tries to convince $\mathrm{Q}$ that $p$ is true but $\mathrm{S}$ believes that $p$ is false. Sartre observes that this necessary condition for lying to others becomes paradoxical when it is applied to cases of self-deception. When one applies this necessary condition for lying to others to the case of self deception, it follows that if $\mathrm{S}$ lies to $\mathrm{S}$, then $\mathrm{S}$ tries to convince $\mathrm{S}$ that $p$ is true and $\mathrm{S}$ believes that $p$ is false, and thus, self-deception would require $\mathrm{S}$ to simultaneously believe $p$ and $\sim p .^{142}$

Sartre correctly observes that self-deception is a different kind of state than deceiving others. A self-deceived person may be lying to oneself, but this is not exactly the same kind of state as lying to another person. Self-deception is structurally different than other-deception. It is more plausible to construe self-deception as being more akin to wishful thinking than to other-deception. ${ }^{143}$ Self-deception is not identical with wishful thinking, but one thing they have in common is that both involve believing something without sufficient evidence and believing it on the basis of motivational states other than belief. More specifically, if $\mathrm{S}$ is self-deceived in believing that $p$, then $p$ is false, and $\mathrm{S}$ has poor evidence for believing that $p$ is true but $S$ believes that $p$ is true because of other motivational states (emotion or desire). Consider a case in which Lisa is self-deceived in believing that her husband, Alex is not guilty of a criminal charge. Although Alex is guilty of the charge and Lisa has very strong reasons for believing that he is guilty

\footnotetext{
${ }^{142}$ It is not strictly paradoxical to maintain that $\mathrm{S}$ simultaneously believes $p$ and $\sim p$, but it is certainly strange. Richard Moran Authority and Estrangement (Princeton, N.J., Princeton University Press, 2001) discusses the relation of Sartre's views on the topic of self-deception and the phenomenon of Moorean Absurdity (which involves sincere assertions of claims such as "It is raining outside but I do not believe it is raining outside.”).

${ }_{143}$ Alfred Mele argues for this claim in Self-Deception Unmasked (Ibid.) and 'Self-Deception and Hypothesis Testing' (in Cartographies of the Mind: Philosophy and Psychology in Intersection, eds., De Caro, M., Ferretti, F., and Marraffa, M, Dordrecht, The Netherlands: Springer, 2007, 159-168).
} 
(perhaps she heard him commit the crime), she refuses to believe that he is guilty because she loves him so much and she wants him to remain out of jail.

Not all self-deception is inimical to integrity. Self-deception about one's abilities at playing a certain video game would not directly undermine one’s moral commitments or one's moral decency. Self-deception about one's moral commitments undermines integrity because it prevents one from integrating one’s commitments. Moral ignorance, in general, undermines integrity. Self-deception is a special case of moral ignorance that is worthy of discussion in its own right, because it is such a commonplace occurrence.

\section{II.3 Fanaticism}

WHEN someone is honestly 55\% right, that's very good and there's no use wrangling. And if someone is 60\% right, it's wonderful, it's great luck, and let him thank God. But what's to be said about 75\% right? Wise people say this is suspicious. Well, and what about $100 \%$ right? Whoever says he's $100 \%$ right is a fanatic, a thug, and the worst kind of rascal. ${ }^{144}$

Fanatics zealously cling to their principles, projects and commitments regardless of the evidence or the consequences. Fanaticism is a simulacrum of integrity. It involves rigidity with regards to one's own convictions. Fanaticism is a form of encratic action (i.e., strength of will). A fanatic may have the “courage of one's convictions” without possessing the discernment that accompanies the actual virtue of courage, which is the kind of courage that is required for integrity. A fanatic has strength of will but he either refuses to or is unable to question his moral compass. Fanatics may display loyalty but it is not a moral virtue since persons may be loyal to unjust principles, projects, groups and persons. Loyalty may be an admirable characteristic and it does have its own moral

\footnotetext{
${ }^{144}$ Czeslaw Milosz attributes this quotation to “An Old Jew of Galicia” (in The Captive Mind, trans. Jane Zielonko, New York: Vintage International Edition, 1990, vi).
} 
significance, but it may become rigid and lead to biases in one's outlook that protect one from having a clear sense of one’s externalist commitments. ${ }^{145}$

Someone might object that there is one kind of fanatic that can have integrity: a moral fanatic. Moral fanatics are those moralists who have intense moral convictions and commitments and they usually loudly stand up for them. Since moral fanatics have moral commitments and they stand up for their commitments, so this objection goes, surely moral fanatics have integrity. I grant that moral fanatics have moral commitments and that they stand up for their commitments; however, they do not have integrity because they do not posses the virtues of moral commitment and standing up for that commitment. The virtue of moral commitment requires a certain open-mindedness and awareness of one's own fallibility that is lacking in fanatics. The virtue of moral commitment requires clear moral reflection that is not distorted by pride, vanity or cruelty: it involves moral attention that is not guided by self-seeking or self-consoling distortions. ${ }^{146}$ The virtue of moral commitment requires being somewhat open-minded about the deliverances of one's moral deliberations. Too much moral seriousness can lead to single-minded solemnity that is dangerous and oppressive-moral fanaticism. Moral fanatics lack integrity. Integrity has substantive requirements: persons of integrity must have morally decent commitments. However, having morally decent commitments is not

\footnotetext{
${ }^{145}$ For a thoughtful treatment of the moral significance of loyalty, see George Fletcher Loyalty: An Essay on the Morality of Relationships (Oxford: Oxford University Press, 1993).

${ }^{146}$ For enlightening reflections on the nature of moral attention and its relation to pride, see Simone Weil 'Human Personality' (in Simone Weil: An Anthology, ed., Sian Miles, New York: Grove Press, 1986, 4978) and Iris Murdoch Existentialists and Mystics (New York: Penguin, 1997). Aquinas's conception of the conscience also supports the kind of moral thinking suggested here: he emphasizes that virtuous persons know that their conscience is fallible. (However, Aquinas's conception of moral deliberation is more legalistic than that of Weil and Murdoch.) For a plausible interpretation of Aquinas's conception of the conscience, see Alasdair MacIntyre "Natural Law as Subversive: the Case of Aquinas" and "Aquinas and the Extent of Moral Disagreement" (in his Ethics and Politics, Selected Essays, Vol.2, Cambridge: Cambridge University Press, 2006).
} 
sufficient for integrity. Getting the content of one's commitments right is not enough to have integrity. Persons of integrity have morally decent convictions and they have them in the right way. Integrity is a matter of integrating the form and content of one's convictions and commitments. Persons of integrity have internalist and externalist commitments that are idiosyncratic and the full integration of their commitments renders the distinction between internalist and externalist commitments to be purely conceptual.

III. Psychopathy and Immoralism. Psychopaths and morally wicked persons are ineligible candidates for possessing integrity. Wicked persons know that their actions are wrong. Psychopaths do not. Psychopaths are not morally wicked persons because they lack the intention to do wrong to others. ${ }^{147}$ Psychopaths lack the concepts associated with moral normativity, i.e., the concepts of moral rightness and wrongness. A psychopath does not have a conscience. Psychopaths may use the language of morality, rights and duties in order to avoid punishment or unpleasant reactions from others but they only use moral language to reach their own non-moral, purely prudential goals. For psychopaths moral language is meaningless talk that only has an instrumental and narrowly prudential function. Arguably, psychopaths are dangerous moral patients; they either completely lack or have a greatly diminished capacity of moral agency. They can exhibit deliberative and purposive behavior, but they cannot have integrity since they are not moral agents. The condition of psychopathy is blindness, not disregard, of moral considerations. (The term 'psychopathy' is an item of psychiatric jargon whose nature is debated in the

\footnotetext{
${ }^{147}$ For a classic study of psychopathy, see Hervey Cleckley's The Mask of Sanity (5 $5^{\text {th }}$ Edition, Augusta, GA: C.V. Mosby Co., 1988). The primary value of Cleckley's study resides in the case studies that he provides: some of the most striking cases involve persons who do not care about themselves or anyone else.
} 
philosophy of psychiatry. ${ }^{148}$ ) Psychopathy and integrity have an inverse relationship: as psychopathy increases in an individual, the capacity for moral integration decreases.

Psychopaths are often confused with another type of individual: the moral monster. Moral monsters choose to do what they know to be immoral. Consider examples of demonic or Satanic characters who have a keenly developed capacity for moral reflection but they choose to do what is evil. ${ }^{149}$ These villains are commonly found in comic books and the horror genre, they occasionally show up in literature and they also appear on rare occasions in real life. Moral monsters have a heterogeneous set of motives for pursuing evil. ${ }^{150}$ Some of them share the core principle of Milton’s Satan: "Evil be Thou my Good!” (Perhaps the adversary from the Book of Job shares this principle, but it is unclear whether the adversary is a moral monster - the adversary may think that Yahweh is evil. ${ }^{151}$ Unfortunately, the Book of Job does not explicitly describe the adversary’s motivations for challenging Yahweh.) Judge Holden in Cormac McCarthy’s Blood Meridian is a brutal and terrifying example of a figure devoted to evil as evil. ${ }^{152}$ These villains celebrate the presence of cruelty, suffering and chaos. Moral monsters sometimes choose what is evil because they embrace a type of aesthetic perspective that

\footnotetext{
${ }^{148}$ See the symposium on Piers Benn "Freedom, Resentment and the Psychopath" in Philosophy, Psychiatry and Psychology, 6.1, 1999.

${ }^{149}$ I discuss the evaluative outlook of one moral monster, Batman's nemesis the Joker, in my essay 'The Joker's Comedy of Existence' (in Supervillians and Philosophy, ed., Ben Dyer, Chicago: Open Court, 2009, 127-136). I sketch a conception of desiring the bad in this essay.

${ }^{150}$ Here I do not discuss the important and difficult topic of desiring the bad. Two dominant views in the literature are that (1) evil persons choose to do what is evil under the guise of evil (this is a rough statement of the position David Velleman defends in 'The Guise of the Good' (Noûs, 26, 1992, 3-26) and (2) evil persons choose to do what is evil under the guise of the good and, thus, evil persons see their evil doings as good (this is a approximation of the views defended by Elizabeth Anscombe Intention, $2^{\text {nd }}$ Edition (Cambridge, MA: Harvard University Press, 2000, §36-40) and Thomas Scanlon in What We Owe to Each Other (Cambridge, MA: Harvard University Press, 1998, 32-41)).

${ }^{151}$ Or, perhaps, like Milton's Satan, he does not understand God's nature and his primary goal is to take control of heaven. I should also note that Milton's Satan is a morally ambiguous character.

${ }^{152}$ Cormac McCarthy Blood Meridian: Or the Evening Redness in the West (New York: Vintage, 1985).
} 
regards the world as devoid of value, or full of mediocre forms of value, or they attempt to bring value, or higher values, into the world via acts of cruelty and sadism.

Moral monsters usually exemplify a certain kind of unified will. Moral monsters may unify their lives by wholeheartedly pursuing evil and standing up for that pursuit. However, it would be a mistake to think that moral monsters have the integrity of a moral agent. Moral monsters may exemplify consistency, constancy, strength of will, the courage of their convictions or some other type of formal integrity, but those qualities are simulacra of integrity. Moral monsters may exemplify various forms of quasi-integrity but they cannot have the integrity of moral agents because they characteristically exemplify immoral commitment.

IV. Unjust Social Structures as Threats to Moral Agency. There are reasons to doubt that persons of integrity must be morally decent. The strongest reasons of which I am aware involved purported counterexamples to my conception of integrity. These types of cases involve conscientious persons who, through no fault of their own, end up pursuing immoral ends. Consider a case of a conscientious advocate of a totalitarian regime. Many advocates of totalitarianism, and genocidal regimes, are not fanatics and they endorse their state's cause as a result of careful moral reflection. ${ }^{153}$ There were conscientious Nazis, Fascists and Stalinists who converted to their respective ideologies as the result of reflecting on the ideology, and, after their conversions, they stayed true to their ideologies and they were willing to stand up, and even die, for them. These conscientious soldiers put in the hard work of moral reflection and they stood up for the

\footnotetext{
153 The character studies described in Czeslaw Milosz The Captive Mind (New York: Vintage International Edition, 1990) provide a striking array of motivations for accepting Stalinist ideology.
} 
verdicts of their reflection. Another, related, kind of case involves persons that have conscientiously formed moral principles that are more common than those found in totalitarian states. Consider the case of an abusive patriarch who is cruel to his wife and children. His violence is intended to sustain his vision of himself as the man of the house. He justifies his violence by arguing that his beatings and insults "teach them a lesson" and "make them tough.” He often reflects about whether he should stop being violent but he reaches the conclusion that he needs to "stay firm" in order to have a good family. He does not enjoy hurting his wife and children but he continues to "have a strong hand" because doing so is what he, on reflection, thinks is best for his family. His conception of being a good father and a good husband is the primary source of his violence. Since he does engage in genuine moral reflection and he stands up for what he thinks is right (he does not lie to anyone about his violent behavior at home), the argument goes, it would be unfair to deny that he has integrity simply because his reasoning is misguided.

It is question-begging and simply too easy to say that in these types of cases one is considering persons who have quasi-integrity and lack the genuine integrity of moral agents. So, I shall take up a different line of argument to show that these persons lack integrity. I suspect that in many cases like those of the conscientious totalitarians and conscientious patriarchs described above, their reflection is either performed too hastily, blurred by sentimentality and cliché, riddled with fantasy, deflects emotionally upsetting insights, or exemplifies some kind of narcissistic defect. In many cases of alleged or unsound conscientiousness, a certain kind of pride that involves subordinating others to one's own will charades as integrity-for a good example of this kind of charade consider the deeds and fate of Police Captain Hank Quinlan (played by Orson Welles) in 
the film A Touch of Evil, which is a classic tale of crime and police corruption. Quinlan frames a man and his bride, Mike and Susan Vargas (played by Charlton Heston and Janet Leigh) on charges of drugs and murder as the direct result of Quinlan’s inflamed desire to get credit for solving every crime in his jurisdiction and Quinlan’s rivalry with Mike Vargas. As the film critic Roger Ebert perceptively observes,

Although the line of the plot is possible to follow, the real point is the way Quinlan veers from the investigation to follow his own agenda. He's prejudiced against Mexicans, resents Vargas for invading his turf, and supports "hunches" by planting evidence. ${ }^{154}$

The virtue of moral commitment is guided by moral attention that is not distorted by pride, vanity, and cruelty—it lacks such self-consoling distortions. These distortions may be intentional on some occasions (for instance, these deliberators may choose to ignore intense feelings of guilt or they may choose to overcome those feelings because the feelings are construed as signs of weakness) and they may be unintentional on others (perhaps the education and life experience of these deliberators does not provide them with the vocabulary, logical skills or observations to fully understand the nature of their own actions). These characters try to take up the hard work of genuine moral reflection but they fail to acquire clear moral vision. ${ }^{155}$

It is possible that a person S seriously attends to the moral considerations in S'S life, S does not succumb to the distortions that I've listed above, but due to bad luck S

\footnotetext{
${ }^{154}$ Roger Ebert, 'Review of Touch of Evil', September 13, 1998, URL: $<$ http://rogerebert.suntimes.com/apps/pbcs.dll/article?AID=/19980913/REVIEWS08/401010367/1023>

${ }^{155}$ For a vivid description of some striking forms of distorted moral reflection, see the various forms of moral thinking deployed by the main characters in Tolstoy's Hadji Murat. The clouded moral vision of tsar Nicholas is particularly striking. Here's a vivid description of Nicholas's distorted moral reflection: "The blatant, unceasing flattery of those around him had so far detached him from reality that he was no longer aware of his own inconsistency and ceased to relate his words and actions to reality, logic or plain common sense, fully convinced that all his decisions, however senseless, unjust and inconsistent they were in fact, became sensible, just and consistent simply by virtue of being made by him” (in Master and Man and Other Stories, Penguin, 1979, 215).
} 
comes to form a moral outlook that is not a response to moral normativity but actually leads one to become an evil person. In this kind of case, in which S has done the hard work of genuine moral reflection and due to bad luck has chosen to pursue a course of action or project that is evil, $\mathrm{S}$ fails to have integrity. $\mathrm{S}$ is experiencing an unconscious conflict between S's internalist commitments (which are leading S to do things that are evil) and S's externalist commitments. If S knew the true nature of S's own actions and was aware that S's own internalist commitments were misguided, then S would reject those internalist commitments. S fails to have integrity because $\mathrm{S}$ is unable to morally integrate S's own commitments: a conflict remains in S's actions that prevents S from being a morally decent person.

Unjust social structures constitute a serious threat to integrity because they breed collective moral ignorance and ignorance about the nature of one's own actions. ${ }^{156}$ Unjust societies often encourage a fantastical national mythology and they construct a litany of clichés and officialese that shield their members from reality and encourage the distorted picture of the world that supports the regime. ${ }^{157}$ Integrity cannot flourish in conditions that distort moral reflection and narrow the moral imagination because such conditions make moral decency a rare achievement.

V. Varieties of Moral Luck. Integrity requires two main forms of moral luck: the luck required for having morally decent ends and the luck required to achieve one's ends.

\footnotetext{
${ }^{156}$ For an outstanding discussion of this issue see Alasdair Macintyre, 'Social Structures and Their Threat to Moral Agency' in his Ethics and Politics, Selected Essays, Volume 2. (Cambridge: Cambridge University Press, 2006, 186-204).

157 A subtle description of this phenomenon is described in Hannah Arendt's Eichtman in Jerusalem: A Report on the Banality of Evil, Revised Edition (New York: Penguin Books, 1992). A nice literary example of this point is suggested by George Orwell's invention of Newsspeak in 1984 (New York: Penguin Books, 1981).
} 
Since human beings are fallible and there is the persistent threat that one's conscientious deliberation is mistaken, there is an element of luck involved in whether one's intentions, projects, principles and character are morally decent. This kind of luck is a matter of one’s internalist commitments being consistent with one’s externalist commitments, regardless of whether one is aware of this consistency. The second kind of moral luck that integrity requires pertains to whether one has the good fortune to complete actions that are the products of sound moral deliberation. Persons of integrity engage in moral deliberation, form intentions on the basis of that deliberation and act on the basis of those intentions. Bad luck can terminate sound moral action at any point in the process. Misfortunes can put an end to deliberation, prevent one from forming an intention on the basis of sound deliberation or prevent one from acting on the basis of an intention that is formed. Being a morally decent person requires several levels of moral luck. 


\section{Chapter 5 Social and Political Dimensions of Integrity}

I. Introduction. This chapter illustrates some practical implications of the conception of integrity that has been defended in the preceding chapters. The brief arguments of this chapter are intended to give a sense of the wide range of important practical applications that a developed conception of integrity can have. The modest goal of this chapter is to show how my conception of integrity applies to a wide range of issues in practical life. ${ }^{158}$ One consolation for the brevity of these arguments is that they may provide the foundation for future research on these topics.

II. Political Liberty and Respecting the Separateness of Persons. What would be the basic structure of a society that is arranged by policies that either serve to promote or would not impede the integrity of its members? More precisely, what would be the basic structure of a society that is either arranged by policies that instill the virtues of moral commitment and standing up for that commitment in its citizens or structured by policies that do not prevent citizens from having the virtues of integrity? A society that is concerned with instilling the virtues of integrity in its members would probably place centralized power in hands of moral authorities who would have the moral and physical capacities to instill the virtues of integrity in its citizens. A society concerned with making its citizens virtuous is in the business of soul-craft: it would not have the basic structure of a liberal society. ${ }^{159}$ One major problem facing theories that construe statecraft as soul-craft is that they require a state's rulers to possess knowledge of what would

\footnotetext{
158 Alan Montefiore and David Vines, eds. Integrity in the Public and Private Domains (London: Routledge, 1999) contains a selection of essays that nicely canvasses a wide range of ethical questions and public policy issues to which a theory of integrity could be applied.

${ }^{159}$ For defenses of this kind of view, see Plato Republic and David Thunder 'Rethinking Modern Citizenship: Towards a Politics of Integrity and Virtue' (Ibid.).
} 
constitute the good life for all the members of that state, and not only would it be unlikely that the rulers of actual states could posses such knowledge or demonstrate that they possess it, but it is difficult to grasp how it would even be possible for a state's rulers to possess such knowledge. Another major set of problems facing state-mandated attempts to instill virtue in citizens involves issues of compliance and enforcement. Given the plurality of values that exist and the various comprehensive conceptions of the good that are pursued by moral agents, and given human tendencies toward disobedience and rebellion, instilling virtue in the citizens of a state would probably require a soul-crushing totalitarian regime. In light of these considerations, it seems best to focus on the topic of what would be the basic structure of a society that would not impinge on the integrity of its citizens? In other words, what would be the basic structure of a society that would not prevent its citizens from possessing the virtues of moral commitment and standing up for that commitment?

Some version of liberalism would probably describe the best basic structure for a society that would not impinge on the integrity of its citizens. Liberals of various kinds are united by their emphasis on the central importance of political freedom: liberals maintain that governing policies should not undermine the political freedom of the members of a society. A society that is structured to provide the maximal amount of political freedom to all of its members would provide its members with an outstanding opportunity to cultivate their own individual projects and commitments in a fashion that would not impinge on the integrity of other members of that society. John Stuart Mill's eloquent reflections on the value of inquiry and individuality and his strong case for the 
Harm Principle provide a firm basis for assigning the preservation of individual liberty a top priority in arranging the basic structure of a just society. ${ }^{160}$

Liberals are united by their emphasis on political freedom, but they face challenging questions about the nature of political freedom. One major issue that divides liberals is whether political freedom is best construed as a form of negative freedom or a form of positive freedom? ${ }^{161}$ The former conception of political freedom is usually stressed by classical liberals and it emphasizes the importance of being free from a wide range of harms. Classical liberals usually construe political freedom as a matter of free individuals having the opportunity to pursue their own conception of the good and their own personal projects in a manner that does not impinge on the free activity of other individuals. Welfare liberals (e.g., John Rawls) often emphasize the importance of positive freedom, which involves the government provision of a wide range of welfare goods in order for citizens to be free. Welfare liberals usually construe political freedom as a form of civic freedom; i.e., freedom to associate in civil society. Both of these liberal traditions place a strong presumption in favor of liberty (hence, their title as 'liberal' positions). A strong presumption in favor of protecting integrity is also a key justification for the concern with liberty that is affirmed by Rawlsian liberals and Nozickian libertarians. Rawls's concern with liberty is expressed by his first principle of justice and the lexical priority given to it. ${ }^{162}$ The first principle of justice states: "each person is to have an equal right to the most extensive scheme of equal basic liberties compatible with

\footnotetext{
160 John Stuart Mill, 'On Liberty', in Three Essays: On Liberty, On Representative Government, The Subjection of Women, ed. Richard Wollheim, Oxford: Oxford University Press, 1975

161 The distinction between two forms of liberalism that is presented here is largely inspired by Chapter 5 , 'Two Concepts of Liberalism', of Loren Lomasky Persons, Rights and the Moral Community (Oxford: Oxford University Press, 1987).

162 John Rawls, A Theory of Justice, Revised Edition (Cambridge, MA: Harvard University Press. 2001).
} 
a similar scheme of liberties for others.”"163 Among the basic liberties that are protected by this principle of justice, Rawls lists

political liberty (the right to vote and to hold public office) and freedom of speech and assembly; liberty of conscience and freedom of thought; freedom of the person, which includes freedom from psychological oppression and physical assault and dismemberment (integrity of the person); the right to hold personal property and freedom from arbitrary arrest and seizure as defined by the concept of the rule of law. ${ }^{164}$

Rawls also maintains that the first principle of justice has "lexical priority" with regards to the second (the difference principle): “This ordering means that infringements of the basic equal liberties protected by the first principle cannot be justified, or compensated for, by greater social and economic advantages.”165 Rawls’s central justification for his first principle of justice is his emphasis on the moral significance of respecting the separateness of persons. ${ }^{166}$ In a similar vein as Williams's charge that utilitarianism attacks the integrity of individuals; Rawls rejects utilitarianism on the grounds that it attacks the separateness of persons. ${ }^{167}$ Rawls maintains that utilitarianism does not respect the separateness of persons because it conflates "all persons into one through the imaginative acts of the impartial, sympathetic spectator."168 There are serious issues about whether Rawls's own theory of justice respects the separateness of persons, ${ }^{169}$ an issue beyond the scope of this discussion, but Rawls is correct to draw attention to the

\footnotetext{
${ }^{163}$ Ibid., 53.

${ }^{164}$ Ibid., 53

165 Ibid., 53, 54.

166 Rawls's argument that utilitarianism does not respect the separateness of persons and that moral theories should do so is presented in Chapter 1, 'Justice as Fairness', of A Theory of Justice (Ibid.).

167 Williams describes the differences between their views on this issue in 'Persons, Character and Morality' in his Moral Luck (Cambridge: Cambridge University Press, 1981).

${ }^{168}$ Ibid., 24.

${ }^{169}$ For a variety of arguments that Rawls's own theory does not respect the separateness of persons, see Bernard Williams, 'Persons, Character and Morality' (Ibid.), Jan Narveson Respecting Persons in Theory and Practice (Lanham, MD: Rowman and Littlefield, 2002), Nicholas Wolterstorff 'The Role of Religion in Decision and Discussion of Political Issues' (Ibid.), David Thunder ' Rethinking Modern Citizenship: Towards a Politics of Integrity and Virtue' (Dissertation, Notre Dame, 2006) and Michael Sandel Liberalism and the Limits of Justice, $2^{\text {nd }}$ Edition (Cambridge: Cambridge University Press, 1998).
} 
way that the moral significance of respecting the separateness of persons is one of the primary justifications for placing a presumption in favor of liberty in matters of public policy. Moral theories that respect the separateness of persons acknowledge the central importance of integrity.

The rejection of moral theories that do not respect the separateness of persons is one point of common ground that Rawls's theory shares with Robert Nozick's entitlement theory in Anarchy, State and Utopia. ${ }^{170}$ Both Rawls and Nozick reject utilitarianism on the grounds that it does not respect the separateness of persons. Nozick's version of classical liberalism emphasizes the importance of "moral side constraints." Nozick writes, "Side constraints express the inviolability of other persons." ${ }^{171}$ He also maintains that "The moral side constraints upon what we may do, I claim, reflect the fact of our separate existences.” ${ }^{172}$ According to Nozick's conception of the night-watchman state, certain side constraints, as formulated by his Lockean entitlement theory, are front and center in his argument that liberty disrupts patterns (often known as "the Wilt Chamberlin argument”) and in his critique of Rawls's second principle of justice (the difference principle). Although Nozick and Rawls disagree about the difference principle, both of their theories give a strong presumption in favor of liberty: this is why they are both liberals. Moreover, it is helpful to see this presumption as motivated by a concern for protecting the integrity of persons. Liberalism is not well served by the ideal of liberal

\footnotetext{
${ }^{170}$ Robert Nozick, Anarchy, State and Utopia (New York: Basic Books, 1974).

${ }^{171}$ Ibid., 32.

${ }^{172}$ Ibid., 33.
} 
neutrality: liberalism is supported by a moral argument that is concerned with protecting integrity by placing a strong presumption in favor of considerations of liberty. ${ }^{173}$

The conception of integrity defended in the preceding chapters coheres nicely with the liberal tradition of political theorizing. Integrity consists in the virtues of moral commitment and standing up for that commitment, and these virtues require persons of integrity to be morally decent. A presumption in favor of liberty in the articulation of policies that arrange the basic structure of a society provides citizens that live in those societies with the freedoms (1) to pursue their own conceptions of the Good, (2) to engage in a wide array of experiments in living, (3) to pursue a wide range of personal and public projects, (4) to be protected from having one's own projects and commitments thwarted by the immoral actions of others, and (5) to be prevented from doing evil to others. These freedoms serve to protect the integrity by providing citizens in liberal societies with the space to integrate their moral commitments with their non-moral commitments. Many questions remain about the role of considerations of equality, security and prosperity in relation to the presumption in favor of liberty, but those issues are beyond the scope of the current inquiry.

The protection of integrity is not, and should not be considered to be, merely a concern for government and individuals. Other organizations (e.g., professions and businesses) that inhibit the liberties protected under Rawls's first principle of justice serve to undermine the integrity of the members of those organizations by undermining

\footnotetext{
${ }^{173}$ John Rawls Political Liberalism (New York: Columbia University Press, 1996) provides a substantial departure from A Theory of Justice. In Political Liberalism Rawls argues for a conception of free public reason that is freestanding from any comprehensive moral theory: to state his view roughly, he argues that decision and policies in politics ought to be governed by freestanding political considerations that are not based in any ethical or moral considerations. I believe that Rawls's own conception of free public reason presupposes a substantive moral outlook but I shall not argue for that claim here.
} 
the integrity of the individuals that are the lifeblood of those professions. Professions may need to place certain restrictions on the liberties of its practitioners (e.g., a lawyer should not have the liberty to divulge information about his or her clients). However, in order for professionals to have integrity, they need to live in societies that provide them with the room to cultivate the virtues of integrity.

III. Professional Integrity. Professional integrity is an ever-deepening process of understanding the nature, value and demands of one’s own work in a profession. ${ }^{174}$ Professional integrity involves a process of becoming an exemplar in one’s professional community and being an exemplar is a process of continuous learning. ${ }^{175}$ Professional integrity is one kind of personal integrity and they are not at odds with one another. Persons who exemplify professional integrity are persons who have integrity and display it in their professions. ${ }^{176}$ The virtues of integrity are the basis for multifarious forms of professional integrity: academic integrity, scientific integrity, legal integrity, medical integrity, and artistic integrity. A person has professional integrity insofar as that person exemplifies the virtues of integrity within the context of his or her profession. So, for instance, academic integrity consists in the virtues of integrity being exemplified by a person who has taken on an academic role (student, professor, post-doc, or administrator). Persons that have professional integrity have moral commitments that are

\footnotetext{
${ }^{174}$ See footnotes 110 and 126: my discussion of professional integrity is greatly indebted to Gaita's work on vocations.

${ }^{175}$ For a compelling meditation on the value of work that contains numerous insights into the nature of professional integrity (although the issue is not explicitly discussed), see Michael Crawford's Shop Class as Soulcraft: An Inquiry into the Value of Work, New York: Penguin, 2009. The author's self-satisfied and overly macho tone is one of the main shortcomings of the book.

${ }^{176}$ Robert Solomon Ethics and Excellence: Cooperation and Integrity in Business (Ibid.) provides an outstanding discussion of the nature and value of professional integrity.
} 
partial and particularistic: professionals that have integrity are committed to particular endeavors, projects, agreements and personal relationships.

Someone might object to this conception of professional integrity on the grounds that a person can have artistic or scientific integrity but have no interest in morality and thus integrity does not require moral commitment. This objection raises important and challenging issues about (1) the relation of non-moral values to moral value and (2) the role of moral considerations in artistic and scientific inquiry. I shall set aside these challenging topics and briefly reply to the objection at hand. The virtues of moral commitment and standing up for that commitment, and the form of moral integration that those virtues involve, gives a lot of room for persons of integrity to carry out a wide range of personal projects, and the main restriction that is placed on these projects is that they are not morally wicked endeavors. Artistic norms and scientific methodology do not fully determine the answers to questions facing artists and scientists (e.g., the practical questions that they face in their respective professions) and where those methods leave room for indeterminacy, there is room for moral considerations (such as whether a certain endeavor or practice is immoral) to be relevant. The virtues of integrity do require agents to reflect upon the moral decency of their lives, and when professionals do not do so because of their exclusive concern with other aspects of their professions (e.g., writing a book or completing a painting), their integrity may be at risk.

A related objection to my conception of professional integrity is that there are professions that are immoral by their very nature (e.g., contract killers), and thus, professional integrity in those domains cannot consist in the virtues of moral commitment and standing up for that commitment. An easy and question-begging answer to this 
objection would be to deny those "professions" were real and to argue that they are quasiprofessions. However, I am inclined to say that these practices are genuine professions but they are professions that are morally bankrupt and their practitioners do not have professional integrity. Professional integrity is not possible within professions that make their practitioners immoral. These professionals may exemplify various forms of quasiintegrity (honesty, sincerity, strength of will, zeal, consistency or coherence) but the integrity of these professionals is undermined by the nature of their profession. If a practitioner of one of these professions does manage to achieve a moderate degree of integrity (e.g., Leon, the hitman, in Luc Besson's film The Professional), it is because of factors extrinsic to their professions (e.g., Leon's love for a young orphaned neighbor).

IV. Marital Commitment and Divorce. The freedoms of marriage and divorce are essential for societies to respect the integrity of their members. (Given the widespread cross-cultural differences in marriage practices and the various conceptions of marital commitment, I will not attempt to give a definition or analysis of marital commitment here. My examples will remain at an intuitive level and focus on marriage practices in America. ${ }^{177}$ ) Marriages are deeply significant relationships that are expressed as vows that are usually made in the name of God: a standard marital vow is the commitment "to have and to hold from this day forward, for better for worse, for richer or poorer, in sickness and in health, to love and to cherish, until we are parted by death.” The marriage vow carries greater moral weight and spiritual significance than an ordinary promise. The Roman Catholic tradition considers marriage to be a holy sacrament and it does not

\footnotetext{
${ }^{177}$ My description of traditional marriage practices in America draws from Chapter 8 'Until We are Parted' and Chapter 9, ‘To Have and To Hold’ of Stephen L. Carter Integrity (New York: Harper Collins, 1996).
} 
acknowledge civil divorce and refuses to allow remarriages in their churches. Even if one does not consider marriage to be a holy sacrament, the termination of a marriage is often an especially painful and difficult experience for at least one of the parties involved. The marriage vow is expressed as a promise, but how, exactly does it differ from other legitimate promises and what is the nature of the commitment that it places on spouses?

One way in which the marital vow is different than other types of promises, is that the marital vow of a lover to his or her beloved does not merely generate or create a legitimate expectation to the beloved, but the marital vow is also a public affirmation of a significant relationship that is in process and unfolding. The marital vow "to love and to cherish" is, importantly, the expression of a lover's commitment to endeavor to achieve a richer and fuller understanding of his or her beloved and to act accordingly with that understanding. ${ }^{178} \mathrm{~A}$ great deal of beauty and happiness may result from this mutual endeavor, but it may also result in misery. Even if a couple has been especially careful and discerning in their decision to marry, marriages can become tyrannical, oppressive, abusive, stultifying or unbearable and in those circumstances exit is usually the best option. Marital commitment is not merely a matter of staying true to one's vows. It is not primarily a matter of keeping one's vows forever. Marriage is often a mutually reciprocating process of ever deepening understanding that allows each spouse to see the unique and inherent good of the other. Marital vows signal a major and arduous commitment that should not be undertaken lightly. A lover's decision to get married should result from a clear apprehension of the nature and value of the beloved, and it should not involve fantasies or other distortions of the beloved or the nature of the

\footnotetext{
${ }^{178}$ This conception of the marital vow is related to the reflections on marriage in Kierkegaard's Stages on Life's Way that is described by Roy Holland, 'Morality and the Two Worlds Concept' (in his Against Empiricism: On Education, Epistemology and Value, Totowa, N.J.: Barnes and Noble Books, 1980, 75-91).
} 
relationship. Marriages can be a source of integrity when they are a good stabilizing force. However, marriages can be legitimately terminated if they turn out to rest upon misguided or outdated marriage vows.

Just as the freedom to marry is a wonderful way for a committed couple to publicly affirm their moral commitment to one another, the freedom to divorce is an important exit strategy for relationships that are no longer integrated and committed. ${ }^{179}$ Both of these freedoms are essential for allowing integrity to flourish in a society. In many traditional marriage practices the husband has greater liberty to exit the relationship than the wife. The husband is empowered to dissolve the marriage of his own volition. Whereas, the wife in this marital setting must have her husband's approval in order to exit the relationship and thereby the wife has less (negative) liberty than her husband. It is important that all persons have a legal right to divorce: both husband and wife should have the same (de jure and de facto) rights to exit from the relationship.

\footnotetext{
${ }^{179}$ A strong case for this point, and a case for the value of dissociation, is presented in Loren Lomasky, 'The Paradox of Association', Social Philosophy and Policy, 25, 2008, 182-200.
} 


\section{Concluding Remarks}

Contemporary ethical theory is experiencing a resurgence of interest in virtue ethics. This revival of virtue ethics has created widespread and growing interest in philosophical perspectives on integrity. The revitalization of virtue ethics and the accompanying philosophical research on moral development, narrativity and the ethics of personal relationships have inspired a growing body of research in philosophical ethics that bridges the divide between Continental and Anglo-American philosophical traditions. The Virtues of Integrity contributes to that growing body of research.

My analysis of integrity has focused on the following questions. What is the nature of integrity? Is integrity a virtue? If it is a virtue, what kind of virtue is it? Is it possible for evil persons to possess integrity? The previous chapters articulate a conception of integrity that describes it as (1) a form of wholeness (moral integration), (2) a form purity (being morally decent) and (3) a kind of virtue (the virtues of moral commitment and standing up for that commitment). According to this conception of integrity, persons of integrity are true to their commitments. Persons of integrity cannot be evil because evil persons cannot integrate their commitments: evil persons do not fulfill their commitment to being morally decent (and, thus, being free from evil). Doing what one thinks is best, all things considered, is not sufficient for having integrity because conscientious action is not sufficient for being morally decent and being free from evil. Thus, the virtues of integrity place certain objective constraints on the content of the commitments of their possessor. 
The previous chapters have also identified a set of bad character traits that correspond to the virtues of integrity. Certain types of wantonness, weakness of will, selfdeception, fanaticism, psychopathy and moral wickedness directly undermine a person’s integrity. Moreover, various types of unjust social structures serve to undermine the integrity of their citizens. I claim that governments ought to institute policies that protect the integrity of their citizens. Three types of policies that help governments in this regard are discussed: placing a presumption in favor of liberty, focusing on the moral dimension of professional integrity and loosening restrictions on the entrance and exit costs of marriages.

Perhaps most or even all of the main conclusions that I have reached here are mistaken. I have changed my mind about most of the main theses in this dissertation at some point during the process of writing it. The product that you find before you describes the conception of integrity that I currently find to be the most plausible in light of the arguments that are provided in the previous chapters. However, as things go in philosophy, there is much more work to be done on these topics.

Philosophical perspectives on integrity are of central importance to many different domains of normative philosophy. A more comprehensive discussion of integrity would discuss its relevance to other areas of political philosophy, business ethics, philosophy of law and the philosophy of psychiatry. ${ }^{180}$ Perhaps those topics will be addressed in my future work.

\footnotetext{
${ }^{180}$ For discussion of integrity-based objections to Rawlsian liberalism, see Robert Audi and Nicholas Wolterstorff, eds.. Religion in the Public Square: The Place of Convictions in Political Debate (New York: Rowman and Littlefield, 1997) and David Thunder Rethinking Modern Citizenship: Towards a Politics of Integrity and Virtue (Dissertation, Notre Dame, 2006). For an excellent argument for giving virtue ethics, and the role of integrity, a central place in business ethics, see Robert Solomon, Ethics and Excellence: Cooperation and Integrity in Business (Oxford: Oxford University Press, 1992). For an account of integrity in the law, see Ronald Dworkin Law's Empire (Cambridge, MA: Harvard University Press, 1997). For
} 


\section{Bibliography}

Adams, Robert. A Theory of Virtue: Excellence in Being for the Good, Oxford: Oxford University Press, 206-211.

Anscombe, G.E.M., Intention, $2^{\text {nd }}$ Edition, Cambridge, MA: Harvard University Press, 2000

Arendt, Hannah. Eichtman in Jerusalem: A Report on the Banality of Evil, Revised Edition, New York: Penguin Books, 1992.

Aristotle. Nicomachean Ethics, $2^{\text {nd }}$ Edition, trans., Terence Irwin, Indianapolis, IN: Hackett Publishing, 1999.

Audi, R. and Wolterstorff, N., eds.. Religion in the Public Square: The Place of Convictions in Political Debate. New York: Rowman and Littlefield, 1997.

Austin, J.L. How to Do Things with Words, Cambridge, MA: Harvard University Press, 1962.

Baron, Marcia. Kantian Ethics Almost Without Apology, Ithaca, N.Y.: Cornell University Press, 1995.

Barth, Karl. Dogmatics in Outline, New York: Harper and Row, 1959.

Benn, Piers. 'Freedom, Resentment and the Psychopath', Philosophy, Psychiatry and Psychology, 6, 1999.

Bennett, Jonathan. 'The Conscience of Huckleberry Finn’, Philosophy, 49, 1974.

Bigelow, John and Robert Pargetter, 'Integrity and Autonomy', American Philosophical Quartely, 44, 2007, 39-49.

Blustein, Jeffrey. Care and Commitment: Taking the Personal Point of View, Oxford: Oxford University Press, 1991

Bok, Sissela. Lying: Moral Choice in Public and Private Life, New York: Vintage Books, 1979.

Bostock, David. Aristotle’s Ethics, Oxford: Oxford University Press, 2000.

Brewer, Talbot. 'Two Kinds of Commitments (And Two Kinds of Social Groups)', Philosophy and Phenomenological Research. 66, 2003, 554-583.

discussions of the role of integrity in psychoanalytic theory, see R.D. Laing, The Divided Self (New York:

Penguin Books, 1990) and Jonathan Lear, Freud (London: Routledge, 2005). 
. The Retrieval of Ethics, Oxford: Oxford University Press; 2009.

Calhoun, Cheshire. 'Standing for Something', Journal of Philosophy, 92, 1995, 235-260.

Carr, Spencer. ‘The Integrity of a Utilitarian’, Ethics, 86, 1976, 298-311

Carter, Stephen. Integrity, New York: Harper Collins, 1996.

Crawford, Matthew. Shop Class as Soulcraft: An Inquiry into the Value of Work, New York: Penguin, 2009.

Copleston, Frederick. A History of Philosophy, Vol.2, Medieval Philosophy, New York: Doubleday, 1993.

Cox, Damian, Marguerite LaCaze, and Michael Levine. Integrity and the Fragile Self, Burlington, VT: Ashgate Publishing, 2003. . 'Integrity' The Stanford Encyclopedia of Philosophy, ed., Edward N. Zalta, URL<http://plato.stanford.edu/archives/fall2005/entries/integrity/>

Diamond, Cora. 'Integrity', The Encyclopedia of Ethics, $2^{\text {nd }} E d$., vol. 2, eds. Lawrence Becker and Charlotte Becker, New York: Routledge, 2001, 863-866.

. 'The Dog that Gave Himself the Moral Law' Midwest Studies in Philosophy, 13, 1988, 161-179

Dworkin, Ronald. Law's Empire, Cambridge, MA: Harvard University Press, 1997 . Is Democracy Possible Here? Principles for a New Political Debate, Princeton, N.J.: Princeton University Press, 2006.

Fletcher, George. Loyalty: An Essay on the Morality of Relationships. Oxford: Oxford University Press, 1993.

Frankfurt, Harry. The Importance of What We Care About, Cambridge: Cambridge University Press, 1988. . The Reasons of Love, Princeton, N.J.: Princeton University Press. 2004.

Gaita, Raimond. Good and Evil: An Absolute Conception, $2^{\text {nd }}$ Edition, New York: Macmillan, 2004

. 'Narrative, Identity and Moral Philosophy', Philosophical Papers, 32, 261-277.

. A Common Humanity: Thinking About Love and Truth and Justice. London: Routledge, 2002. 
Geach, Peter. The Virtues, Cambridge: Cambridge University Press, 1977.

Guignon, Charles. On Being Authentic, London: Routledge, 2004.

Hare, R.M. Freedom and Reason, Oxford: Oxford University Press, 1969.

Herman, Barbara. 'Integrity and Impartiality' in her The Practice of Moral Judgment, Cambridge: Harvard University Press, 1993, 23-44.

Hill, Christopher. Liberty Against the Law, New York: Penguin, 1996.

Hill, Thomas E.. Human Welfare and Moral Worth: Kantian Perspectives, Oxford: Clarendon Press, 2002

Holland, R.F., 'The Two Worlds Concept and Morality', in his Against Empiricism: On Education, Epistemology and Value, Totowa, N.J.: Barnes and Noble Books, 1980, 75-91

Kant, Immanuel. Religion within the Boundaries of Mere Reason and Other Writings, trans. and eds., Allen Wood and George Di Giovanni, Cambridge: University of Cambridge Press, 1999.

. Groundwork for the Metaphysics of Morals, trans. Thomas E.Hill Jr. and Arnulz Zweig, Oxford: University of Oxford Press, 2002.

Kekes, John. 'The Reflexivity of Evil', in Miller, Paul, and Paul, q.v., 216-232.

Kerr, Fergus. After Aquinas: Versions of Thomism, Oxford: Blackwell Publishing, 2002, 114-133.

Kierkegaard, Søren. Purity of the Heart is to Will One Thing, trans., Douglas Steere, New York: Harper Torchbooks, 1948.

. Concluding Unscientific Postscript to Philosophical Fragments, 2 vols., Kierkegaard's Writings 12, trans., Howard Hong and Edna Hong. Princeton, N.J.: Princeton University Press, 1992.

. Either/Or, 2 vols. Kierkegaard's Writings 3-4, trans. Howard Hong and Edna Hong. Princeton, N.J.: Princeton University Press, 1990.

. Fear and Trembling and Repetition, Kierkegaard's Writings 6, trans., Howard Hong and Edna Hong. Princeton, N.J.: Princeton University Press, 1983.

Korsgaard, Christine. Creating the Kingdom of Ends, Cambridge: Cambridge University Press, 2000. 
. The Sources of Normativity, Cambridge: Cambridge University Press, 2000.

. The Constitution of Agency: Essays on Practical Reason and Moral Psychology, Oxford: Oxford University Press, 2008.

. Self-Constitution: Agency, Identity and Integrity, Oxford: Oxford University Press, 2009.

Laing, R.D., The Divided Self: An Existential Study in Sanity and Madness, New York: Penguin Books, 1990.

Lear, Jonathan. Freud, London: Routledge, 2005.

Lomasky, Loren. ‘A Refutation of Utilitarianism', Journal of Value Inquiry, 17, 1983, 259-279.

. Persons, Rights and the Moral Community, Oxford: Oxford University Press, 1987

. 'Its Own Reward', Reason, August/September, 1996.

. 'The Paradox of Association', Social Philosophy and Policy, 25, 2008, 182-200.

MacIntyre, Alasdair. After Virtue, $2^{\text {nd }}$ Edition, Notre Dame, IN: Notre Dame Press, 1984. . Ethics and Politics, Selected Essays, Volume 2, Cambridge: Cambridge University Press, 2006.

Markovits, Daniel. 'The Architecture of Integrity' in Reading Bernard Williams, ed., Daniel Calcutt, London: Routledge, 2009, 110-138

McCarthy, Cormac. Blood Meridian: Or the Evening Redness in the West, New York: Vintage, 1985.

McConnell, Terrance. 'Moral Dilemmas' The Stanford Encyclopedia of Philosophy, ed., Edward N. Zalta, URL<http://plato.stanford.edu/entries/moral-dilemmas/>

Mele, Alfred. Self-Deception Unmasked, Princeton, N.J.: Princeton University Press, 2001.

. 'Self-Deception and Hypothesis Testing' in Cartographies of the Mind:

Philosophy and Psychology in Intersection, eds., De Caro, M., Ferretti, F., and Marraffa, M, Dordrecht, The Netherlands: Springer, 2007, 159-168. 
Mill, J.S. Three Essays: On Liberty, On Representative Government, The Subjection of Women, ed. Richard Wollheim, Oxford: Oxford University Press, 1975.

Miller, F., Paul, E., and Paul, J., eds. Virtue and Vice, Cambridge: Cambridge University Press, 1998.

Milosz, Czeslaw. The Captive Mind, trans. Jane Zielonko, New York: Vintage International Edition, 1990.

Montefiore, Alan and David Vines, eds. (1999) Integrity in the Public and Private Domains, London: Routledge, 1999

Moran, Richard. Authority and Estrangement, Princeton, N.J., Princeton University Press, 2001.

Moseley, Daniel. 'The Joker's Comedy of Existence', Supervillians and Philosophy, ed., Ben Dyer, Chicago: Open Court, 2009, 127-136

Murdoch, Iris. The Sovereignty of Good, London: Routledge, 1971. . Existentialists and Mystics, New York: Penguin, 1997

Murphy, Liam. Moral Demands in Nonideal Theory, Oxford: Oxford University Press, 2000.

Narveson, Jan. Respecting Persons in Theory and Practice, Lanham, MD: Rowman and Littlefield, 2002.

Nietzsche. Beyond Good and Evil, trans., Walter Kaufmann. New York: Vintage Books, 1966.

. The Genealogy of Morals and Ecce Homo, trans. and ed., Walter Kaufmann. New York: Vintage Books, 1967

. Twilight of the Idols, in The Portable Nietzsche, ed., Walter Kaufmann, New York: Penguin, 1976.

. The Gay Science, ed., Bernard Williams, trans., Josefine Nauckhoff, Cambridge: Cambridge University Press. 2001

Nozick, Robert. Anarchy, State and Utopia, New York: Basic Books, 1974.

Olafson, Frederick. Principles and Persons: An Ethical Interpretation of Existentialism. Baltimore, MD: The Johns Hopkins Press, 1967.

Orwell, George. 1984, New York: Penguin Books, 1981. 
Parfit, Derek. Reasons and Persons, Oxford: Clarendon Press, 1987.

Plato. Gorgias. trans., Donald Zeyl. Indianapolis, IN: Hackett Publishing, 1987.

. Republic, trans., G.M.A. Grube, revised by C.D.C. Reeve, Indianapolis, IN: Hackett Publishing, 1992

Railton, Peter. 'Alienation, Consequentialism and the Demands of Morality'. Philosophy and Public Affairs, 13, 1984, 134-171.

Rawls, John. A Theory of Justice, Revised Edition, Cambridge, MA: Harvard University Press.2001

Robinson, John. Honest to God. London: SCM Press, 1963.

Rousseau, Jean-Jacques. Emile, trans., Alan Bloom, New York: Basic Books, 1979.

. Basic Political Writings: Discourse on the Sciences and the Arts, Discourse on the Origins of Inequality, Discourse on Political Economy, On The Social Contract, trans. and ed., Donald Cress, intro. Peter Gay, Indianapolis, IN: Hackett Publishing Company, 1987.

Rowlands, Mark. The Philosopher and the Wolf, New York: Pegasus Books, 2009.

Sandel, Michael. Liberalism and the Limits of Justice, $2^{\text {nd }}$ Edition (Cambridge: Cambridge University Press, 1998

Sartre, Jean-Paul. Being and Nothingness, trans., Hazel Barnes, New York: Washington Square Press, 1984.

Sayre-McCord, Geoffrey. 'A Moral Argument Against Moral Dilemmas’, unpublished . 'Rational Agency and Normative Concepts', unpublished.

Scanlon, T. M.. 'Promises and Practices’ Philosophy and Public Affairs, 19, 1990, $199-226$ . What We Owe to Each Other, Cambridge, MA: Harvard University Press, 1998

Schauber, Nancy. 'Integrity, Commitment and the Concept of a Person', American Philosophical Quarterly, 33, 1996, 119-129

Scheffler, Samuel. The Rejection of Consequentialism, Oxford: Oxford University Press, 1982 
Schneewind, J.B. 'Virtue, Narrative and Community: MacIntyre and Morality' Journal of Philosophy, 79, 1982, 653-663.

. The Invention of Autonomy: A History of Modern Moral Philosophy, Cambridge: Cambridge University Press, 1998.

Solomon, Robert. Ethics and Excellence: Cooperation and Integrity in Business, Oxford: Oxford University Press, 1992.

. “The Virtues of a Passionate Life: Erotic Love and 'The Will to Power'”, in Miller, Paul, and Paul, q.v., 1998, 91-118.

Swanton, Christine. 'Can Nietzsche be both an Existentialist and a Virtue Ethicist?' in Values and Virtues: Aristotelianism in Contemporary Ethics, ed. Timothy Chappell, Oxford: Clarendon Press, 2006, 171-188.

Taylor, Charles. The Ethics of Authenticity, Cambridge, MA: Harvard University Press. 2002.

Taylor, Gabriele. 'Integrity' Proceedings of the Aristotelian Society, Supplementary Volume, 55, 1981, 143-159.

Thunder, David. 'Rethinking Modern Citizenship: Towards a Politics of Integrity and Virtue’, dissertation, Notre Dame, 2006.

Tolstoy, Leo. 'Hadji Murat' in Master and Man and Other Stories, trans., Peter Foote, New York: Penguin, 1977, 127-271.

Trilling, Lionel. Sincerity and Authenticity, Cambridge, MA: Harvard University Press. 1972

Trianosky, Gregory. 'Moral Integrity and Moral Psychology: A Refutation of Two Accounts of the Conflict between Utilitarianism and Integrity', Journal of Value Inquiry, 20, 1986, 279-288

Velleman, David. 'The Guise of the Good', Noûs, 26, 1992, 3-26.

. 'Narrative Explanation', The Philosophical Review, 112, 2003, 1-25.

Weil, Simone. 'Human Personality', in Simone Weil: An Anthology, ed., Sian Miles, New York: Grove Press, 1986, 49-78.

Wilhelm Wurzer. 'Nietzsche's Dialectic of Intellectual Integrity: A Propaedeutic Study', Southern Journal of Philosophy, 13, 1975, 235-45. 
Williams, Bernard. Morality: An Introduction to Ethics. New York: Harper Torchbooks. 1972.

. Utilitarianism: For and Against, eds. J.J.C. Smart and Bernard Williams, Cambridge: Cambridge University Press, 1973.

. Problems of the Self, Cambridge: Cambridge University Press, 1973.

. Moral Luck, Cambridge: Cambridge University Press, 1981

. Ethics and the Limits of Philosophy, Cambridge, MA: Harvard University Press, 1985.

. Truth and Truthfulness, Princeton, N.J.: Princeton University Press, 2002.

.The Sense of the Past: Essays in the History, ed., Myles Burnyeat, Princeton N.J.: Princeton University Press, 2006. 